CARLOS ALBERTO ROMBALDO JUNIOR

PROPOSTA DE UM FRAMEWORK DE PERSISTÊNCIA DE OBJETOS EM BASES DE DADOS OBJETO-RELACIONAL

São Paulo 
CARLOS ALBERTO ROMBALDO JUNIOR

\section{PROPOSTA DE UM FRAMEWORK DE PERSISTÊNCIA DE OBJETOS EM BASES DE DADOS OBJETO-RELACIONAL}

Dissertação apresentada à Escola Politécnica da Universidade de São Paulo para obtenção do Título de Mestre em Ciências.

São Paulo 
CARLOS ALBERTO ROMBALDO JUNIOR

\section{PROPOSTA DE UM FRAMEWORK DE PERSISTÊNCIA DE OBJETOS EM BASES DE DADOS OBJETO-RELACIONAL.}

Dissertação apresentada à Escola

Politécnica da Universidade de São

Paulo para obtenção do Título de Mestre em Ciências.

Área de Concentração:

Sistemas Digitais

Orientadora:

Profa. Dra. Solange Nice Alves de Souza

São Paulo

2012 
Este exemplar foi revisado e alterado em relação à versão original, sob responsabilidade única do autor e com a anuência de seu orientador.

São Paulo, 09 de março de 2011.

Assinatura do autor

Assinatura do orientador

FICHA CATALOGRÁFICA

Rombaldo Junior, Carlos Alberto

Proposta de um Framework de persistência de objetos em bases de dados objeto-relacional / C.A. Rombaldo Junior. -- ed. ver. -- São Paulo, 2012.

$88 \mathrm{p}$.

Dissertação (Mestrado) - Escola Politécnica da Universidade de São Paulo. Departamento de Engenharia de Computação e Sistemas Digitais.

1. Frameworks 2. Bases de dados 3. Arquitetura de software 4. Desenvolvimento de software I. Universidade de São Paulo. Escola Politécnica. Departamento de Engenharia de Computação e Sistemas Digitais II. t. 


\section{DEDICATÓRIA}

Dedico este trabalho a todas as pessoas que, de alguma forma, contribuíram para a realização deste, sendo de forma direta, revisando, contribuindo com ideias e orientações, ou indiretamente, torcendo e apoiando emocionalmente. 


\section{AGRADECIMENTOS}

A professora doutora Solange Nice Alves de Souza, que tanto se dedicou na orientação deste trabalho. Atuando de forma humana e comprometida.

Agradeço aos meus pais, Carlos Alberto Rombaldo e Vera Lucia Scatolin Rombaldo que de inúmeras formas me ajudaram, possibilitando hoje concluir mais uma etapa. 


\section{RESUMO}

Este trabalho apresenta o desenvolvimento de um Framework de persistência que utiliza banco de dados objeto-relacional como mecanismo de persistência. Tendo por objetivo usar os conceitos de orientação a objetos descritos na norma SQL:2008, conceitos como: objeto (atributos e métodos), herança, agregação, composição, referências (REF) e estruturas multivaloradas (arrays e multiset). Para tanto se desenvolveu e formalizou (XSD) um arquivo XML que representa um esquema de objetos através da norma SQL:2008. Da mesma forma definiu-se um conjunto de anotações Java, com o intuito de facilitar a utilização e configuração do Framework, o qual é chamado de O-ODBM (Object Object-Relational Database Management).

Palavras-chave: Banco de Dados Objeto-Relacional. Framework de Persistência. Framework Objeto Objeto-Relacional. Mapeamento Objeto Relacional. Mapeamento Objeto Objeto-Relacional. Java Anotações. Tipo Definido pelo Usuário. 


\begin{abstract}
Persistent Frameworks have been used to aid developers, managing all access to DBMS. This kind of tool maps objects from $\mathrm{OO}$ applications to relational databases. Besides, allow developers to persist objects without solid knowledge about DBMSs and specific languages, making better the developers' productivity, mainly when different DBMS is used. On the other hands, since 1999 the SQL specification has introduced new features to manipulate objects in relational databases which since then has been called ObjectRelational Database (ORDB). At present, many DBMS offer resources to manipulate objects in database, but the most of the application developers just map class to relations tables, failing to exploit the strength of O-R model. The lack of the tools that aid the project of database contributes to this situation. Considering the vantages of use of the persistent frameworks and the ORDBs, this article introduces the O-ODM (Object-Object Database Mapping) a persistent framework for relational object databases.
\end{abstract}

Keywords: Object-Relational Databases. Persistence Framework. Object ObjectRelational Framework. Object Relational Mapping. Object Object-Relational Mapping. Java Annotations. User Defined Types. 


\section{LISTA DE FIGURAS}

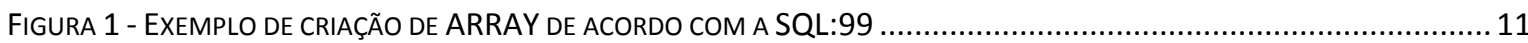

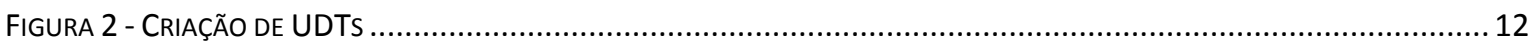

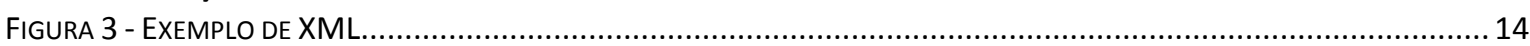

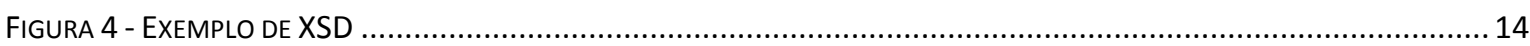

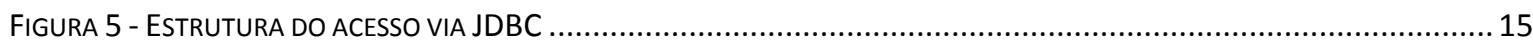

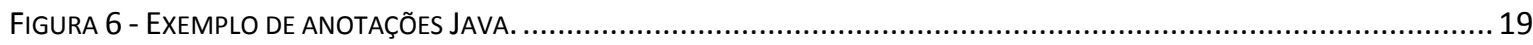

FIGURA 7 - EXEMPLO DE UM ESQUEMA CONCEITUAL DESCRITO POR UM DIAGRAMA DE CLASSE UML.................................25

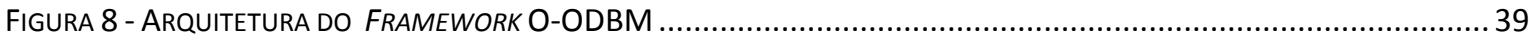

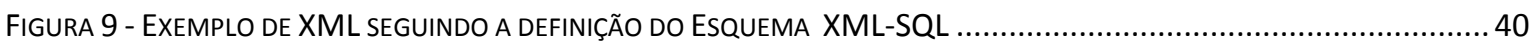

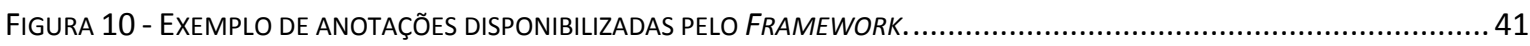

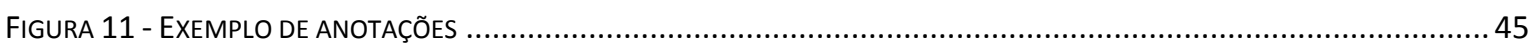

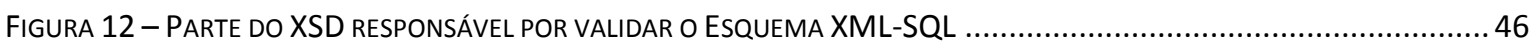

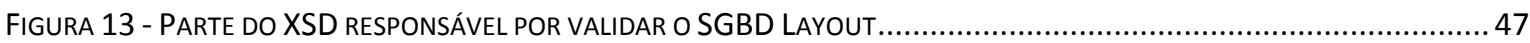

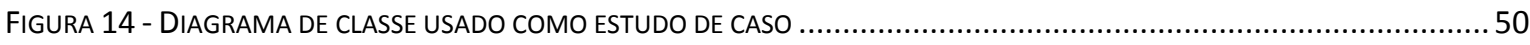

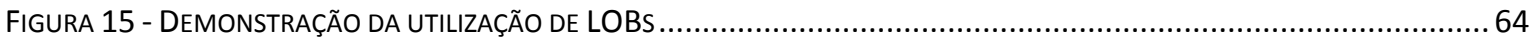

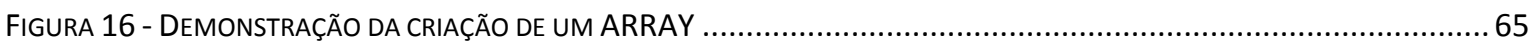

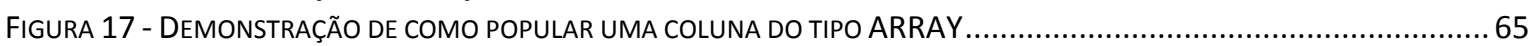

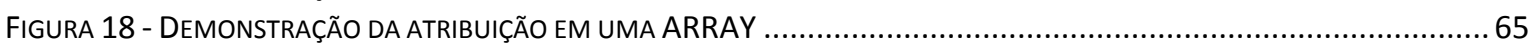

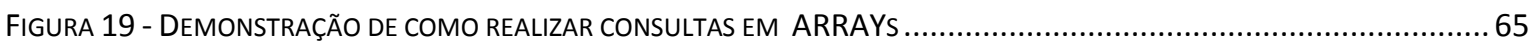

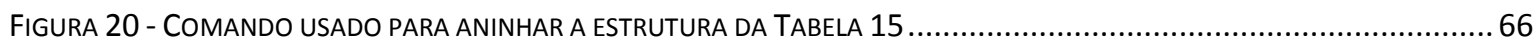

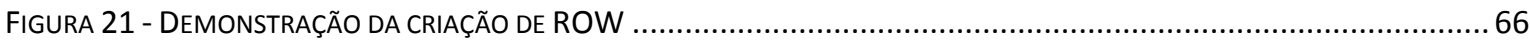

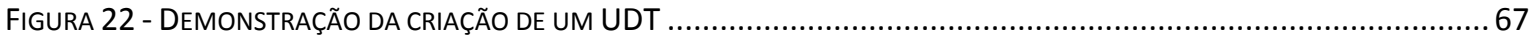

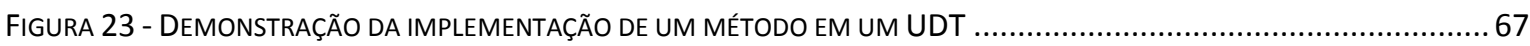

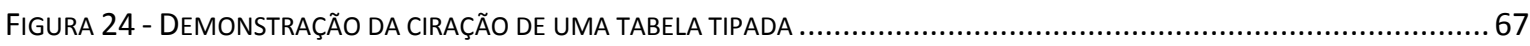

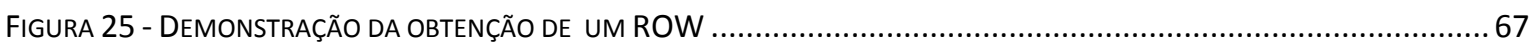

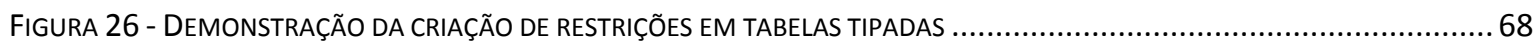

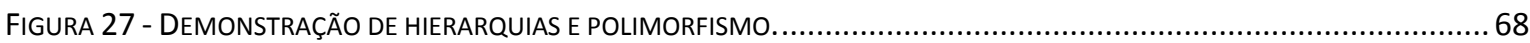

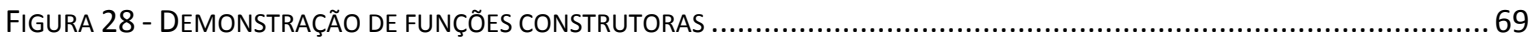

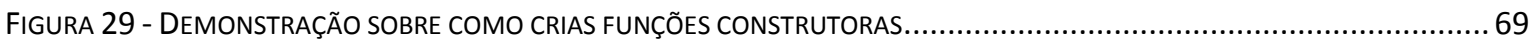

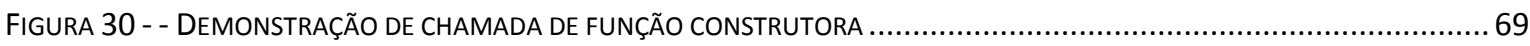

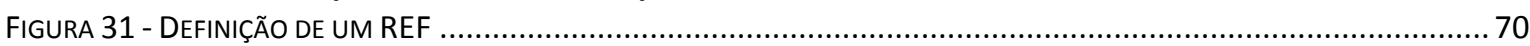

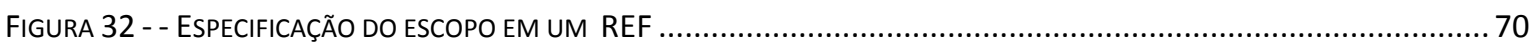

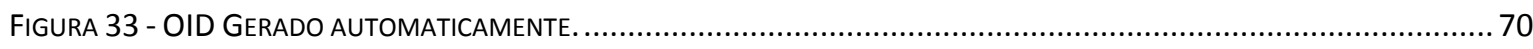

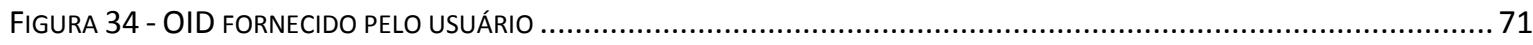

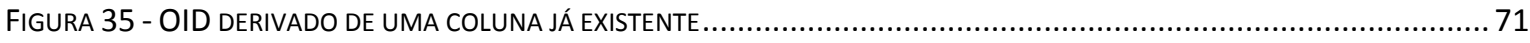

FIGURA 36 - RECUPERANDO UM A TRIBUTO DE UM OBJETO REFERENCIADO POR UM REF............................................ 71

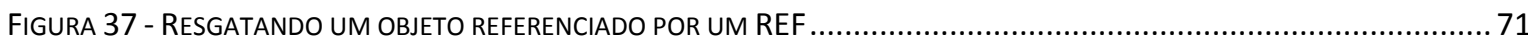

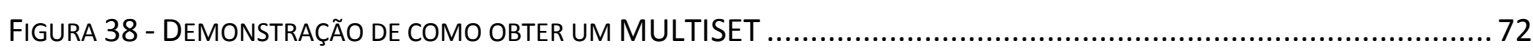




\section{LISTA DE TABELAS}

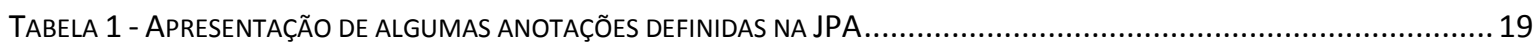

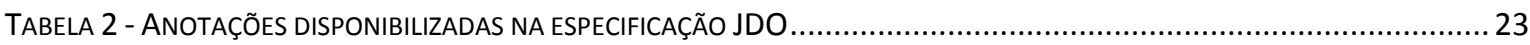

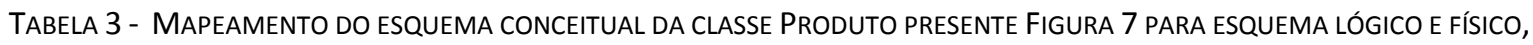
CONSIDERANDO A NORMA SQL:2008 E OS SGBDS ORACLE E DB2 ....................................................... 26

TABELA 4 - MAPEAMENTO do ESQUEMA CONCEITUAL DA CLASSE SOFTWARE PRESENTE FIGURA 7 PARA ESQUema LóGICO E FísICO,

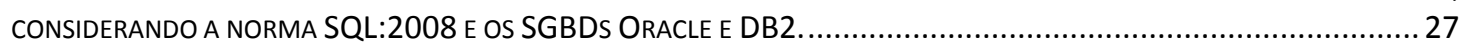

TABela 5 - MAPEAMENTO do ESQUEMA ConCEITUAL dA CLASSE HARDWARE PRESENTE FIGURA 7 PARA ESQUema LóGICO E Fí́IICO, CONSIDERANDO A NORMA SQL:2008 E OS SGBDS ORACLE E DB2 ................................................. 27

TABELA 6 - MAPEAMENTO do ESQUEMA CONCEITUAL DA CLASSE ITEM PRESENTE FIGURA 7 PARA ESQUEMA LóGICO E FísICO,

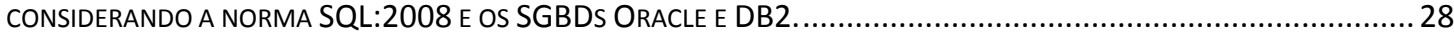

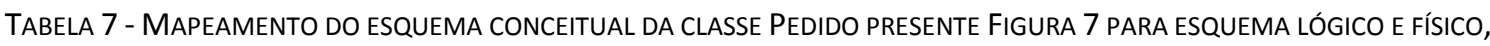

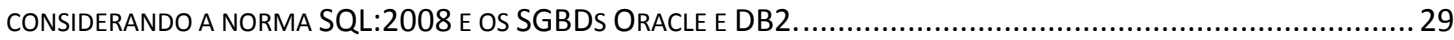

TABELA 8 - MAPEAMENTO DO ESQUEMA CONCEITUAL DA CLASSE ENDEREÇO PRESENTE FIGURA 7 PARA ESQUEMA LÓGICO E Fí́SICO, CONSIDERANDO A NORMA SQL:2008 E OS SGBDS ORACLE E DB2

TABELA 9 - MAPEAMENTO dO ESQUEMA CONCEITUAL DA CLASSE CLIENTE PRESENTE FIGURA 7 PARA ESQUeMA LóGICO E FÍSICO, CONSIDERANDO A NORMA SQL:2008 E OS SGBDS ORACLE E DB2

TABELA 10 - MAPEAMENTO DE OBJETOS DA APLICAÇÃO EM OBJETOS DE BDOR - ADAPTADO DE (CASTRO ET AL., 2010)(CASTRO, 2011)

TABELA 11 - MAPEAMENTO DE ASSOCIAÇÕES E HIERARQUIAS EM BDOR - ADAPTADO DE (CASTRO ET AL., 2010)(CASTRO, 2011).

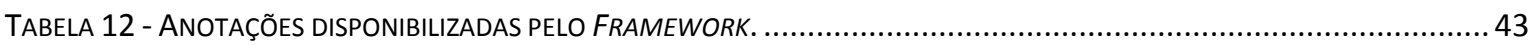

TABELA 13 - CONFIGURAÇÕES AVANÇADAS USANDO AS ANOTAÇÕES DISPONIBILIZADAS PELO FRAMEWORK............................44

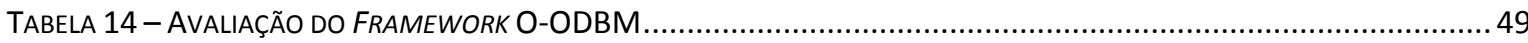

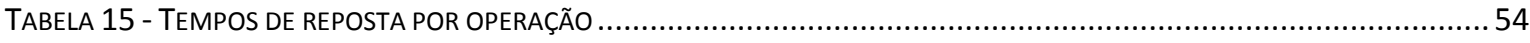

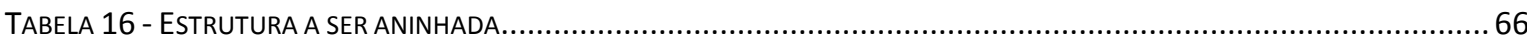

TABELA 17 - AVALIAÇÃo / COMPARAÇÃO dOS FRAMEWORKS HIBERNATE E APACHE TORQUE USANDO OS REQUISITOS DEFINIDOS EM 4.2 


\section{LISTA DE ABREVIATURAS E SIGLAS}

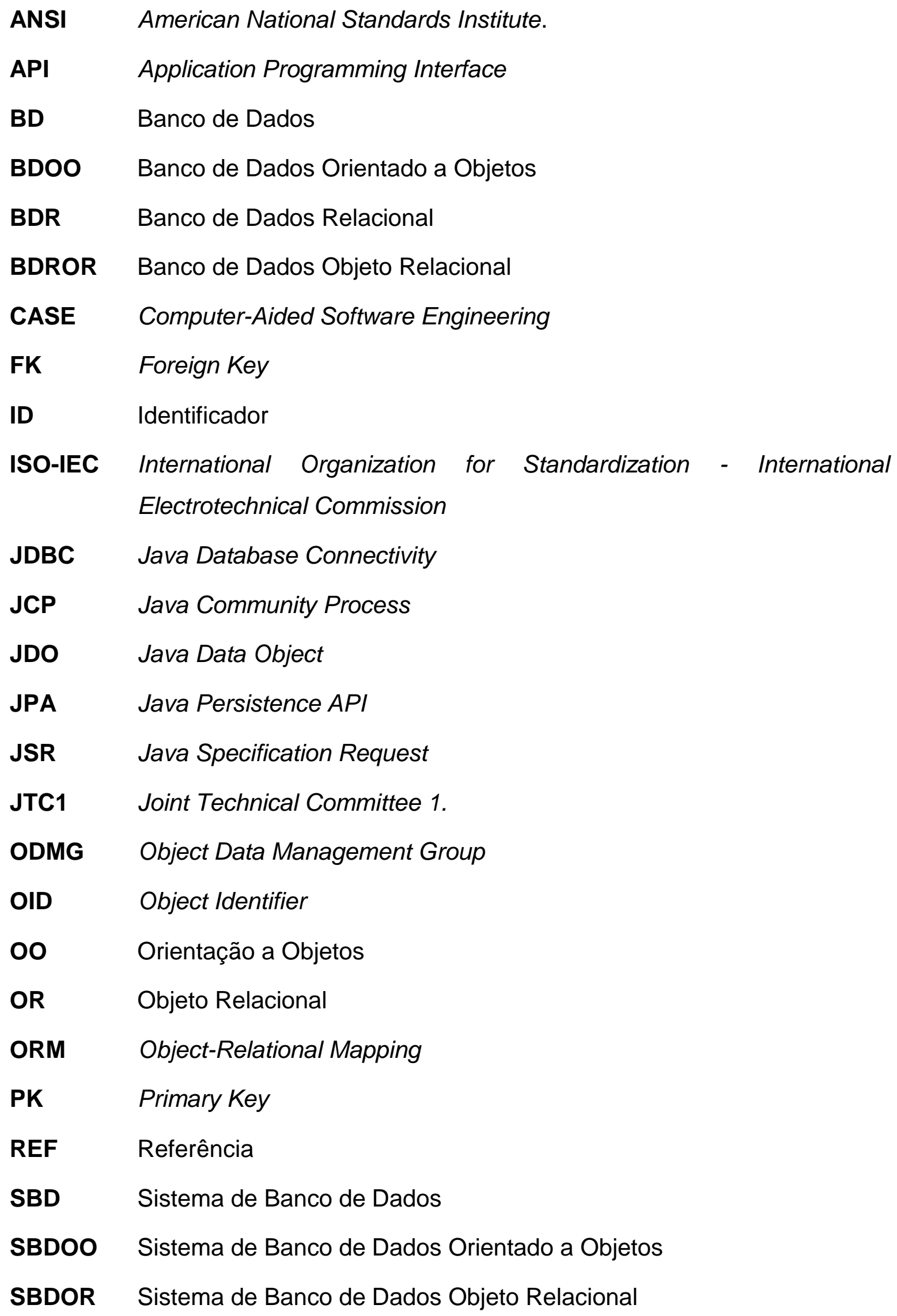


SGBD Sistema Gerenciador de Banco de Dados

SGBDR Sistema Gerenciador de Banco de Dados Relacional

SGBDOO Sistema Gerenciador de Banco de Dados Orientados a Objetos

SGBDOR Sistema Gerenciador de Banco de Dados Objeto-Relacional

SQL Structured Query Language

SQL:2003 Norma "ISO/IEC 9075:1992 - Database Language" divulgada em 2003.

SQL:2008 Norma "ISO/IEC 9075:1992 - Database Language" divulgada em 2008.

SQL:99 Norma "ISO/IEC 9075:1992 - Database Language" divulgada em 1999

UDT Tipo Definido pelo Usuário

W3C World Wide Web Consortium

XML eXtensible Markup Language

XSD XML Schema Definition 


\section{SUMÁRIO}

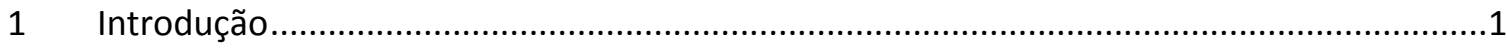

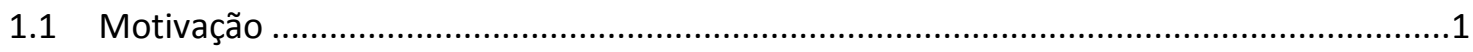

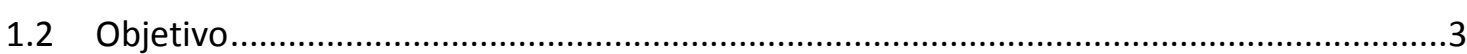

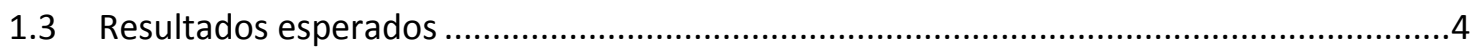

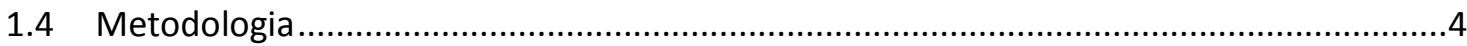

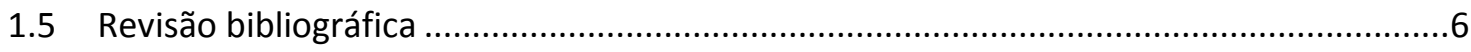

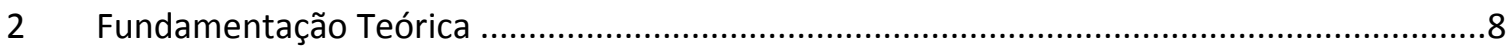

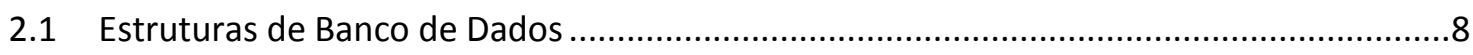

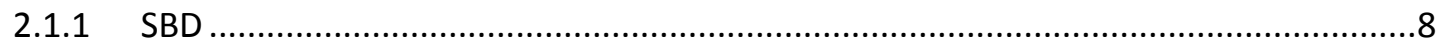

2.1.1.1 BDR e a Normatização ANSI e ISO/IEC SQL .....................................................

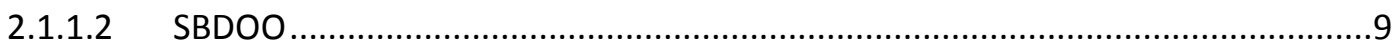

2.1.1.3 SBDOR e a Normatização ISO/IEC SQL ….........................................................10

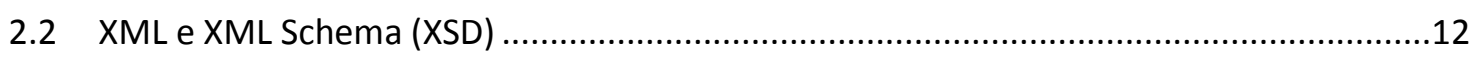

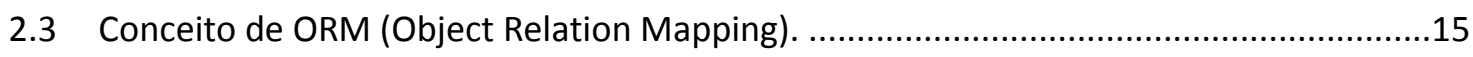

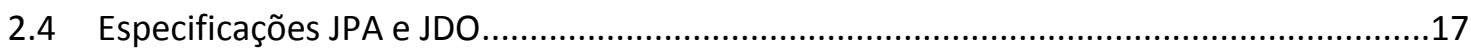

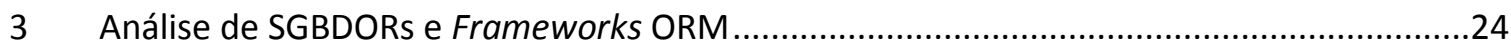

3.1 Diferenças de implementação entre os SGBDs Oracle e DB2:.........................................24

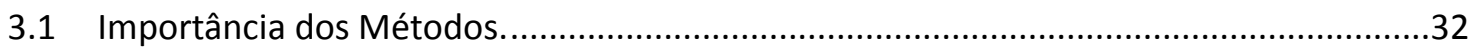

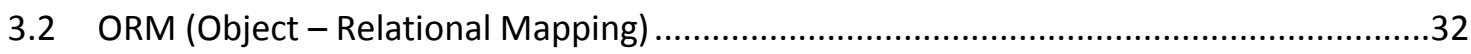

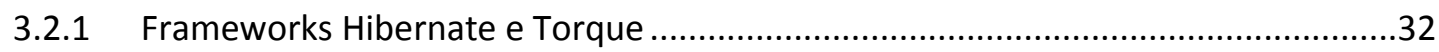

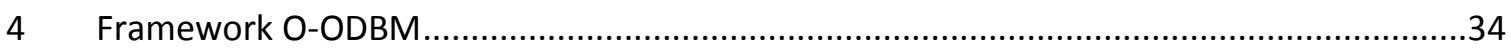

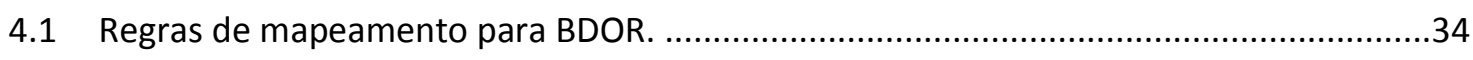

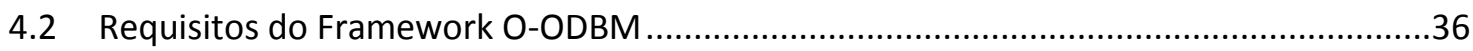

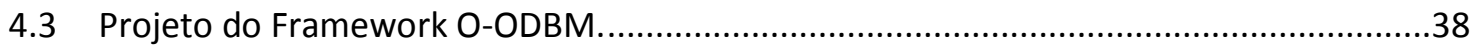

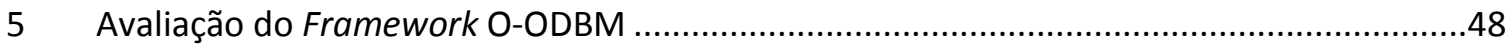

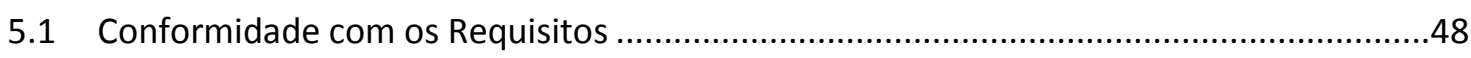

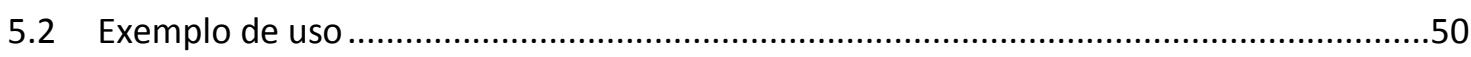

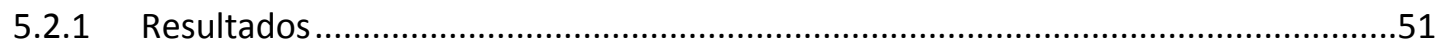

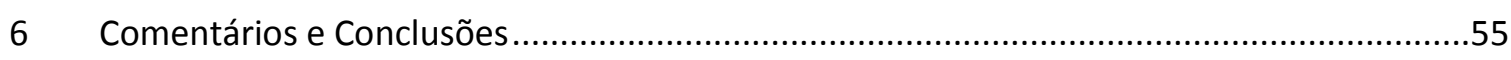

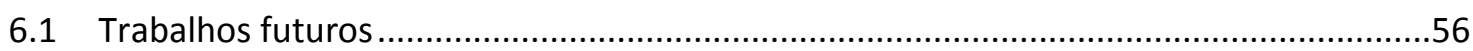

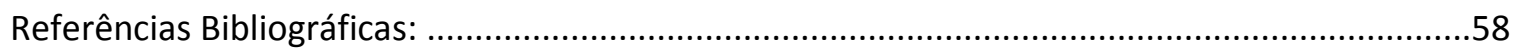

APÊNDICE A Recursos OR presentes na norma que foram empregados no trabalho. ..............64

APÊNDICE B Avaliação dos Frameworks Hibernate e Apache Torque. ......................................74 


\section{Introdução}

No decorrer das últimas décadas diversos Sistemas Gerenciadores de Bancos de Dados (SGBDs) originados de diferentes estruturas como: hierárquico, em rede e relacional foram criados. Com o tempo, predominou a utilização de SGBDs relacionais (SGBDR - Sistemas Gerenciadores de Banco de Dados Relacionais). Contudo, com o aparecimento de novas aplicações que exigiam a manipulação de dados complexos, a estrutura relacional até então bastante apropriada para aplicações convencionais administrativas e comerciais mostrou-se inadequada. Para tais aplicações a representação de objetos, hierarquias, relacionamentos de agregação e composição, além da manipulação de estruturas do tipo listas e dados multimídia são imprescindíveis. A incorporação do paradigma de orientação a objetos a banco de dados deu origem aos Sistemas de Banco de Dados Orientados a Objetos (SBDOOs) e, posteriormente, aos Sistemas de Banco de Dados Objeto-Relacionais (SBDORs) [57].

SBDOR consiste da extensão de SBDR com características de objetos. Os fabricantes de Sistemas Gerenciadores de Banco de Dados Relacionais (SGBDR) introduziram um conjunto de características aos seus produtos para a manipulação de objetos, gerando então os SGDBs Objeto-Relacionais (SGBDOR). Apesar da existência da especificação SQL:2003 e SQL:2008, ainda verifica-se que as características introduzidas em produtos SGBDOR (ex. Oracle, SQLServer, DB2. Postgre, etc.) não são homogêneas (existem diferenças entre o que está disponível em cada produto). Essa não normatização (ou padronização) é consequência da especificação SQL:1999 (primeira a trazer especificações de objetos) ter sido publicada posteriormente a incorporação de fatores de orientação a objetos em SGBDs produtos, ou seja, primeiro houve a implementação e depois a formulação de uma especificação. Fabricantes de produtos como da Oracle, Postgre e DB2 disponibilizaram versões possuindo suporte a $\mathrm{OO}$ antes da publicação da norma.

\subsection{Motivação}

Existe no mercado um grande abismo entre o paradigma adotado no contexto de desenvolvimento de aplicações e o adotado no SGDB (Sistemas Gerenciador de Banco de Dados). 
O emprego de SBDR tornou-se dominante no mercado antes da difusão e uso de paradigmas OO (Orientação a Objetos) como abordagem para o desenvolvimento de aplicações [57].

Apesar do desenvolvimento de aplicações ter seguido a OO, onde se possibilita manipulação de problemas mais complexos; os dados continuaram, na maioria das aplicações, a ser persistidos em bases relacionais.

Com o intuito de minimizar o descasamento de impedâncias, entre essas tecnologias [08], criaram-se mecanismos (mapeamento, tradução e conversão) para possibilitar o armazenamento e a recuperação dos objetos da aplicação. Assim ao longo do tempo, inúmeros Frameworks têm surgido. Tais ferramentas fazem o mapeamento/conversão entre objetos da aplicação e objetos (relações e tuplas de relações) da base de dados automaticamente. Como exemplos de Frameworks deste tipo, é possível citar Hibernate, EJB, iBATIS, HyperLink, JDO, OpenLink, OpenJPA entre outros; uma lista mais completa pode ser encontrada em [62].

SGBDOR são sistemas de gerência de banco de dados com características de objetos construídos sobre o modelo relacional. Tais sistemas permitem o uso convencional de relações (ou tabelas) e/ou o uso das extensões para objetos e seus tipos associadas.

As versões mais recentes de muitos SGBDs disponíveis no mercado já possuem características OR, no entanto o uso deste suporte é pouco difundido e explorado pelas aplicações (e principalmente os Frameworks de persistência). Acredita-se que os motivos da não utilização deste suporte envolvem o não conhecimento do desempenho com o crescimento da base de dados, quando as estruturas de objetos e suas associações (agregações, hierarquias) tenham sido empregadas; além da falta de ferramentas de apoio à construção e manutenção dessas bases.

Como explanado, vários Frameworks de persistência de objetos para uso entre as aplicações desenvolvidas sob o paradigma de $\mathrm{OO}$ e banco de dados relacionais foram desenvolvidos. No entanto problemas como herança, estruturas multivaloradas e comportamento de objetos (métodos) são tratadas de forma ad hoc por tais Frameworks.

Por outro lado, o uso de tais Frameworks tem permitido aos desenvolvedores se aterem mais ao desenvolvimento da aplicação (aspectos da linguagem e do paradigma de OO), sem a preocupação de conhecer/manipular uma linguagem e estruturas específicas para a persistência dos dados. Também o uso de tais ferramentas permite maior independência de dados, no sentido de que o acesso a dados fica concentrado sob o Framework. Outro aspecto importante do uso desses Frameworks é que quando há a necessidade de alteração 
do SGBD utilizado, em geral apenas uma diretiva é alterada, indicando qual o novo SGBD, e todo o código de mapeamento produzido pela ferramenta para o SGBD X é alterado automaticamente para o SGBD Y. Esta facilidade é muito útil, pois sem ela, o desenvolvedor deveria produzir o novo código de acordo com as características do novo SGBD. Esses aspectos auxiliam tanto do ponto de vista da manutenção dos sistemas quanto da produtividade dos desenvolvedores. Assim, entende-se que o uso de Frameworks de persistência traz um conjunto direto de benefícios que não devem ser ignorados. Porém é necessário, considerar SGBDOR.

\subsection{Objetivo}

O presente trabalho tem como objetivo o desenvolvimento de um Framework que faça o mapeamento dos objetos da aplicação para as estruturas de objeto disponíveis em SGBOR. Uma das vantagens da utilização de um SGBDOR é a eliminação do descasamento de impedância entre as duas abordagens (objeto e relacional) associadas à proximidade semântica entre a aplicação e a base de dados. Outra é a possibilidade do emprego de um único modelo conceitual para ambas as camadas (aplicação e base de dados) [11][12]. Quando se emprega a plataforma relacional, em geral utilizam-se dois modelos conceituais, um modelo de classes UML para representar os objetos da aplicação e um Modelo Entidade-Relacionamento (MER) para representar os objetos da base de dados. Este último é facilmente mapeado para relações do modelo relacional. Apesar da facilidade, existe um overhead para fazer o mapeamento, além do associado ao tempo necessário para elaborar o modelo E-R, isso sem considerar a necessidade de conhecimento específico para gerar este modelo.

Para a criação de tal Framework foram estudadas as especificações que agrupam e/ou definem características implementadas nos Frameworks de persistência. Além disso, alguns Frameworks open sources, tendo sido escolhidos aqui o Torque e o Hibernate (utilizando da Java Persistence API) foram estudados. Não foram utilizados de fato os códigos fontes destes Frameworks.

Não houve a pretensão em estender nenhum desses Frameworks, pois os mesmos foram desenvolvidos para geração de códigos SQL (Structured Query Language) tendo em vista o modelo relacional, e toda sua arquitetura foi baseada na conversão de OO para relacional. Considerando que a presente proposta era o emprego de um Framework de persistência 
que fosse capaz de armazenar e recuperar as informações fazendo uso das estruturas de objetos disponíveis no SGBDOR, a extensão não era viável.

\subsection{Resultados esperados}

O Framework proposto neste trabalho deverá persistir objetos da aplicação em objetos de banco de dados, permitindo realmente especificar hierarquias e comportamento de objetos no BD. Para tanto este Framework é voltado para BDOR.

A difusão de novas tecnologias se dá a partir do suporte fornecido por ferramentas automatizadas. Por exemplo, BDR são apoiados por inúmeras ferramentas CASE (Computer-Aided Software Engineering) e Frameworks de persistência que facilitam a manipulação de relações do BD. Por outro lado, faltam ferramentas que façam uso dos novos elementos para manipulação de objetos de BDORs. Como comentado anteriormente, essa ausência de ferramentas para BDORs dificulta seu emprego. Assim, espera-se que o Framework possa auxiliar na difusão do uso de SGBDORs.

\subsection{Metodologia}

A fim de que se torne possível a conclusão deste trabalho algumas pesquisas foram realizadas, Estas pesquisas tiveram como principal fonte, artigos publicados em comunidades cientificas como IEEE, CITESEER, portal ACM e SBC (Sociedade Brasileira de computação). Além destes, houve uma procura em dissertações e livros. O foco inicial destas pesquisas era a evolução da normatização da SQL procurando acompanhar a incorporação dos recursos de OO. Inicialmente as versões da especificação SQL estudadas foram a SQL:99, SQL:2003 e SQL:2008. Nesta fase, alguns trabalhos encontrados na literatura merecem destaque, são eles, [20] [21] [44] [54] [55] [34] [38] [39] [54] [55].

À medida que a pesquisa sobre os recursos de $\mathrm{OO}$ incorporados na norma evoluiu, em paralelo, foi investigado o suporte destes recursos em alguns SGBDs (inicialmente Oracle e Postgre). Ao termino desta fase, um artigo contendo estes resultados foi publicado [56]. O próximo passo do trabalho foi a pesquisa sobre Frameworks de persistência, em especial o Hibernate, cujo código fonte foi avaliado juntamente com sua documentação. O objetivo era entender os procedimentos internos de um Framework ORM. Este estudo teve como foco os processos de configuração, de geração de códigos SQL, o tratamento da diferença 
(sintaxe, tipos de dados, etc.) entre os SGBDs e, por último, a forma com que o Framework interpreta o esquema de objetos ${ }^{1}$ da aplicação (e como o desenvolvedor especifica quais objetos serão persistidos e como).

Durante estudos e análises do Hibernate, ficou evidente que era melhor criar um Framework do zero, ou seja, sem estender um já existente, como era pretendido no começo do trabalho. Isso conduziu a investigação do Framework Torque da apache. O Objetivo era entender, comparar e incorporar no Framework proposto boas características de diferentes Frameworks.

Ao comparar o suporte dos recursos OO da norma SQL:2008 em SGBDs, percebeu-se que o Oracle possuía suporte a quase todos os recursos e, de uma forma muito parecida como definido pela norma. Enquanto o Postgre possuía um suporte consideravelmente restrito comparado ao Oracle, maiores detalhes sobre essa comparação pode ser encontrado em [56]. Outros SGBDs foram avaliados, o objetivo era encontrar outro que oferecesse suporte a objetos em um nível igual ou superior ao Oracle. Ao termino deste estudo decidiu-se pelo DB2 em substituição ao Postgre.

Estudos comparativos foram realizados, investigando detalhes de sintaxe e comportamento dos recursos OO suportados pelos SGBDs escolhidos. Pretendia-se com isto chegar a uma padronização que permitisse representar todo o esquema de objetos da aplicação. Isto possibilitaria a interação deste Framework com outras ferramentas que possuíssem tal suporte. Outro fator considerado foi a possível evolução do suporte a recursos OO por parte do SGBDs, de forma a tornar mais simples a incorporação de tal evolução no Framework.

A escrita do texto da qualificação foi iniciada juntamente com a codificação de uma prova de conceito da viabilidade do desenvolvimento do Framework. Estudou-se a linguagem de programação Java e melhores práticas de programação, bem como XML (eXtensible Markup Language). Usando XML permite-se a interoperabilidade entre os componentes do Framework (e eventualmente com outros). Foram realizados estudos sobre XSD (XML Schema Definition) para a padronização/validação dos XML.

Após a escrita e apresentação da qualificação, foram realizados estudos sobre as principais especificações disponíveis no mercado como JPA (Java Persistence API) e JDO (Java

${ }^{1}$ Este trabalho usa o termo esquema de objetos para se referenciar às classes Java que representam os objetos a serem persistidos, em outras palavras a estrutura de objetos da aplicação que serão persistidos no BD. 
Data Object), encontradas algumas características consideradas importantes para o trabalho. Com base nestas foi possível compilar alguns requisitos, a fim de guiar o projeto e o desenvolvimento do Framework. A partir da definição dos requisitos, foi iniciado o projeto do Framework proposto, gerando-se sua arquitetura. Logo após iniciou-se a implementação. O Framework O-ODBM, proposto neste trabalho, foi testado usando uma aplicação como exemplo. Além disso, foi feita uma comparação com o Hibernate e os resultados são discutidos na dissertação.

A dissertação engloba e complementa a revisão da qualificação, que ocorreu paralelamente ao desenvolvimento do Framework.

\subsection{Revisão bibliográfica}

Nesta seção abordam-se aspectos de alguns trabalhos considerados importantes para o desenvolvimento da proposta desta dissertação.

Os trabalhos [54][55][20][21] apresentam as funcionalidades de OR trazidas pela SQL: 2003 (algumas revisadas da SQL 99). São mostrados exemplos de manipulação e sintaxe. Também comentam de forma superficial, o suporte destas funcionalidades em alguns SGBDs. O foco dos trabalhos, citados, é apenas de apresentar as funcionalidades.

[56] apresenta os elementos incorporados à especificação SQL que permitem a definição de objetos e hierarquias em base de dados, mostra a correspondência entre objetos da aplicação e base de dados, e faz um comparativo sobre o suporte das características OR nos SGBD Oracle e Postgre.

[22] aponta uma "metodologia" para modelagem de dados usando os recursos da norma para modelar conceitos como agregação e composição. Conceitos como generalização, herança e reuso também são apresentados, assim como regras sobre o uso de OID (Object IDentifier) e chaves primarias (PK).

Os trabalhos [38][39][40][41][42] representam a norma ISO/IEC da linguagem SQL.

[11][12][22][26][36][37] apresenta funções de mapeamento de classes em estrutura OR, mostrando o respectivo suporte SQL para os objetos e suas características como atributos, métodos e relacionamentos (agregação e composição).

Ainda sobre modelagem de relacionamentos em bases OR entram os trabalhos [36] [37] que focam em funções de mapeamento do Modelo Conceitual para o Esquema Físico e na proposta de um modelo gráfico para os objetos de bases de dados OR. 
[44] apresenta formas de modelar estruturas aninhadas usando UDT (recurso específico de base de dados OR). Tal trabalho foi baseado em [36] [37], estendendo e exemplificando os conceitos trazidos por [36].

Em [08] ressalta o descasamento de impedância entre a abordagem relacional dos bancos de dados e a abordagem $\mathrm{OO}$ das aplicações, mostrando algumas estratégias/alternativas para minimizar este descasamento. Este trabalho não entra no mérito da utilização de BDOR. [14] também apresenta os problemas de descasamento de impedância, e aborda o mapeamento objeto para relações (tabelas) de forma automática.

[09] faz uma comparação entre o desenvolvimento de aplicação acessando diretamente a base de dados (via JDBC - Java Database Connectivity) e usando um Framework ORM. Os autores ressaltam a complexidade da implementação de relacionamentos "um para um", "um para muitos" e "muitos para muitos", e a respectiva quantidade de código usado em cada uma das abordagens. Destaca também as limitações para representação de herança e polimorfismos para acessos via JDBC, além da dificuldade de se obter a portabilidade entre os SGBDs.

Os trabalhos de [15] [16] [17] tratam sobre persistência de objetos Java. Tais trabalhos fazem uma comparação de alguns Frameworks ORM atuais. Destacam vantagens e desvantagens destes Frameworks assim como dicas de uso. Fornece também uma descrição sobre as duas principais especificações ORM (JPA) e (JDO).

[02] [03] faz também a comparação entre as especificações JPA e JDO e os suportes oferecidos.

[13] apresenta de forma detalhada o uso de alguns Frameworks, e faz um comparativo mostrando vantagens e desvantagens do emprego ou não de Frameworks de persistência. Uma lista mais completa sobre os Frameworks disponíveis pode ser encontrada em [62]. 


\section{Fundamentação Teórica}

Esta seção aborda conceitos e aspectos de tecnologias empregadas neste trabalho.

\subsection{Estruturas de Banco de Dados}

\subsubsection{SBD}

Um SBD (Sistema de Banco de Dados) é um sistema de armazenamento e controle dos dados.

"É basicamente um sistema computadorizado de manutenção de registros; ou seja é um sistema computadorizado cuja finalidade geral é armazenar informações e permitir que os usuários busquem e atualizem essas informações quando as solicitar” [18].

Existe uma confusão entre os termos SGBD e BD.

SGBD é o sistema que possui as regras de manipulação, armazenamento e consistência dos dados. Enquanto BD trata-se do repositório/depósito dos dados. A junção do BD com o SGBD forma o SBD. No restante deste trabalho algumas vezes utiliza-se o termo BD significando SGBD, mas o contexto permite facilmente entender seu real significado.

\subsubsection{BDR e a Normatização ANSI e ISO/IEC SQL}

BDR (Banco de Dados Relacional) consiste num repositório onde as informações/dados são armazenadas em tabelas ou relações. BDR baseia-se nas relações (ou associações) entre estas tabelas [57].

A linguagem padrão utilizada nos BDRs é a SQL. No início dos anos 70 a IBM lançou a primeira versão da linguagem SQL, chamava-se SEQUEL, era parte do sistema denominado R. Este por sua vez foi o primeiro SGBD relacional a demonstrar bom desempenho no processamento de transações. SGBD relacionais posteriores ao sistema $\mathrm{R}$ construíram sua arquitetura e componentes baseados no sistema R. Com a difusão e o sucesso da linguagem em 1986, o instituto norte americano ANSI (American National Standards Institute) padronizou as implementações. No ano seguinte o comitê internacional ISO (International Organization for Standardization) assumiu também a 
padronização da Linguagem SQL, mais especificamente a comunidade internacional trabalhou através da ISO/IEC/JTC1 - órgãos responsáveis por desenvolver e manter os padrões referentes à Tecnologia da Informação. Dentro do JTC1 tem-se o Subcomitê SC32 (Data Management And Interchange), este por sua vez é formado por vários grupos de trabalhos (Working Groups - WG), sendo o WG3 (Database Languages) o responsável pelo padrão SQL 61 [42].

Seguindo uma ordem cronológica das publicações das padronizações SQL, tem-se a SQL86, primeira versão, publicada pelo ANSI, todas as subsequentes, SQL-89 e SQL-92 (também conhecido como SQL2) foram publicadas pelo ISO. Este é em relação ao modelo relacional o padrão adotado pela grande maioria dos SGBRs.

Dado a difusão de uso desta estrutura e a grande quantidade de referências existente[57] [18] [46] [32], ela não será aqui detalhada. Todos os Frameworks estudados foram projetados para a estrutura relacional devido ao grande emprego e aceitação de SGBDRs. Um trabalho que reforça tal afirmação pode ser encontrado em [15] [16] [17].

\subsubsection{SBDOO}

SBDOO - (Sistemas de Banco de Dados Orientados a Objetos) armazena as informações como objetos. Tal sistema foi inicialmente construído baseando-se em linguagens de programação orientadas a objetos [57].

SGBOO são apropriados para aplicações como: projeto e fabricação auxiliados por computador (CAD/CAM - Computer-Aided Design/Computer-Aided Manufacturing); fabricação integrada ao computador (CIM - Coordinated Incident Management); engenharia de software auxiliada por computador (CASE); sistemas de informações geográficas (GIS - Geographic Information System); ciência, medicina e armazenamento e recuperação de documentos. Que são áreas com necessidades específicas de manipulação de dados [18].

Segundo [18] "Uma das razões do sucesso dos SGBDs relacionais comerciais é o padrão SQL. A ausência por vários anos de um padrão para SGBDOs pode ter sido a causa de alguns potenciais usuários terem recuado na conversão para essa nova tecnologia”. Subsequentemente um consórcio de fornecedores de SGBDOs, ODMG (Object Data Management Group), apresentou um padrão que é conhecido como ODMG-93 ou ODMG 1.0, o qual foi revisado originando o ODMG 2.0. Mais detalhes sobre ODMG pode ser encontrado em [47]. Este é basicamente composto por: linguagem de definição de objetos 
ODL (Object Definition Language); linguagem de consulta a objetos OQL (Object Query Language) e acoplamentos (bindings) para as linguagens de programação orientadas a objetos (C++, SMALLTALK e JAVA). Este modelo de objetos fornece tipos de dados, construtores e outros conceitos que podem ser utilizados na ODL para especificar esquemas de SGBDOO. Desta forma, ele deve fornecer um modelo de dados para SGBDOO, da mesma forma que o padrão SQL descreve um modelo de dados para SGBDR.

\subsubsection{SBDOR e a Normatização ISO/IEC SQL}

SBDOR - (Sistema de Banco de Dados Objeto Relacional) consiste em uma estrutura OO construída sobre o SBDR. [57].

Alguns SGBDs comercializados como relacionais, como é o caso do Oracle e do DB2 possuem suporte OR. Contudo, o suporte oferecido por esses SGBDs não é padronizado, conforme detalhado na seção 3.1

As versões subsequentes à SQL-92 incorporam os conceitos de OO, sendo a SQL-1999² ou SQL3 a primeira a trazer esses aspectos [42]. Tal versão foi estruturada em cinco partes, são elas:

SQL/Framework - descreve estrutura da norma.

SQL/Foundation - Contem toda a base da especificação.

SQL/CLI - (Call Level Interface)

SQL/PSM - (Persistent Store Modules)

SQL/Bindings

O presente trabalho usa predominantemente a SQL/Foundation.

A norma apresenta novos tipos de dados como LOB (Large Object) e ARRAY.

ARRAY, similarmente ao existente em linguagens de programação, é um tipo de dado complexo que armazena uma coleção de dados do mesmo tipo (podendo ser complexo). Cada elemento dessa coleção está associado a uma posição ordinal. Um ARRAY mantém a ordem de inserção de seus elementos. A Figura 1 exemplifica a criação de um ARRAY.

2 Agora o nome inclui os quatros dígitos do ano (1999 ao invés de 99), isto se deu devido a preocupação de não se confundir a versão SQL-02 com a SQL2 como era conhecida a versão SQL-92 


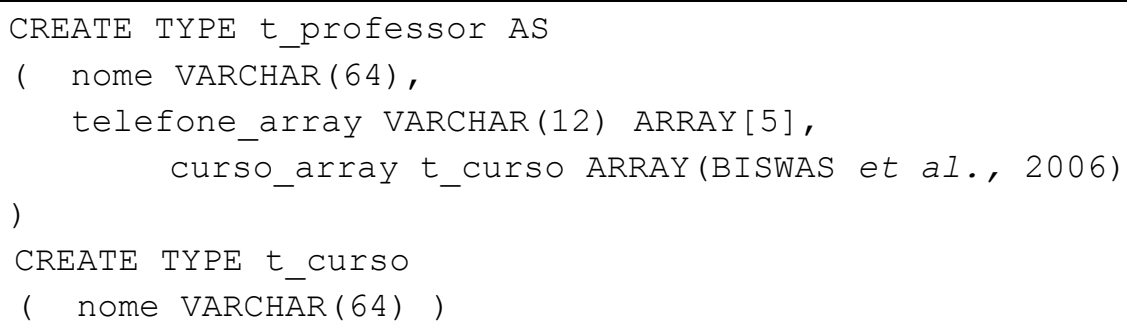

Figura 1 - Exemplo de criação de ARRAY de acordo com a SQL:99

Na Figura 1, o objeto t_professor é constituído pelos atributos nome, telefone_array e curso_array. Pode-se registrar até cinco valores para telefone_array, sendo cada valor uma cadeia de até 12 caracteres (ou seja, todos os elementos do array são do mesmo tipo). Similarmente, curso_array pode registrar até dez valores do tipo t_curso (um tipo que foi definido pelo usuário).

A SQL:2003 seguida da SQL:2008, versões que sucedeu SQL-99, apresentou uma revisão sobre os tipos de dados, principalmente os relacionados a objetos e campos multivalorados, além da abordagem de novas funcionalidades/tipos de dados para manipulação de XML [40][41]. Os tipos de dados referentes ao suporte OR e que merecem destaque para o trabalho são: UDT, ROW, REF.

UDT (User Defined Type) é um tipo complexo definido pelo usuário, é o equivalente ao objeto (OO) no contexto do banco de dados. Um UDT encapsula atributos e métodos da mesma forma que um objeto OO. Um UDT implementa herança e polimorfismo (incluindo overload e overhead [48]). Um UDT pode ser usado para gerar uma tabela (tabela tipada). Somente tabelas podem persistir dados e somente tabelas tipadas, diferentemente das tabelas convencionais, podem ser organizadas em hierarquias de herança e apresentar métodos. A tabela tipada é originada a partir de um UDT e possui a mesma estrutura deste. A Figura 2 (a) (b) e (c) mostra a criação de UDTs. Em BDOR um UDT é um tipo (tipo definido pelo usuário), no exemplo t_pessoa, t_curso e t_professor são nome de tipos UDT.

Na Figura 2(a) t_pessoa é formado pelos atributos nome, professor e data_nascimento. A cláusula NOT FINAL especifica que este tipo pode ser especializado, ou seja, gerar subtipos (ex. t_professor). A cláusula METHOD especifica a declaração de um método, get_idade na Figura 2. O atributo curso é do tipo REF para o tipo t_curso. REF faz referência para objetos armazenados em tabelas. 


\begin{tabular}{|c|c|}
\hline $\begin{array}{l}\text { (a) } \\
\text { CREATE TYPE t_pessoa AS } \\
\text { ( cPf NUMBER(12), } \\
\text { nome VARCHAR(64), } \\
\text { data_nascimento DATE, } \\
\text { curso REF (t_curso), } \\
\text { endereco ROW(num INTEGER, CEP VARCHAR) } \\
\text { ) NOT FINAL } \\
\text { METHOD get_idade (data_atual DATE) RETURN } \\
\text { INTEGER }\end{array}$ & $\begin{array}{c}\text { (b) } \\
\text { CREATE TYPE t_curso } \\
(\text { nome } \operatorname{VARCHAR}(64))\end{array}$ \\
\hline $\begin{array}{c}\text { (c) } \\
\text { CREATE TYPE t_professor UNDER t_pessoa }\end{array}$ & $\begin{array}{l}\text { (d) } \\
\text { CREATE TABLE tb_curso of } \\
\text { t_curso; }\end{array}$ \\
\hline $\begin{array}{c}(\mathbf{e}) \\
\text { CREATE TABLE tb_professor of t_professor } \\
(\text { curso WITH OPTIONS SCOPE tb_curso) }\end{array}$ & \\
\hline
\end{tabular}

Figura 2 - Criação de UDTs

Apenas tabelas persistem dados (e não UDTs). Na Figura 2 (d) e (e), mostra-se a criação das tabelas tipadas tb_curso e tb_professor, respectivamente. Em tb_professor o literal SCOPE informa que os objetos referenciados pelo atributo "curso" estarão persistidos na tabela tb_curso. Todo REF obrigatoriamente deve possuir o escopo informado, ou seja, em qual tabela o objeto referenciado estará persistido.

O tipo ROW define uma estrutura composta por um ou vários campos. Cada elemento é definido pelo par nome do campo e respectivo tipo de dados. Figura 2 (a) mostra a criação de um ROW, o atributo endereço é composto pelos campos numero e cep. É possível fazer buscas com base nos valores de um, ou dos dois campos.

MULTISET é uma estrutura multivalorada semelhante ao ARRAY, não possui ordenação e não possui uma cardinalidade, ou seja, um número máximo de elementos. $\mathrm{O}$ MULTISET pode ser utilizado para implementar composições, ou objetos complexos. Atualmente a versão mais recente da norma é a SQL:2008 [40].

\subsection{XML e XML Schema (XSD)}

XML (eXtensible Markup Language) é um especificação mantida pela W3C (World Wide Web Consortium), na qual define-se a representação da informação usando uma linguagem de marcação de forma semiestruturada [63]. XSD (XML Schema Definition) é uma 
especificação, também desenvolvida pela W3C, que formaliza e valida um esquema de um documento XML. Assim, Um XSD é utilizado para verificar se um documento XML é estruturalmente válido, como também se as informações contidas no documento estão dentro do domínio especificado no XSD [63].

Para registrar o mapeamento de classes Java para UDTs e outras estruturas e objetos do BDOR, especificou-se um XSD (Figura 4). Neste, apresenta-se: um tipo complexo ${ }^{3}$ chamado de UDT, o qual é composto pelos elementos: NAME: tipo simples (alfanuméricos de três ou mais caracteres), e é definido como obrigatório; PERSISTENT: tipo simples (booleano), definido como obrigatório; INHERITS: tipo complexo, composto pelo tipo "java-class" (definido no começo do XSD), que é responsável por armazenar o nome de uma classe Java; pelo atributo "strategy" (pode ser 0, 1 ou 3).

Todo XSD é também um XML, que por sua vez é formalizado por um XSD definido pelo W3C. A Figura 3 apresenta um exemplo de XML, definido com base no XSD da Figura 4. Na parte inicial da Figura 4 tem-se o elemento "schema", o qual apresenta três URLS que indicam o XSD, e o caminho do arquivo. No XML é apresentado a hierarquia da classe, os atributos, relacionamentos, métodos e seus parâmetros.

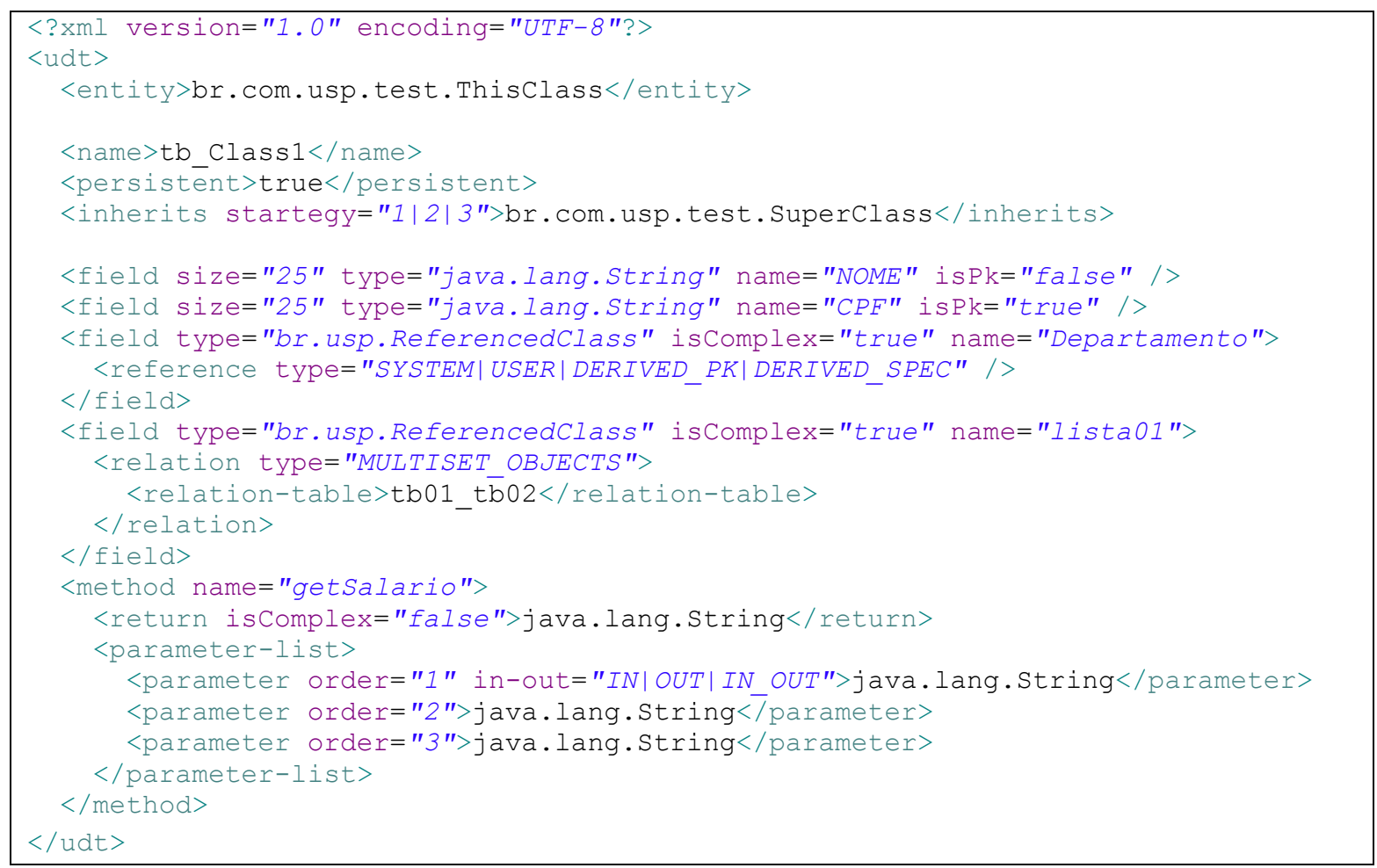

${ }^{3}$ Tipo complexo é um tipo de dados composto por um ou mais elementos, podendo ser simples ou composto. Enquanto o tipo simples possui uma única informação de um único domínio (por exemplo: numérico, alfanumérico, temporal, etc.). 
Figura 3 - Exemplo de XML

Documentos XML são utilizados para permitir a troca de informações, facilitando a interoperabilidade. Tendo acesso ao XSD, qualquer documento XML baseado naquele $\mathrm{XSD}$, pode ser lido por qualquer ferramenta de mesmo propósito, que tenha o suporte à XML. Assim, XML também é um meio apropriado para registrar internamente uma informação que precisa ser mapeada ou traduzida para diferentes dialetos, como é o caso do Framework proposto, o qual precisa gerar esquemas lógicos para diferentes SGBDs.

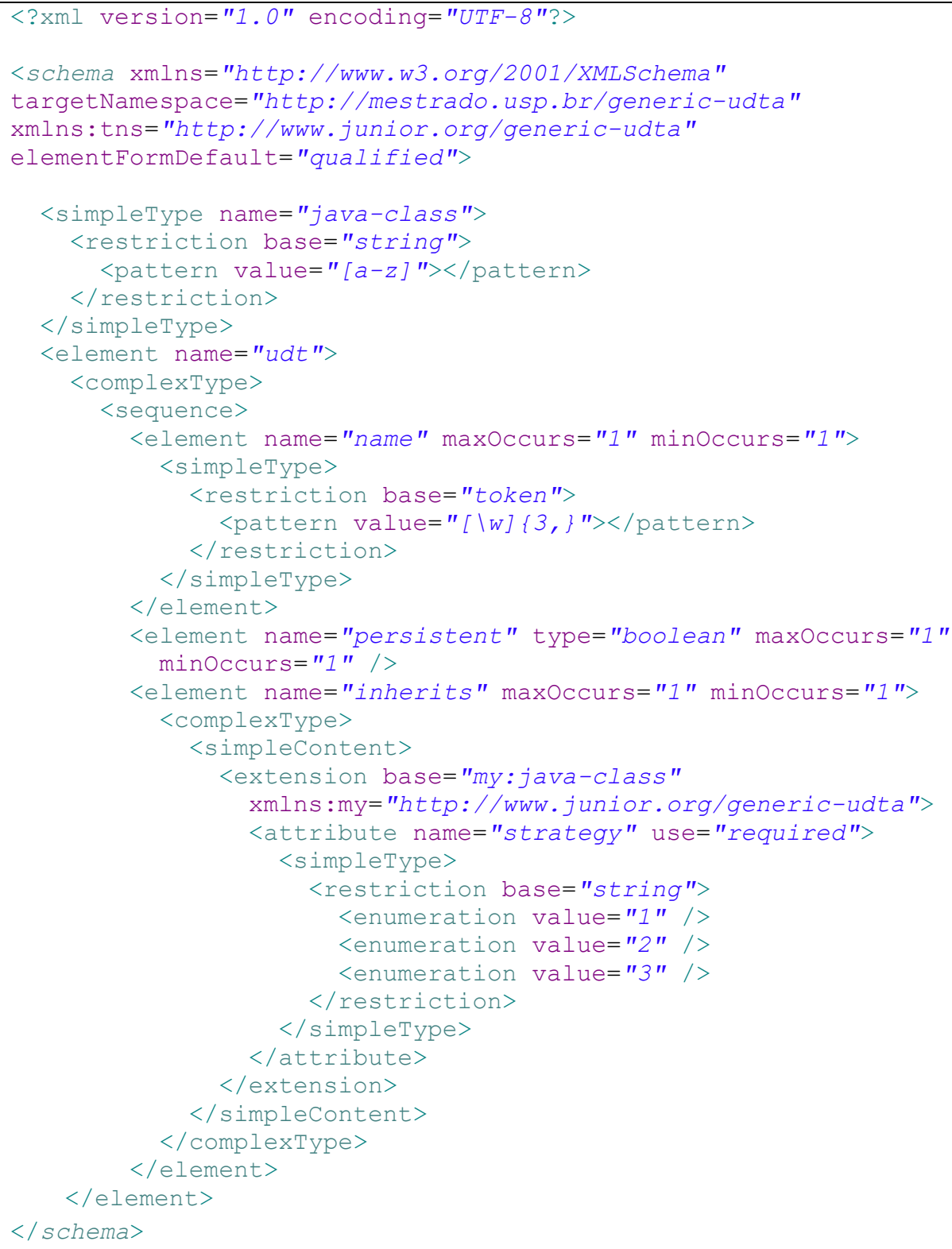




\subsection{Conceito de ORM (Object Relation Mapping).}

JDBC (Java Database Connectivity) é uma API (Aplication Program interface), baseada no conceito de ODBC (Open Database Conectivity), disponibilizada junto com a linguagem Java, que fornece um conjunto de interfaces para gerenciar as conexões, executar comandos SQL e encapsular resultados nas interações com o SGBD. A Figura 5 mostra a estrutura da API JDBC - a implementação do JDBC Driver (referente ao SGBD escolhido) é transparente para a aplicação. Cada fabricante de SGBD disponibiliza uma implementação desta API seguindo a especificação JDBC [59], com isso a interface disponível para a aplicação para conexão é sempre a mesma, independente do SGBD utilizado. Essa forma de acesso á chamada aqui de acesso direto. A migração de SGBD que também deveria ser transparente, não é, pois a SQL apresenta diferenças entre SGBDs. Assim, se for necessário acessar diferentes SGBDs é necessário, via esse tipo de conexão, reescrever código SQL apropriado a cada um deles [59].

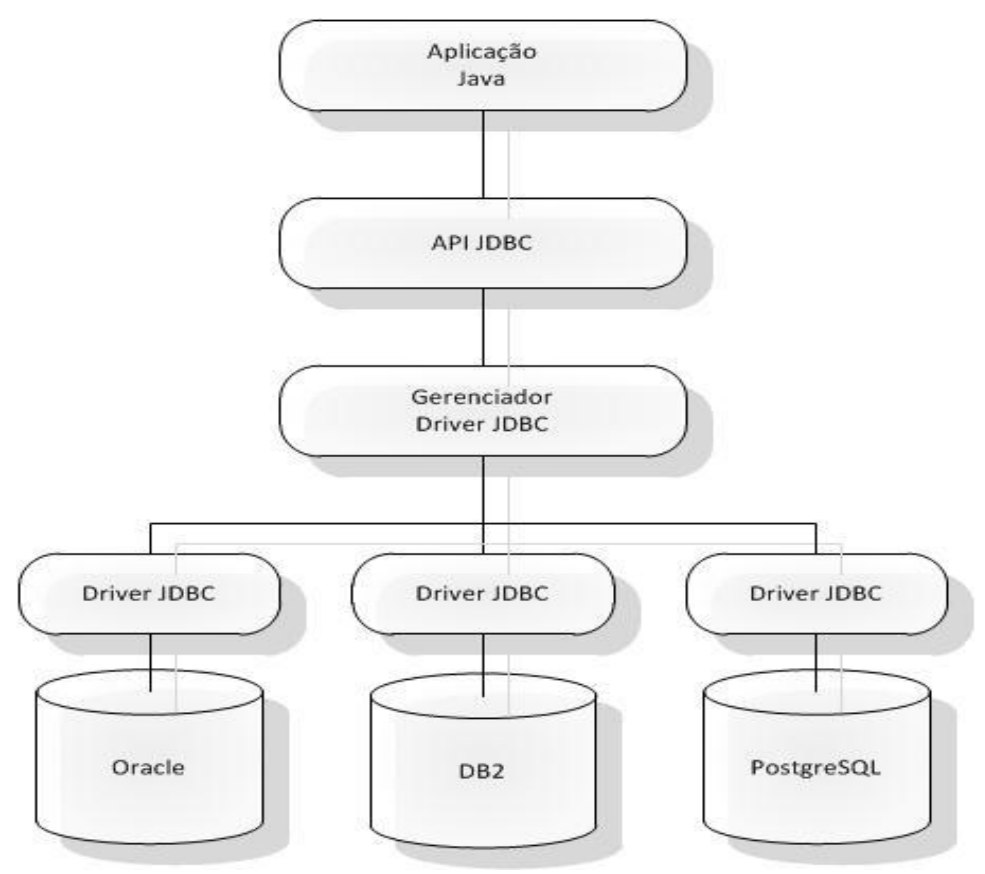

Figura 5 - Estrutura do acesso via JDBC

A vantagem de seu utilizar o acesso direto é o total controle sobre todas as interações com o SGBD. Em contrapartida tem-se o trabalho gasto com o mapeamento entre objetos e tabelas, atributos de objetos e colunas em tabelas, e ainda conversões entre os tipos de dados da aplicação e do BD, que muitas vezes requerem uma série de tratamentos e conversões. 
Outro problema é a manutenção do código da aplicação, como o mapeamento é feito manualmente, qualquer alteração que ocorra tanto na base de dados quanto na aplicação deve ser refletida por todo o mapeamento. Outro agravante são os comandos SQL, que podem ficar espalhados pela aplicação, dificultando ainda mais a manutenção. Aliado a isso, como o código SQL é dependente do SGBD utilizado, qualquer necessidade de uso de outro SGBD conduz a muito esforço para as alterações necessárias. Assim, para ambientes de banco de dados multiplataforma, o acesso direto exige tempo extra do desenvolvedor, o qual pode aumentar conforme o código de acesso ao BD esteja espalhado pela aplicação. Nesse contexto, a migração para outros SGBDs pode tornar-se um processo difícil e pouco produtivo. Além disso, como todo código SQL é gerado manualmente a probabilidade de ser falho tende a ser maior.

Outro ponto negativo nesta estratégia para persistência dos dados é que o desenvolvedor precisa ter sólidos conhecimentos sobre BDRs, SGBDs e SQL.

Segundo [09], para conexões via JDBC, 35\% do código da aplicação é gasto no gerenciamento da conexão com o SGBD e no mapeamento de objetos em tabelas.

Esses problemas conduziram à tentativas de automatização do processo de persistência em base de dados.

Alternativamente à estratégia de uso de ODBCs (ou JDBC) e de SGBDs, tentou-se persistir objetos em sua forma nativa, ou seja, sem a necessidade de mapeá-lo em tabelas. Seguindo esta estratégia, incialmente partiu-se para a serialização dos objetos, que consistia em transformar todo o objeto (incluindo os objetos relacionados recursivamente) em uma cadeia (vetor) de bytes, para assim persisti-lo [09]. Esta abordagem apresentou muitos problemas, primeiro, não era possível recuperar apenas alguns dos objetos persistidos (obrigatoriamente todos os objetos eram recuperados), o mesmo acontecia para a atualização, o que conduziu a problemas de desempenho. Outro problema que inviabilizou esta abordagem foi a dificuldade de controlar a concorrência nos acessos a estes dados [09].

Outro passo na evolução da persistência de objetos, mas persistindo os objetos em banco de dados relacionais, foi a criação de uma camada de software para a realização do mapeamento de objetos em colunas e tabelas. Esta camada ficou conhecida como ORM (Object Relation Mapping). Nesta estratégia segue-se a conexão do banco via uma API (ODBC ou JDBC), contudo o código gerado para acesso ao banco de dados, incluindo a parte que define o mapeamento de classes em tabelas, fica confinado a um ponto de acesso 
ou a uma camada [09]. Esta estratégia é uma evolução da primeira aqui descrita e facilita a reutilização e manutenção.

Ao longo dos últimos anos, vários Frameworks ORM, chamados Frameworks de persistência, foram criados. Tais mecanismos encapsulam o acesso via JDBC e funcionam como único ponto de acesso ao banco de dados. Como exemplos dessas ferramentas, podese citar o Hibernate, Torque (ambos melhor detalhados na seção 3.2.1 respectivamente), OpenJPA [06], TopLink [62], iBATIS [62], DataNucleos [62] e ORMLite [62]. Frameworks de persistência são melhor detalhados na seção 3.

\subsection{Especificações JPA e JDO}

Para apresentar ferramentas de ORM é necessário comentar primeiro sobre especificações de persistência (ORM), uma vez que os principais produtos ORM disponíveis no mercado surgiram e seguem especificações. Existe uma diferença entre especificações e implementações. Especificações são padronizações formalizadas sobre uma determinada técnica ou tecnologia, com a finalidade de garantir que todas as soluções que a implementarem, tenham as mesmas características descritas na especificação. Implementações são soluções de software (o Framework propriamente dito) que podem não seguir, ou seguir totalmente ou ainda parcialmente uma especificação [15].

Existem duas grandes especificações de persistência de dados em Java, são elas JPA [52] e JDO [51], as quais definem padrões de mapeamentos de objetos da aplicação para estruturas de SGBDs. Uma comparação entre as duas especificações pode ser encontrado [02], e uma comparação entre as implementações disponíveis das duas especificações em [03].

Java é uma linguagem de programação orientada a objetos, cuja principal vantagem é ser independente do sistema operacional, ou seja, seu código não é compilado em código nativo como acontece com as linguagens tradicionais, mas sim, compilado em bytecode [35], que por sua vez é executado em uma máquina virtual [35]. Com isto tem-se a independência de sistema operacional, bastando apenas ter a máquina virtual instalada. Existem máquinas virtuais disponíveis para os principais sistemas operacionais.

Devido à interoperabilidade e ao elevado número de aplicações corporativas desenvolvidas com Java, esta foi escolhida para o desenvolvimento do Framework proposto. Aliam-se as razões dessa escolha, a grande familiaridade do autor com o ambiente de programação Java. Para a linguagem Java [27] [61] as padronizações (especificações) são registradas 
pelo JCP (Java Community Process) [30]. Cada especificação é conhecida como JSR (Java Specification Requests).

JPA atualmente está na versão 2.0 e registrada na JSR317, trata-se de uma especificação que define uma série de interfaces [48], que definem quais as operações estão disponíveis, e anotações [49][60] para facilitar/padronizar a forma como o desenvolvedor configura a persistência de seus dados. É importante ressaltar que JPA é exclusiva para BDRs.

A especificação JPA descreve também uma linguagem de acesso aos dados, com a qual o desenvolvedor pode realizar suas consultas de forma independente do SGBD. Tal linguagem é denominada JPQL (Java Persistence Query Language), a vantagem desta linguagem é que ela é próxima da linguagem de ambiente (ou seja, Java), o que facilita sua utilização por parte do desenvolvedor. Assim, não há necessidade de aprendizagem de uma linguagem completamente diferente, o que ajuda na melhoria da produtividade. A abordagem deste tipo de linguagem está fora do contexto deste trabalho, contudo maiores detalhes sobre JPA e JPQL podem ser encontrados em [52].

Anotações consistem em um meio de inserir meta informações diretamente nas classes Java, evitando a necessidade de arquivos de configuração. Com anotações é possível acrescentar informações em classes, atributos e métodos diretamente no código. Os literais precedidos do caractere @ indicam uma anotação. A Tabela 1 apresenta algumas definições de anotações e seu significado/propósito (para maiores informações sobre estas ou demais anotações consultar [49] e [60]). A Figura 6 exemplifica algumas anotações. Nesta figura, a anotações “@Entity” e “@Inheritance” foram utilizadas para indicar, respectivamente, que a classe "Funcionário" será persistente no banco de dados e que é uma especialização da classe "Pessoa”. A anotação "@Table” indica informações sobre a tabela na qual a classe é mapeada. A anotação “@Column” é usada para fazer a correspondência entre atributos da classe e as respectivas colunas da tabela, além de indicar seu tipo de dado e possíveis restrições (ex. unicidade = unique $)$. 


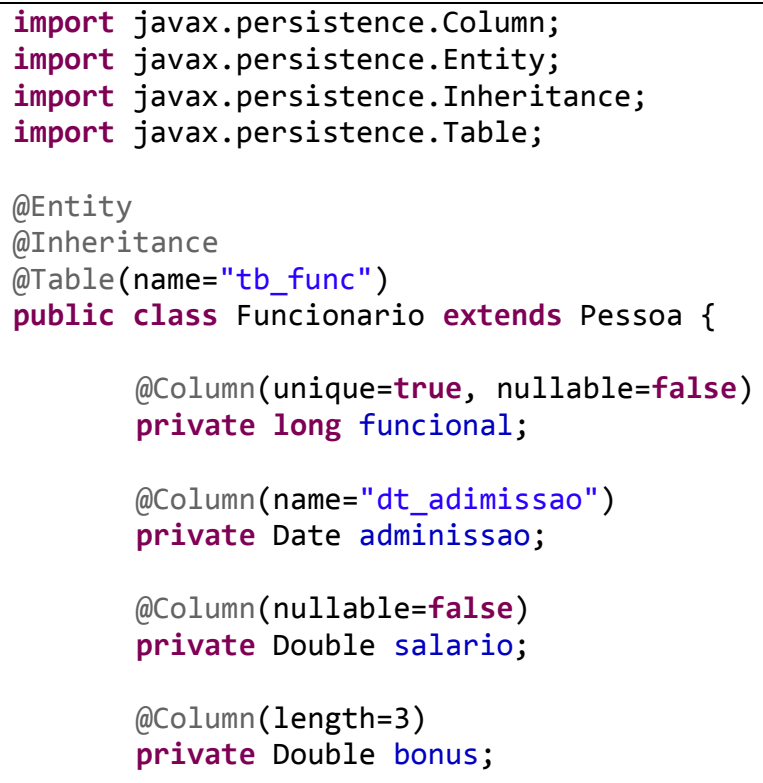

Figura 6 - Exemplo de anotações Java.

Tabela 1 - Apresentação de algumas anotações definidas na JPA

\begin{tabular}{|c|c|c|}
\hline Anotações & $\begin{array}{l}\text { Alvo da } \\
\text { Anotação }\end{array}$ & Propósito \\
\hline @Entity & Classe & Indica que a classe é persistente. \\
\hline @Inheritance & Classe & Indica que a classe é uma especialização. \\
\hline @Table & Classe & mapeia a classe para a tabela especificada. \\
\hline @Embeddable & Classe & $\begin{array}{l}\text { Indica que a classe não será persistida em uma tabela exclusiva. Será } \\
\text { incorporado em outra classe para assim compor uma tabela. Por } \\
\text { exemplo: existe uma tabela funcionário, com as colunas nome e } \\
\text { endereço; na aplicação existe o objeto funcionário com o atributo } \\
\text { nome e um atributo endereço associado a um objeto endereço. Neste } \\
\text { caso, o objeto endereço seria marcado como @embedded para que } \\
\text { seja mapeado para o atributo de funcionário. }\end{array}$ \\
\hline$@$ Id & Atributo & $\begin{array}{l}\text { Indica que o(s) atributo(s) identificam o objeto. No mapeamento, } \\
\text { corresponderá à chave primária. }\end{array}$ \\
\hline$@$ Column & Atributo & $\begin{array}{l}\text { usado para indicar que o atributo será mapeado para uma coluna da } \\
\text { tabela. }\end{array}$ \\
\hline @Temporal & Atributo & $\begin{array}{l}\text { usado para indicar que o tipo de dado do atributo é temporal (date, } \\
\text { datetime, timestamp, etc.), e no mapeamento o campo } \\
\text { correspondente deverá ter tipo de dado similar. }\end{array}$ \\
\hline$@$ Enumerated & Atributo & $\begin{array}{l}\text { usado para indicar que o atributo possui uma enumeração, ou seja, } \\
\text { um conjunto reduzido de possibilidades. No mapeamento, uma } \\
\text { restrição do tipo check será criada. }\end{array}$ \\
\hline$@$ Lob & Atributo & $\begin{array}{l}\text { usado para indicar que o atributo será persistido num campo com } \\
\text { tipo de dado LOB. }\end{array}$ \\
\hline @OneToOne & $\begin{array}{l}\text { Atributo / } \\
\text { Relacionamento }\end{array}$ & $\begin{array}{l}\text { usado para indicar que o atributo representa um relacionamento. No } \\
\text { mapeamento o respectivo campo será uma chave estrangeira. }\end{array}$ \\
\hline $\begin{array}{l}@ \text { ManyToOne } \\
\text { ou } \\
@ \text { OneToMany }\end{array}$ & $\begin{array}{l}\text { Atributo / } \\
\text { Relacionamento }\end{array}$ & $\begin{array}{l}\text { usado para indicar que o atributo representa um relacionamento. No } \\
\text { mapeamento o respectivo campo será uma chave estrangeira. }\end{array}$ \\
\hline @ManyToMany & $\begin{array}{l}\text { Atributo / } \\
\text { Relacionamento }\end{array}$ & $\begin{array}{l}\text { usado para indicar que o atributo representa um relacionamento. No } \\
\text { mapeamento, uma tabela para representar o relacionamento N-N é } \\
\text { criada. }\end{array}$ \\
\hline
\end{tabular}


Uma vantagem do emprego de Frameworks de persistência está na disponibilização de um único canal para controlar a persistência e o acesso aos objetos persistidos em banco de dados relacionais, de forma que o SGBD seja o mais transparente possível para o desenvolvedor. Essa transparência significa que o desenvolvedor não precisa ter sólidos conhecimentos de DB, SQL e do SGBD utilizado. Isso pode levar a melhor produtividade, pois além de poder focar na aplicação, o desenvolvedor não precisa criar código SQL. Este será criado pelo Framework, diminuindo a chance de construção de códigos incorretos, o que simplifica também a manutenção.

Por outro lado, quem sabe definir quais operações devem ser realizadas em conjunto, ou seja, quem sabe definir quais transações serão submetidas, bem como o início e fim dessas transações é o desenvolvedor. Assim, é fundamental para a transparência do SGBD que os Frameworks de persistência forneçam algum mecanismo de gerência de transações. Para esse propósito, a especificação JPA fornece mecanismos para o gerenciamento de transações, disponibilizando algumas classes que permitem definir início e fim de transações.

Outro aspecto importante descrito na especificação JPA [52] diz respeito à eficiência no transporte de dados recuperados do banco de dados. Em aplicações OO o conceito de referência está sempre presente. Por exemplo, no modelo de classes apresentado na Figura 7, tanto a classe Cliente poderia fazer referência aos pedidos a que está associada, quanto a classe Pedido aos seus clientes. Neste caso, ao especificar uma consulta para, por exemplo, listar os clientes existentes, pode não se estar interessado em saber quais são os respectivos pedidos. Então, trazer informações sobre os pedidos referenciados seria desnecessário. Trazer informações desnecessárias significa, uso de memória para manter as informações retornadas, além de acesso desnecessário ao disco para buscar os dados dos pedidos. Analisando simplificadamente e somente sob o ponto de vista de banco de dados, dependendo da quantidade de acessos a discos e do estado da memória, esse processo pode ser muito ineficiente e demorado. E o que é pior, pode-se pagar alto em termos de tempo de resposta devido a acesso a informações desnecessárias.

Para contornar esse problema, os Frameworks oferecem ao recurso Lazy e Eager. Esse recurso permite ao desenvolvedor especificar como o Framework irá recuperar os objetos referenciados pelo objeto resultante da consulta. O conceito de Lazy e Eager está associado a consultas que envolvem um objeto e referências mantidas por este a outros objetos. $\mathrm{O}$ que difere os dois conceitos é o retorno da consulta. Enquanto no Lazy somente o objeto foco é retornado como resultado da consulta, os objetos referenciados por este serão 
retornados (ou buscados) por demanda, ou seja, se forem necessários, uma nova consulta deve ser especificada. No caso do Eager, o objeto foco da consulta e todos os objetos referenciados são retornados como resultado de uma única consulta, em outras palavras, mesmo que objetos referenciados não sejam utilizados, eles são carregados em memória [51] [52].

O conceito de Lazy e Eager trata da recuperação de objetos, existe ainda outro conceito semelhante, chamado cascade, porém no contexto de persistência (ou seja, para operações de inclusão, atualização e remoção) de objetos e não na recuperação [51] [52]. O qual permite ao desenvolvedor especificar se os objetos relacionados serão persistidos junto com o objeto que foi solicitado a persistência. Um exemplo onde se emprega os conceitos Eager e cascade, é quando o desenvolvedor recupera um objeto A, este objeto possui um relacionamento com o objeto $\mathrm{B}$, o qual está configurado como Eager, ou seja, na recuperação do objeto $\mathrm{A}$ o objeto $\mathrm{B}$ é recuperado automaticamente. $\mathrm{O}$ desenvolvedor altera alguns atributos do objeto $\mathrm{A}$ e do objeto $\mathrm{B}$, no entanto o relacionamento entre $\mathrm{A}$ e $\mathrm{B}$ não foi alterado, quando o desenvolvedor solicitar ao Framework (solução JPA) a persistência do objeto A, o Framework de acordo com a configuração cascade, persistirá ou não as alterações no objeto B.

JPA define uma série de outras funcionalidades [10] [52]como, por exemplo, a criação de cache (conhecida como cache de segundo nível) ${ }^{4}$ de objetos na aplicação, controle de índices, consultas predefinidas, etc. Tais funcionalidades não serão aqui detalhadas, pois encontram-se fora do escopo trabalho, o qual visa mostrar a viabilidade da ferramenta, além de investigar, mesmo que superficialmente, a utilidade dos novos elementos de SGBDOR. Contudo, essas funcionalidades precisarão ser consideradas em caso de geração de uma versão para efetivo uso em ambiente de produção. .

A especificação JDO, ODMG (Object Data Management Group) [47], encontra-se na versão 2.0 registrado na JSR243. Diferentemente da especificação JPA, que é voltada exclusivamente para persistência em SGBDs relacionais, a JDO é definida para persistir dados em diferentes estruturas como arquivos em geral, SGBR, SGDBOR, SGBDOO, BD XML, etc. Entretanto muitas das características descritas na JPA também estão presentes

${ }^{4} \mathrm{O}$ uso de cache de objetos fora do SGBD pode ocasionar conflitos para o controle de concorrência ao dado. Objetos podem ser alterados fora do escopo da aplicação, ou seja, se se a aplicação B alterar um objeto que aplicação A mantem em cache, problemas de controle de concorrência são gerados. 
na JDO. Dentre essas características pode-se citar: ser um meio de persistência transparente ao desenvolvedor; controles de desempenho na interação com o BD (Lazy x Eager e cascade); gerenciamento de transações; controle de cache; linguagem própria de acesso aos dados: JDOQL (Java Data Object Query Language) [51]; uso de anotações para fazer o mapeamento de objetos para tabelas, ou qualquer outro meio de persistência (Tabela 2 apresenta estas anotações).

Apesar de a especificação abranger SBDOR como meio de persistência, não foi encontrado nenhum Framework (implementação) com este suporte. Nenhuma referência a elementos e estruturas específicas de BDOR como REF, UDT, campos multivalorados (por exemplo ARRAY e MULTISET) e hierarquia não foram identificados. Conclui-se que apesar da especificação JDO oferecer suporte à SBDOR, este é bastante genérico. A Tabela 2 apresenta exemplos de anotações disponibilizadas pela JDO. 
Tabela 2 - Anotações disponibilizadas na especificação JDO

\begin{tabular}{|c|c|c|}
\hline Anotações & $\begin{array}{l}\text { elemento } \\
\text { alvo da } \\
\text { anotação }\end{array}$ & Propósito \\
\hline$@$ PersistenceCapable & Classe & Indica que a classe é persistente \\
\hline @PersistenceAware & Classe & $\begin{array}{l}\text { Indica que a classe não é persistida, porém acessa atributo de classes } \\
\text { persistidas, ou seja, possui referências para objetos persistidos; ficando a } \\
\text { cargo do Framework recuperar estes objetos de forma transparente ao } \\
\text { desenvolvedor }\end{array}$ \\
\hline @EmbeddedOnly & Classe & $\begin{array}{l}\text { Indica que a classe deverá ficar embutida em outra classe no momento } \\
\text { da persistência, similar a especificação JPA }\end{array}$ \\
\hline @ DatastoreIdentity & Classe & $\begin{array}{l}\text { Indica como será feita identificação do objeto. Este objeto pode estar } \\
\text { persistido em outras estruturas diferentes de BDR }\end{array}$ \\
\hline @ Sequence & Classe & Indica que será criada uma sequência semelhante à sequência de BDR. \\
\hline @Inheritance & Classe & Indica que a classe é uma especialização \\
\hline @Persistent & Atributo & Indica que o atributo será persistido \\
\hline @Serialized & Atributo & Indica que o atributo será persistido de forma serializada $^{5}$ \\
\hline @ NotPersistent & Atributo & $\begin{array}{l}\text { Indica que o atributo não será persistido, mesmo a classe sendo } \\
\text { persistente. }\end{array}$ \\
\hline @Transactional & Método & $\begin{array}{l}\text { Indica que processamento deste método é realizado dentro de uma } \\
\text { transação }\end{array}$ \\
\hline @PrimaryKey & Atributo & $\begin{array}{l}\text { Indica que o atributo compõe a chave primária, desde seja utilizado BDR } \\
\text { / BDOR. }\end{array}$ \\
\hline @Element & Atributo & $\begin{array}{l}\text { Quanto o atributo é multivalorado, indica o tipo de dados dos elementos } \\
\text { desta coleção. }\end{array}$ \\
\hline$@$ Order & Atributo & Em campos multivalorados, indica como os elementos serão ordenados. \\
\hline @ Join & Atributo & $\begin{array}{l}\text { Indica uma junção com outra tabela, ou mesmo com outras estruturas } \\
\text { multivariadas, como por exemplo, vetores. }\end{array}$ \\
\hline$@$ Column & Atributo & $\begin{array}{l}\text { Quando persistido em BDR / BDOR indica detalhes (como nome, tipo } \\
\text { de dado e tamanho do campo) sobre a coluna para a qual será mapeado.. }\end{array}$ \\
\hline @Index & Atributo & Indica a criação de índices. \\
\hline @Unique & Atributo & Indica restrição de unicidade. \\
\hline @ForeignKey & Atributo & Indica uma chave estrangeira, quando persistido em BDR / BDOR. \\
\hline
\end{tabular}

${ }^{5}$ Serializar significa transformar o objeto (juntamente com os objetos referenciados) em uma sequência de bytes, para que assim possa ser persistido ou transportado. 


\section{Análise de SGBDORs e Frameworks ORM}

\subsection{Diferenças de implementação entre os SGBDs Oracle e DB2:}

Como comentado anteriormente, a extensão de SGBDRs para suporte a $\mathrm{OO}$ se deu primeiramente por iniciativa dos fabricantes de SGBDs. Somente depois do surgimento de SGBDs com um recurso ou outro para a manipulação de objetos é que foi publicada a versão da especificação SQL (SQL-99) que padronizava os recursos de OO disponíveis em SGBDOR. Esse processo acabou introduzindo grandes diferenças entre os recursos para manipulação de objetos disponibilizados pelos SGBDORs.

Essa diferença dos recursos ofertados pelos SGBDs para o suporte a $\mathrm{OO}$ em relação à norma introduz complexidade extra quando o objetivo é tratar ou usar ferramentas que traduzam objetos e/ou conceitos de $\mathrm{OO}$ de um modelo ou de um código para estes SGBDs. É preciso verificar o que existe em um SGBD e o que não existe e, neste caso, definir como aquele "conceito" será mapeado.

Para exemplificar as diferenças do suporte a OO de SGBDs apresenta-se a seguir uma comparação entre os SGBDs: Oracle 11g Release 2 e o DB2 versão 9.7.5 Neste estudo foi levado em consideração o suporte às funcionalidades descritas na norma SQL:2008 e principalmente as diferenças de sintaxe entre os dois gerenciadores, devido a sua importância para a implementação do Framework.

Para facilitar a comparação utiliza-se como exemplo o modelo de classes apresentado na Figura 7. O modelo refere-se a um sistema simplificado para uma loja online especializada em produtos de informática. Os seguintes requisitos foram identificados na fase de concepção do sistema:

A loja trabalha com a venda de produtos nos seguimentos de software e hardware;

Clientes cadastrados, identificados por nome e CPF, podem realizar compras dos produtos disponíveis no site da loja;

O sistema deve armazenar o endereço (número e a rua) dos clientes cadastrados;

Os produtos no seguimento de software apresentam o número de versão. Já os produtos no seguimento de hardware apresentam a montadora;

O sistema deve possibilitar a geração de relatórios para clientes, relacionando as compras realizadas em um determinado período, como para gerência. 


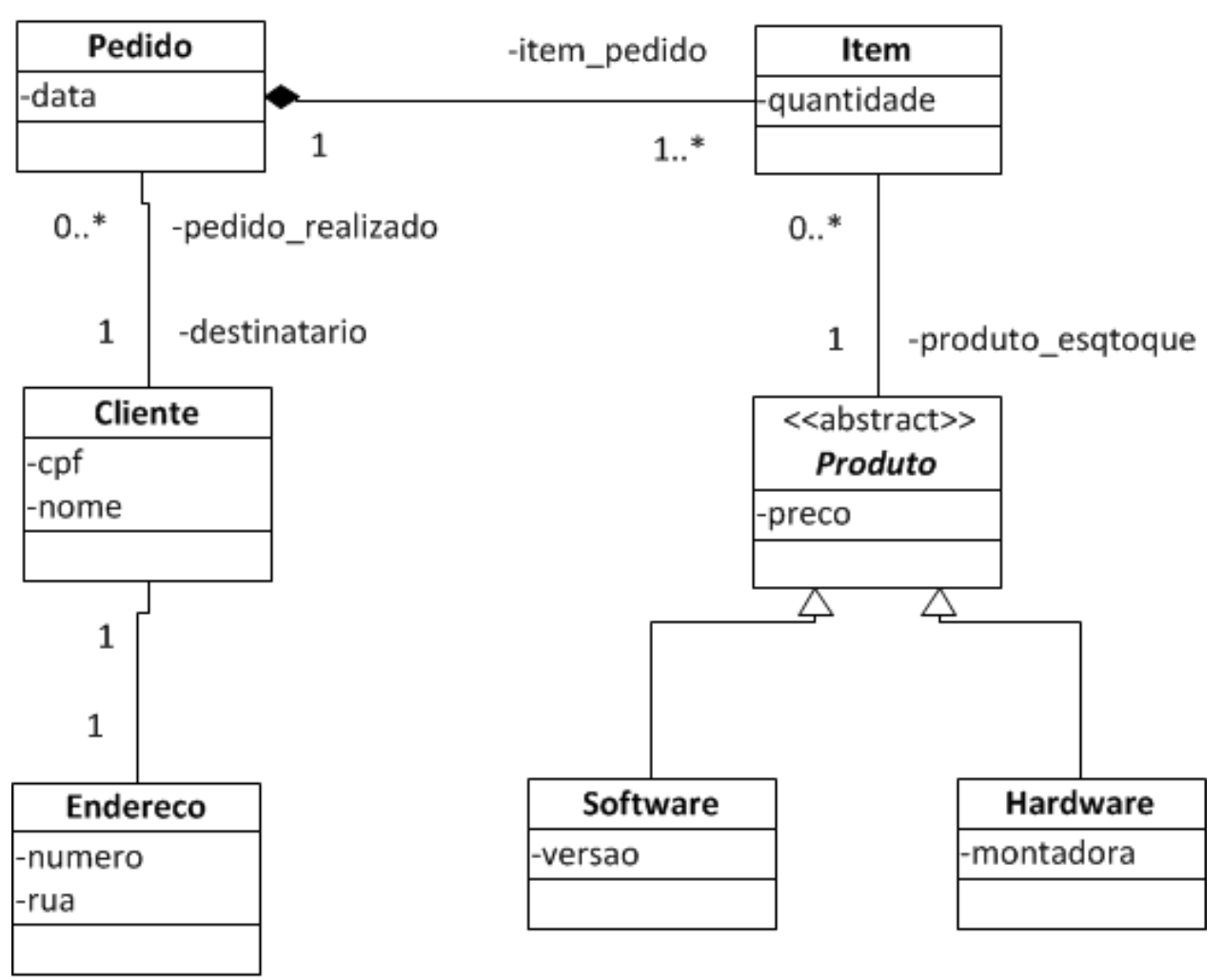

Figura 7 - Exemplo de um Esquema Conceitual descrito por um diagrama de classe UML.

A Tabela 3 apresenta as diferenças entre os SGBDS e entre a SQL:2008 quanto a criação a criação de UDTs e tabelas tipadas sobre os mesmos. Na criação de UDTs o Oracle apresentou a mesma sintaxe que a norma, com a exceção do uso do literal "AS OBJECT" entre o nome e o corpo do UDT, enquanto o DB2 se diferenciou apenas pelo acréscimo do literal "MODE DB2SQL" no final do UDT. 
Tabela 3 - Mapeamento do esquema conceitual da classe Produto presente Figura 7 para esquema lógico e físico, considerando a norma SQL:2008 e os SGBDs Oracle e DB2.

\begin{tabular}{|c|c|}
\hline & Classe Produto \\
\hline SQL:2008 & $\begin{array}{l}\text { CREATE TYPE Produto AS ( } \\
\text { num INTEGER, preCO REAL ) NOT FINAL } \\
\text { CREATE TABLE tb_produto OF Produto( } \\
\text { num WITH OPTIONS PRIMARY KEY) }\end{array}$ \\
\hline Oracle & $\begin{array}{l}\text { CREATE TYPE Produto AS OBJECT ( } \\
\text { num INTEGER, preco REAL ) NOT FINAL } \\
\text { CREATE TABLE to_produto OF Produto( } \\
\text { num PRIMARY KEY) } \\
\text { OBJECT IDENTIEIER IS PRIMARY KEY }\end{array}$ \\
\hline DB2 & $\begin{array}{l}\text { CREATE TYPE Produto AS ( } \\
\text { num INTEGER, preco REAL ) NOT FINAL MODE DB2SQL; } \\
\text { CREATE TABLE tb_produto OF Produto ( } \\
\text { REF IS OID SYSTEM GENERATED } \\
\text { NUM WITH OPTIONS NOT NULL PRIMARY KEY ) }\end{array}$ \\
\hline
\end{tabular}

Vale lembrar que a classe Produto é abstrata, logo não deveria existir uma tabela tipada, uma vez que não seria gerada instancia da classe Produto e consequentemente, não necessitária de uma tabela para persistir. O motivo se criar tabela tipada para este UDT, é o de apresentar herança entre tabela (apresentado ainda nesta seção).

Sobre as diferenças de sintaxe na criação de tabelas tipadas, o Oracle não utiliza o literal "WITH OPTIONS" (descrito na norma) para especificar qual coluna será a primary key, e também foi necessário especificar como seria controlado o OID, no caso "OBJECT IDENTIFIER IS PRIMARY KEY” (sintaxe diferente da norma). O DB2 apresentou a necessidade de se especificar a forma como seria controlado o OID. Sintaticamente o DB2 é exatamente igual a norma na criação de tabelas tipadas.

A Tabela 4 apresenta as diferenças na especialização de UDT e tabelas, em UDTs não houve diferenças entre os SGBDs e a norma, todos apresentam a mesma sintaxe.

Além da herança de UDT a norma também apresenta herança entre tabelas (restrições e dados) (APÊNDICE A ). Neste ponto o DB2 demonstrou a mesma sintaxe que a norma, necessitando apenas incluir a literal "INHERIT SELECT PRIVILEGES" no final, enquanto o Oracle não apresentou suporte à herança de tabelas. 
Tabela 4 - Mapeamento do esquema conceitual da classe Software presente Figura 7 para esquema lógico e físico, considerando a norma SQL:2008 e os SGBDs Oracle e DB2.

\begin{tabular}{|c|c|}
\hline \multicolumn{2}{|r|}{ Classe Software } \\
\hline SQL:2008 & $\begin{array}{l}\text { CREATE TYPE Software UNDER Produto AS ( } \\
\text { versao VARCHAR ) FINAL } \\
\text { CREATE TABLE tb_software OF Software UNDER tb_produto }\end{array}$ \\
\hline Oracle & $\begin{array}{l}\text { CREATE TYPE Software UNDER Produto ( } \\
\text { versao VARCHAR2(15)) FINAL } \\
\text { CREATE TABLE tb_software OF Software( num PRIMARY KEY ) }\end{array}$ \\
\hline DB2 & $\begin{array}{l}\text { CREATE TYPE Software UNDER Produto AS ( } \\
\text { versao VARCHAR(15), FINAL MODE DB2SQL } \\
\text { CREATE TABLE tb_software OF Software UNDER tb_produto } \\
\text { INHERIT SELECT PRIVILEGES }\end{array}$ \\
\hline
\end{tabular}

Ressaltando que a norma permite apenas a definição de chave primaria na tabela raiz da hierarquia, o mesmo acontece com o DB2, já o Oracle como não suporta especialização de tabelas, somente UDT, necessitou especificar chaves primarias em todas as tabelas da hierarquia, onde apenas a estrutura presente no UDT é herdado.

A Tabela 5 não apresentou nenhuma diferença que não tenha sido descrita anteriormente.

Tabela 5 - Mapeamento do esquema conceitual da classe Hardware presente Figura 7 para esquema lógico e físico, considerando a norma SQL:2008 e os SGBDs Oracle e DB2.

\begin{tabular}{|c|c|}
\hline \multicolumn{2}{|r|}{ Classe Hardware } \\
\hline SQL:2008 & $\begin{array}{l}\text { CREATE TYPE Hardware UNDER Produto AS ( } \\
\text { montadora VARCHAR2 ) FINAL } \\
\text { CREATE TABLE to_hardware OF Hardware UNDER to_produto }\end{array}$ \\
\hline Oracle & $\begin{array}{l}\text { CREATE TYPE Hardware UNDER Produto ( } \\
\text { montadora VARCHAR2 (30) ) FINAL } \\
\text { CREATE TABLE to_hardware OF Hardware ( num PRIMARY KEY ) }\end{array}$ \\
\hline DB2 & $\begin{array}{l}\text { CREATE TYPE Hardware UNDER Produto AS ( } \\
\text { montadora VARCHAR(30), FINAL MODE DB2SQL; } \\
\text { CREATE TABLE to_hardware OF Hardware UNDER to_produto } \\
\text { INHERIT SELECT PRIVILEGES }\end{array}$ \\
\hline
\end{tabular}


A Tabela 6 apresenta as diferenças no uso de referencias (REF), tanto na criação do UDT quando tabela tipada. Ambos os SGBDs possuem suporte à REF, sendo o Oracle o único a apresentar diferença em relação a norma, na criação do UDT não foi necessário colocar ente parêntesis o UDT referenciado, na criação de tabelas tipadas todos possuem a mesma sintaxe.

Tabela 6 - Mapeamento do esquema conceitual da classe Item presente Figura 7 para esquema lógico e físico, considerando a norma SQL:2008 e os SGBDs Oracle e DB2.

\begin{tabular}{|c|c|}
\hline \multicolumn{2}{|r|}{ Classe Item } \\
\hline SQL:2008 & $\begin{array}{l}\text { CREATE TYPE Item AS ( } \\
\text { num INTEGER, quantidade INTEGER, } \\
\text { produto_estoque REF(Produto) ) FINAL } \\
\text { CREATE TABLE to_item OF Item ( } \\
\text { produto_estoque WITH OPTIONS NOT NULL SCOPE tb_produto, } \\
\text { num WITH OPTIONS PRIMARY KEY) }\end{array}$ \\
\hline Oracle & $\begin{array}{l}\text { CREATE TYPE Item AS OBJECT ( } \\
\text { num INTEGER, quantidade INTEGER, } \\
\text { produto_estoque REF Produto ) FINAL } \\
\text { CREATE TABLE to_item OF Item ( } \\
\text { num PRIMARY KEY, } \\
\text { produto_estoque WITH OPTIONS SCOPE tb_produto) }\end{array}$ \\
\hline DB2 & $\begin{array}{l}\text { CREATE TYPE Item AS ( } \\
\text { num INTEGER, quantidade INTEGER, } \\
\text { produto_estoque REF(Produto) ) FINAL MODE DB2SQL; } \\
\text { CREATE TABLE tb_item OF Item ( } \\
\text { REF IS OID SYSTEM GENERATED, } \\
\text { produto_estoque WITH OPTIONS SCOPE tb_produto, } \\
\text { num WITH OPTIONS NOT NULL PRIMARY KEY) }\end{array}$ \\
\hline
\end{tabular}

A Tabela 7 mostra a utilização de MULTISET, que é um tipo construído composto, ou seja, uma estrutura multivalorada. O grande problema é que ambos SGBDs não possuem suporte a este tipo, o Oracle ainda apresenta uma alternativa, enquanto o DB2 não possui nenhum tipo equivalente. A alternativa apresentada no Oracle é a utilização de tabelas aninhadas, que são estruturas multivaloradas sem limite de registros e com estrutura definida, similarmente o MULTISET. Sintaticamente não existe nenhuma semelhança, a criação de tabelas aninhadas é feita através da criação de um UDT (item_pedido_nested) contendo a estrutura a ser persistida, ou seja, uma coleção de referencias para o UDT item, e por fim, na criação da tabela utiliza-se o item_pedido_nested [53]. 
O DB2 suporta a criação dos tipos compostos ROW, ARRAY e MULTISET, no entanto estes tipos não podem ser persistidos [28]. Podendo apenas ser usados como variáveis, cursores [18], parâmetros ou retorno de rotinas SQL (funções, instruções compiladas, funções, etc.) [28]. Assim, para o exemplo, optou-se pelo uso da criação de uma tabela (item_pedido) que armazena chaves estrangeiras.

Tabela 7 - Mapeamento do esquema conceitual da classe Pedido presente Figura 7 para esquema lógico e físico, considerando a norma SQL:2008 e os SGBDs Oracle e DB2.

\begin{tabular}{|c|c|}
\hline \multicolumn{2}{|r|}{ Classe Pedido } \\
\hline SQL:2008 & $\begin{array}{l}\text { CREATE TYPE Pedido AS ( } \\
\text { num INTEGER, data DATE, destinatario REF(Cliente), } \\
\text { item_pedido REF(Item) MULTISET ) FINAL } \\
\text { CREATE TABLE tb_pedido OF Pedido ( } \\
\text { num WITH OPTIONS PRIMARY KEY, } \\
\text { item_pedido WITH OPTIONS SCOPE tb_item) }\end{array}$ \\
\hline Oracle & $\begin{array}{l}\text { CREATE TYPE item_pedido_nested AS TABLE OF REF Item } \\
\text { CREATE TYPE Pedido AS OBJECT ( } \\
\text { num INTEGER, data DATE, destinatario REF Cliente, } \\
\text { item_pedido item_nested_table_type) FINAL } \\
\text { CREATE TABLE to_pedido OF Pedido( } \\
\text { num PRIMARY KEY, } \\
\text { item_pedido WITH OPTIONS SCOPE to_item ) } \\
\text { NESTED TABLE item_pedido STORE AS item_pedido_nested }\end{array}$ \\
\hline DB2 & $\begin{array}{l}\text { CREATE TYPE Pedido AS ( } \\
\text { num INTEGER, data DATE, } \\
\text { destinatario REF(Cliente) ) FINAL MODE DB2SQL; } \\
\text { CREATE TABLE to_pedido OF Pedido ( } \\
\text { REF IS OID SYSTEM GENERATED, } \\
\text { num WITH OPTIONS NOT NULL PRIMARY KEY ); } \\
\text { CREATE TABLE item_pedido ( } \\
\text { P_nUm INTEGER, i_num INTEGER, } \\
\text { CONSTRAINT fk_pedido FOREIGN KEY (p_num) } \\
\text { REFERENCES tb_pedido(num), } \\
\text { CONSTRAINT fk_item FOREIGN KEY (i_num) } \\
\text { REFERENCES tb_item(num) ); }\end{array}$ \\
\hline
\end{tabular}


A Tabela 8 mostra a utilização do tipo ROW, neste ponto os SGBDs apresentam uma diferença considerável em relação à norma. Segundo a norma, um ROW pode ser criado diretamente na criação de uma tabela, enquanto nos SGBDs, primeiro deve ser criado um UDT com a estrutura do ROW e na criação da tabela, usa-se o UDT. Isso mostra que efetivamente não há suporte ao tipo ROW pelos SGBDs analisados. [53].

Tabela 8 - Mapeamento do esquema conceitual da classe Endereço presente Figura 7 para esquema lógico e físico, considerando a norma SQL:2008 e os SGBDs Oracle e DB2.

\begin{tabular}{|c|c|}
\hline \multicolumn{3}{|c|}{ Classe Endereço } \\
\hline \multirow{2}{*}{ SQL:2008 } & $\begin{array}{l}\text { CREATE TABLE tb_enderecos ( } \\
\text { Endereco ROW ( numero INTEGER, rua VARCHAR2 ) ) }\end{array}$ \\
\hline \multirow{2}{*}{ Oracle } & CREATE TYPE Endereco AS OBJECT ( \\
numero INTEGER, rua VARCHAR2 (30)) FINAL \\
\hline DB2 & CREATE TYPE Endereco AS ( \\
numero INTEGER, rua VARCHAR (30)) FINAL MODE DB2SQL;
\end{tabular}

A Tabela 9 apresenta a definição do UDT respectivo à classe Cliente, onde se evidencia a declaração de métodos. A norma SQL define dois tipos de métodos: os estáticos (static) e os de instância. De forma similar a UML [48] métodos estáticos podem ser invocados a partir da classe (não necessitando de uma instância) enquanto os métodos de instância, só podem ser invocados em um objeto instanciado. Segundo a norma SQL os literais "static" e "instance" são usados para diferenciar os métodos. De forma diferente o Oracle usa os literais "static" e "member". Enquanto o DB2 não possui suporte a métodos estáticos, logo não faz uso de nenhum literal para diferenciá-los.

Existe ainda um Terceiro tipo de método (não presente na Tabela 9), são chamados de funções construtoras. São funções/métodos (estáticas) responsáveis por gerar instâncias de uma determinada classe, similar ao que se tem em linguagens de programação OO. Toda Classe, assim como todo UDT, possui um construtor implícito, ou seja, um método/função com o mesmo nome que a classe e capaz de gerar instâncias. Através do polimorfismo ainda é possível sobrescrever (e/ou sobrecarregar) o construtor, implementando uma ação especifica. 
Tabela 9 - Mapeamento do esquema conceitual da classe Cliente presente Figura 7 para esquema lógico e físico, considerando a norma SQL:2008 e os SGBDs Oracle e DB2.

\begin{tabular}{|c|c|}
\hline \multicolumn{2}{|r|}{ Classe Cliente } \\
\hline SQL:2008 & $\begin{array}{l}\text { CREATE TYPE Cliente AS ( cPf INTEGER, } \\
\text { nome VARCHAR2(30), } \\
\text { Endereco ROW( numero INTEGER, rua VARCHAR2 ), } \\
\text { pedido_realizado REF(Pedido) MULTISET ) FINAL } \\
\text { CONSTRUCTOR METHOD Cliente( CPf INTEGER, nome VARCHAR2, } \\
\text { endereco ENDERECO) RETURNS SELF AS RESULT, } \\
\text { STATIC METHOD isValidoCPF(cpf INTEGER) RETURNS CHAR, } \\
\text { INSTANCE METHOD addPedidio( pedido PEDIDO ) RETURNS CHAR } \\
\text { CREATE TABLE tb_Cliente OF Cliente ( } \\
\text { nome WITH OPTIONS NOT NULL, } \\
\text { CPf WITH OPTIONS PRIMARY KEY, } \\
\text { pedido_realizado WITH OPTIONS SCOPE tb_pedido) }\end{array}$ \\
\hline Oracle & $\begin{array}{l}\text { CREATE TYPE pedido_nested_table_type AS TABLE OF REF } \\
\text { Pedido } \\
\text { CREATE TYPE Cliente AS OBJECT ( } \\
\text { CPf INTEGER, nome VARCHAR2(30), } \\
\text { myEndereco ENDERECO, } \\
\text { pedido_realizado pedido_nested_table_type, } \\
\text { CONSTRUCTOR FUNCTION Cliente ( } \\
\text { CPf INTEGER, nome VARCHAR2, endereco ENDERECO) } \\
\text { RETURN SELF AS RESULT, } \\
\text { STATIC FUNCTION isValidoCPF(cpf INTEGER) RETURN CHAR, } \\
\text { MEMBER FUNCTION addPedidio ( pedido PEDIDO) } \\
\text { RETURN CHAR ) FINAL } \\
\text { CREATE TABLE tb_cliente OF Cliente ( } \\
\text { nome NOT NULL, cpf PRIMARY KEY) } \\
\text { NESTED TABLE pedido_realizado STORE AS } \\
\text { pedido_realizado_nested_table }\end{array}$ \\
\hline DB2 & $\begin{array}{l}\text { CREATE TYPE Cliente AS ( } \\
\text { CPf INTEGER, nome VARCHAR(30), } \\
\text { myEndereco Endereco) FINAL MODE DB2SQL } \\
\text { METHOD Cliente( cPf INTEGER, nome CHAR, } \\
\text { endereco Endereco ) RETURNS Cliente, } \\
\text { METHOD isValidoCPF(cpf INTEGER) RETURNS CHAR, } \\
\text { METHOD addPedidio( pedido PEDIDO ) RETURNS CHAR ; } \\
\text { CREATE TABLE tb_cliente OF Cliente ( } \\
\text { REF IS OID SYSTEM GENERATED, } \\
\text { nOme WITH OPTIONS NOT NULL, } \\
\text { CPf WITH OPTIONS PRIMARY KEY NOT NULL); } \\
\text { CREATE TABLE item_realizado ( } \\
\text { P_nUm INTEGER, CPf INTEGER, } \\
\text { CONSTRAINT fk_pedido FOREIGN KEY (p_num) } \\
\text { REFERENCES tb_pedido(num), } \\
\text { CONSTRAINT fk_cliente FOREIGN KEY (cPf) } \\
\text { REFERENCES tb_cliente(CPf) ); }\end{array}$ \\
\hline
\end{tabular}




\subsection{Importância dos Métodos.}

SGBDR oferece a garantia de integridade para dados que estão relacionados (integridade referencial), obviamente desde que se informe isso ao SGBD. SGBDOR por sua vez apresentam Referências (REF), que são ponteiros semelhantes aos de aplicação.

No entanto com o uso de REFs não há nenhuma garantia que o objeto referenciado exista, ou seja, imagine que um objeto A mantenha uma REF para o objeto B, o SGBD neste caso não garante a existência do objeto $\mathrm{B}$, ou seja, este pode ser removido sem que o objeto $\mathrm{A}$ seja notificado. Uma estratégia, com o intuito de tirar proveito dos recursos SGBDOR, é implementar a integridade destas referencias através do uso de métodos. . A estratégia seria a criação de um método para garantir que quando um objeto for excluído, seja garantido que não existam referencias perdidas ou então, o objeto não será excluído. Assim, têm-se a integridade referencial, e ainda se mantem a vantagem da navegação entre ponteiros, disponibilizada pelo REF.

\subsection{ORM (Object - Relational Mapping)}

Os Frameworks ORM estudados neste trabalho foram o Hibernate [29] e o Apache Torque [04]. O Hibernate por ter uma gama maior de funcionalidades, por seguir a especificação JPA e pela sua maturidade. Por outro lado o Torque com uma menor contribuição para o trabalho apresenta características importantes.

\subsubsection{Frameworks Hibernate e Torque}

O Framework Hibernate foi desenvolvido por Gavin King, atualmente é mantido pelo JBoss Group, registrada na JSR 317 (JavaTM Persistence 2.0) e JSR220 (Enterprise JavaBeansTM 3.0) ambas podem ser encontradas em [30]. Este Framework é uma solução para a especificação JPA, todas as características da JPA descritas neste trabalho são implementadas pelo Hibernate. Assim, ele não é detalhado nesse trabalho, já que suas características de interesse estão descritas na JPA. Além disso, esse foi o motivo de ter sido investigado e selecionado neste trabalho, além do fato de ser constantemente atualizado. 
O Framework Torque também segue a especificação JPA, em um nível inferior de conformidade comparando com o Hibernate. Teve sua ultima versão disponibilizada há mais de três anos, desde então não houve atualizações, enquanto o Hibernate teve inúmeras atualizações no período. Apesar disso, o Torque possui características importantes para este trabalho, na sequência uma breve apresentação do seu funcionamento e o detalhamento das vantagens.

O Torque é composto por dois módulos; o primeiro responsável por interpretar o esquema de objetos a serem persistidos, nesta etapa o usuário precisa preencher um arquivo XML com o esquema de objetos. A partir desse esquema, o Torque gera um esquema equivalente de tabelas no SGBDR, assim como as classes que representam o esquema de objetos persistentes da aplicação. Neste ponto identifica-se uma desvantagem, o esquema de objetos da aplicação e tabelas no SGBD necessariamente precisa ser gerado pelo Torque, ou seja, o Torque cria o código Java a partir do XML, o que impossibilita o uso deste Framework em cenários onde os esquemas já existam [15][16][17]. Outro problema é a necessidade do usuário preencher o arquivo XML com o esquema de objetos, uma vez que é um processo manual e suscetível à falha, o que poderia ser evitado com o uso de anotações como é o caso do Hibernate. Por outro lado pode ser uma grande vantagem o Framework receber o esquema de objetos em um arquivo XML, pois possibilita a integração com uma ferramenta de modelagem, a qual seria responsável por gerar tal arquivo [05].

Outro ponto importante é a forma como que o Torque gera o esquema e interage com o SGBD, ele possui um repositório de arquivos onde cada arquivo possui a sintaxe especifica para um determinado SGBD. Por exemplo, neste repositório há um arquivo contendo toda a sintaxe e características do SGBD Oracle, existe outro arquivo para o DB2 e assim por diante. Quando o usuário quiser modificar alguma característica ou mesmo acrescentar um novo SGBD, basta editar estes arquivos. Outro fator importante é a existência de outros fabricantes que também disponibilizam estes arquivos, possibilitando ao usuário escolher qual será o comportamento do Framework na interação com um SGBD. Para tal, é suficiente apenas modificar diretivas de configuração.

O segundo módulo é responsável por gerar os scripts SQL para toda a interação entre a aplicação e o SGBD, é também responsável por gerenciar as conexões com o SGBD e suas transações.

Apresenta maiores informações sobre Torque [04]. 


\section{Framework O-ODBM}

O emprego de BDOR apresenta vantagens em relação a BDR, sendo a mais direta, a eliminação do descasamento de impedância entre a aplicação e o banco de dados, em outras palavras, os objetos da aplicação possuem maior proximidade semântica aos objetos do $\mathrm{BD}$, desta forma menos esforço (codificação) e processamento é gasto com mapeamentos e conversões, o que, em teoria, significa maior produtividade e desempenho em relação ao SGBDR.

Desvantagens como possibilidade de códigos SQL espalhados pela aplicação, dificuldade na manutenção, necessidade de conhecimentos mais sólidos sobre DBs e SGBDs, dificuldade na migração entre SGBDs, conforme discutido anteriormente, continuam as mesmas. Estas desvantagens são consequência do acesso direto o SGBD, sendo este relacional ou OR. Uma solução é o uso de Frameworks similares aos Frameworks ORM. Assim, propõe-se o Framework O-ODBM (Objetct - Objec tDatabase Mapping).

Este capítulo apresenta o Framework O-ODBM proposto neste trabalho. Para a criação deste Framework, foi definido um conjunto mínimo de requisitos que a versão aqui produzida deveria atender. Antes da apresentação do Framework, apresentam-se regras de mapeamento de objetos da aplicação para objetos do SGBDOR e a relação do conjunto de requisitos que o Framework deve atender.

\subsection{Regras de mapeamento para BDOR.}

Para dar sequência no projeto e desenvolvimento do Framework O-ODBM foi necessário um estudo sobre as regras de mapeamento para BDOR. Essas regras definem como objetos da aplicação e suas propriedades serão representados no banco de dados. Quando se emprega banco de dados relacionais regras de mapeamento também são empregadas, tais regras são amplamente conhecidas e aceitas [18][32][46][56] e não serão aqui detalhadas.

É importante ressaltar que tais regras são válidas para SGBDOR, já que estes permitem a especificação de relações ou tabelas convencionais. Contudo, um SGBDOR permite definir, além de tabelas convencionais, elementos que representam objetos de banco de dados e suas propriedades, sendo necessário então ampliar as regras de mapeamento, de forma que tais elementos possam ser "enxergados" pelo Framework. Cabe ressaltar que 
neste caso, objetos da aplicação são mapeados em objetos de banco de dados, não havendo assim descasamento de impedância. Vários trabalhos presentes na literatura [11][12][22][26][36][37]tratam das regras de mapeamento considerando os novos elementos de SGBDOR. Não é parte desta dissertação discutir essas regras, mas sim empregá-las. Particularmente, serão aqui utilizadas as regras apresentadas em [11] e [12], os quais são acréscimos importantes aos trabalhos [22][26][36][37], pois analisam e complementam sob a ótica do uso em aplicações reais. A Tabela 10 mostra o mapeamento de elementos da aplicação (classe, objetos, atributos e métodos) em elementos correspondentes do BD.

Tabela 10 - Mapeamento de objetos da aplicação em objetos de BDOR - adaptado de [11][12].

\begin{tabular}{|l|l|l|}
\hline OO & $\begin{array}{l}\text { Correspondente no } \\
\text { BDOR }\end{array}$ & Justificativa \\
\hline \multirow{3}{*}{ Classe } & Tabela & Classes podem ser mapeadas para tabelas convencionais. \\
\cline { 2 - 3 } & Tabela Tipada & $\begin{array}{l}\text { Para cada objeto da aplicação é criado um UDT no BD, Se o } \\
\text { objeto for abstrato [48] apenas o UDT é criado, caso contrário } \\
\text { também é criado uma tabela tipada para armazenar instâncias } \\
\text { deste objeto. }\end{array}$ \\
\hline $\begin{array}{l}\text { Classe } \\
\text { abstrata }\end{array}$ & $\begin{array}{l}\text { Uma classe abstrata não deve ser instanciada, podendo ser } \\
\text { utilizada na definição de uma classe concreta (que pode ser } \\
\text { instanciada). Sugere-se a utilização de um UDT sem a criação de } \\
\text { uma tabela tipada associada, pois o UDT poderá ser utilizado na } \\
\text { definição de outros UDTs, e como não possui tabela tipada } \\
\text { associada, não haverá instâncias sendo persistidas. }\end{array}$ \\
\hline $\begin{array}{l}\text { Atributo } \\
\text { simples }\end{array}$ & $\begin{array}{l}\text { Tipo } \\
\text { (build-in) }\end{array}$ & $\begin{array}{l}\text { A SQL:2008 dá suporte a diversos tipos primitivos, como o tipo } \\
\text { inteiro, real etc. Dessa forma, é possível achar um correspondente } \\
\text { em SQL para cada tipo simples definidos em Java. }\end{array}$ \\
\hline $\begin{array}{l}\text { Atributo } \\
\text { multivalorado }\end{array}$ & Array ou Multiset & $\begin{array}{l}\text { Essas estruturas multidimensionais são adequadas para armazenar } \\
\text { atributos de um mesmo tipo (coleções). }\end{array}$ \\
\hline $\begin{array}{l}\text { Métodos } \\
\text { Métodos de um UDT }\end{array}$ & $\begin{array}{l}\text { Os UDTs suportam a declaração de métodos em sua definição. } \\
\text { Assim, o desenvolvedor pode optar por codificar determinados } \\
\text { métodos na base de dados e não na aplicação. }\end{array}$ \\
\hline
\end{tabular}


A Tabela 11 mostra o mapeamento de hierarquias e associações em elementos correspondentes BD.

Tabela 11 - Mapeamento de associações e hierarquias em BDOR - adaptado de [11][12].

\begin{tabular}{|l|l|l|l|}
\hline Associação & \multicolumn{2}{|l|}{ Correspondente em BDOR } \\
\hline $\begin{array}{l}\text { Associação } \\
\text { Bidirecional }\end{array}$ & $\begin{array}{l}\text { Composição/ } \\
\text { / Agregação/ } \\
\text { / Associação }\end{array}$ & $\begin{array}{l}\text { Define-se uma Referência cruzada, ou seja, cada classe mantém a } \\
\text { referência (REF) para a outra. }\end{array}$ \\
\cline { 2 - 3 } & $\begin{array}{l}\text { Define-se também uma referência cruzada, porém a classe agregadora } \\
\text { terá um Array ou um Multiset de Referências. }\end{array}$ \\
\hline Associação Unidirecional & $\begin{array}{l}\text { Similares às respectivas associações bidirecionais apresentadas acima, no } \\
\text { entanto a referência(s) irá existir em apenas uma tabela. }\end{array}$ \\
\hline $\begin{array}{l}\text { Associação N-ária (três ou } \\
\text { mais classes) }\end{array}$ & $\begin{array}{l}\text { Define-se uma tabela ou um UDT com o nome do papel da associação. A } \\
\text { tabela ou o UDT (e posteriormente a tabela tipada) deve referenciar as } \\
\text { classes envolvidas. }\end{array}$ \\
\hline Classe Associativa & $\begin{array}{l}\text { Similarmente a Associação N-ária, pode-se definir uma tabela ou um UDT } \\
\text { para a classe de associação. }\end{array}$ \\
\hline $\begin{array}{l}\text { Generalização- } \\
\text { Especialização }\end{array}$ & $\begin{array}{l}\text { Define-se um UDT para cada classe da hierarquia. Tabelas tipadas serão } \\
\text { posteriormente definidas, caso dados precisem ser persistidos. }\end{array}$ \\
\hline
\end{tabular}

\subsection{Requisitos do Framework O-ODBM}

Tendo como base os estudos realizados, foi definido um conjunto de requisitos aos quais o Framework O-ODBM deve atender. Esses requisitos são listados a seguir.

R1 - A restrição de chave estrangeira está associada à regra de integridade referencial [57] [18], a qual é verificada e controlada pelo SGBD a partir do momento que a restrição (constraint) é declarada. Em SGBDOR é possível definir relacionamentos entre objetos com o uso de REF e seria necessário também controlar a regra de integridade referencial. Por exemplo, caso um objeto Departamento faça uma referência para um objeto Empregado, se este for, por exemplo, removido, o departamento que o referenciava apresentaria uma referência nula. Isso vai contra a regra de integridade referencial. Para que o controle apropriado seja feito pelo SGBD é necessário definir uma operação para isso. O Framework O-ODBM deve implementar métodos associados aos objetos referenciados a fim de garantir a regra de integridade referencial.

R2 - Frameworks ORM apresentam a vantagem de permitir que o SGBD seja trocado por outro de forma muito simples para o desenvolvedor, conforme comentado anteriormente na seção 2.3. O Framework O-ODBM deve fornecer ao desenvolvedor a mesma facilidade, para tal deverá fornecer uma interface para configuração pelo desenvolvedor para indicação do SGBD. Esse requisito será identificado como flexibilidade para 
multiplataforma de banco de dados. Cabe observar, conforme já comentado, que existem diferenças quanto ao suporte de objetos oferecido pelos SGBDOR existentes e, assim, este pode ser o requisito mais difícil de ser atendido.

R3 - Não necessitar de conhecimentos sólidos de SQL e BD por parte do desenvolvedor. Para tanto, o Framework deverá oferecer uma linguagem ou um mecanismo de manipulação de objetos próximo(a) às linguagens de programação OO (se comparado com a SQL). O objetivo é facilitar o aprendizado do desenvolvedor, evitando que o mesmo precise conhecer SQL para interagir com SGBD.

R4 - Gerenciar conexões com o SGBD. Abrir, fechar e verificar o tempo limite (timeout) destas conexões. Quando existirem transações não finalizadas, o Framework manterá a conexão até o término (commit ou rollback) destas transações, ou forçará a interrupção destas, mas tomando medidas (por exemplo, rollback) para manter a integridade dos dados no banco de dados .

R5 - Gerenciar execução de transações. Disponibilizar uma interface para que o usuário consiga definir suas transações.

R6 - Geração automática de códigos para criação dos esquemas de objetos para o BD, incluindo códigos para manipulação destes objetos.

R7 - Funcionar como ponto concentrado de acesso à base de dados, que não seja necessário a aplicação se conectar ao BD diretamente, sem fazer uso do Framework.

R8 - Ser facilmente configurado pelo usuário, e que este não despenda muito esforço para configurar seu esquema de objetos. Caso contrário, não existirá ganho na produtividade. Todo Framework deve, não somente os de persistência, ter a capacidade de agilizar e facilitar o desenvolvimento, o que do ponto de vista do desenvolvedor significa melhora de produtividade. Este foi o principal motivo para a utilização dos conceitos de anotações no Framework proposto [60].

R9 - Implementar conceitos de herança, seguindo a OO. Permitir que a hierarquia dos objetos da aplicação sejam representadas de forma similar no BD.

R10 - Implementar relacionamentos unidirecionais, bidirecionais e multivalorados, usando, quando possível, referências (REF) a objetos [48].

R11 - Capacidade de não degradar o desempenho da aplicação. Este é um ponto bastante relevante sobre os Frameworks convencionais devido ao fato de terem de realizar mapeamento e conversões de OO para Relacional, o que acarreta um maior processamento. Espera-se que o Framework proposto necessite de menos processamento com mapeamento 
e conversões entre o objeto da aplicação e do SGBD, uma vez que SGBDOR possui uma maior proximidade semântica com a aplicação.

R12 - Capacidade de recuperar dados sobre demanda, ou seja, de acordo com o que foi definido pelo desenvolvedor, adiar ou não a recuperação de dados (Eager, Lazy) relacionados para melhorar a eficiência no acesso a dados [31]. Esse é um aspecto importante sob a ótica de desempenho se considerar que objetos referenciados, podem referenciar outros e assim por diante. Um cascateamento de busca de objetos degradaria inquestionavelmente o desempenho do SGBD no acesso ao dado.

R13 - Capacidade de persistir dados sobre demanda, característica definida como cascade (seção 2.4) na especificação JPA. Neste caso, o Framework poderá persistir outros objetos associados, fazendo o cascateamento, também para evitar a existência de referências “nulas" (a objetos inexistentes).

\subsection{Projeto do Framework O-ODBM.}

O Framework O-ODBM deve atender os requisitos e as regras de mapeamento apresentados anteriormente neste capítulo. O Framework, cuja arquitetura é mostrada na Figura 8, espera como entrada um esquema de objetos com dois possíveis formatos: código java, onde classes persistentes estão declaradas; ou arquivo XML, representando código no dialeto SQL do SGBD escolhido. No primeiro caso, as classes deverão apresentar as anotações apropriadas. Um conjunto possível de anotações que podem ser empregadas é disponibilizado pelo próprio Framework, similarmente aos Frameworks ORM. Internamente à ferramenta, o código Java anotado é então traduzido para um arquivo XML, baseado na norma SQL:2008, e denominado Esquema XML-SQL. No segundo caso, o arquivo XML é gerado por uma ferramenta case [12] com suporte para SGBDOR. Neste caso, pretende-se que o Framework possa vir a conectar-se com a ferramenta CASE, permitindo que a partir da construção de um modelo lógico conceitual, a base de dados OR seja automaticamente implementada no SGBDOR escolhido e possa então ser acessada através do Framework.

Conforme a Figura 8, internamente o Framework gera os scripts SQL tanto para criação do esquema no SGBD quanto para persistência e recuperação de objetos. Para isto o Framework faz uso de arquivos XML contendo a sintaxe especifica de cada SGBD, na Figura 8 estes arquivos são chamados de SGBD Layout. O componente Gerenciador de Conversão recebe o Esquema XML-SQL junto com o SGBD Layout referente ao SGBD 
escolhido, e gera como produto o script SQL para a criação do esquema. De forma similar, scripts SQL são gerados para acesso aos objetos persistidos. O componente responsável por toda a interação com o SGBD, é o Gerente de Conexão. O Controlador de Transação gerencia as transações associadas às conexões. Estes componentes são, a seguir, descritos com maiores detalhes.

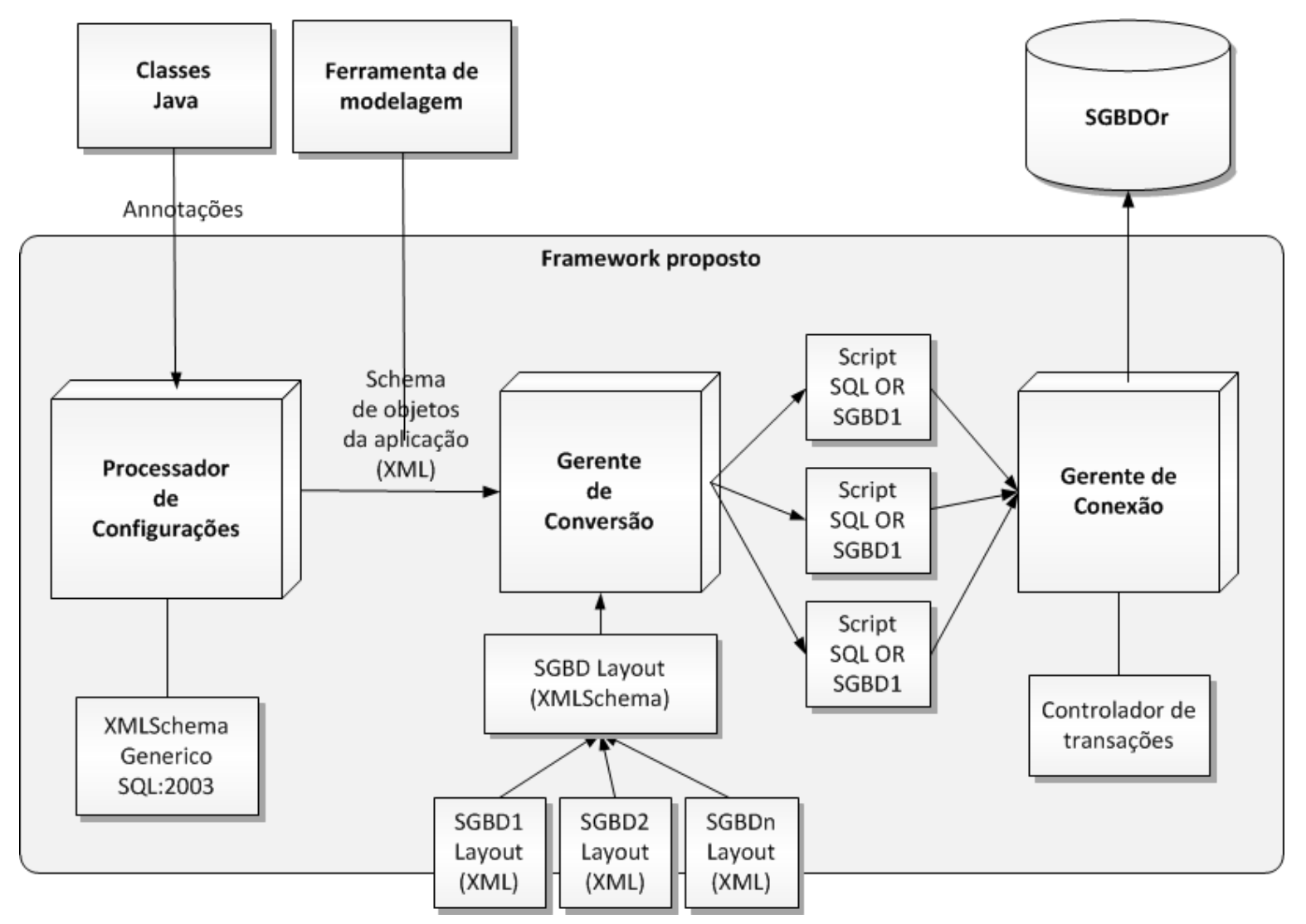

Figura 8 - Arquitetura do Framework O-ODBM

Processador de Configurações: tem por função ler as classes Java que representam os objetos persistentes da aplicação. As classes devem estar anotadas com as anotações disponibilizadas pelo Framework. Uma vez tendo interpretado as classes Java, este módulo processa as anotações e gera código XML contendo uma estrutura OR baseado na SQL:2008. A norma SQL:2008 apresenta os elementos e definições que permitem definir objetos de banco de dados. Os SGBDs implementam todos ou apenas parte desses elementos, além disso, a implementação de um determinado elemento pode ser diferente entre os SGBDs e mesmo em relação ao que está especificado na norma. Em outras palavras, em alguns SGBDs é possível definir, por exemplo, tipos ROW, MULTISETS, 
UDTs, herança, em outros não. A norma pode ser facilmente traduzida para qualquer dialeto SQL. Assim, optou-se por primeiro gerar o código SQL com base na norma e, posteriormente, a tradução para o dialeto de um SGBD específico. O Esquema XML-SQL, corresponde a representação do esquema de objetos na base de dados equivalente ao esquema de objetos da aplicação. A Figura 9 apresenta parte de um código Java com uma classe (persistente) anotada e a Figura 10 ilustra o Esquema XML-SQL correspondente. O Esquema XML-SQL gerado pelo Processador de Configurações é a entrada do componente Gerente de Conversão.

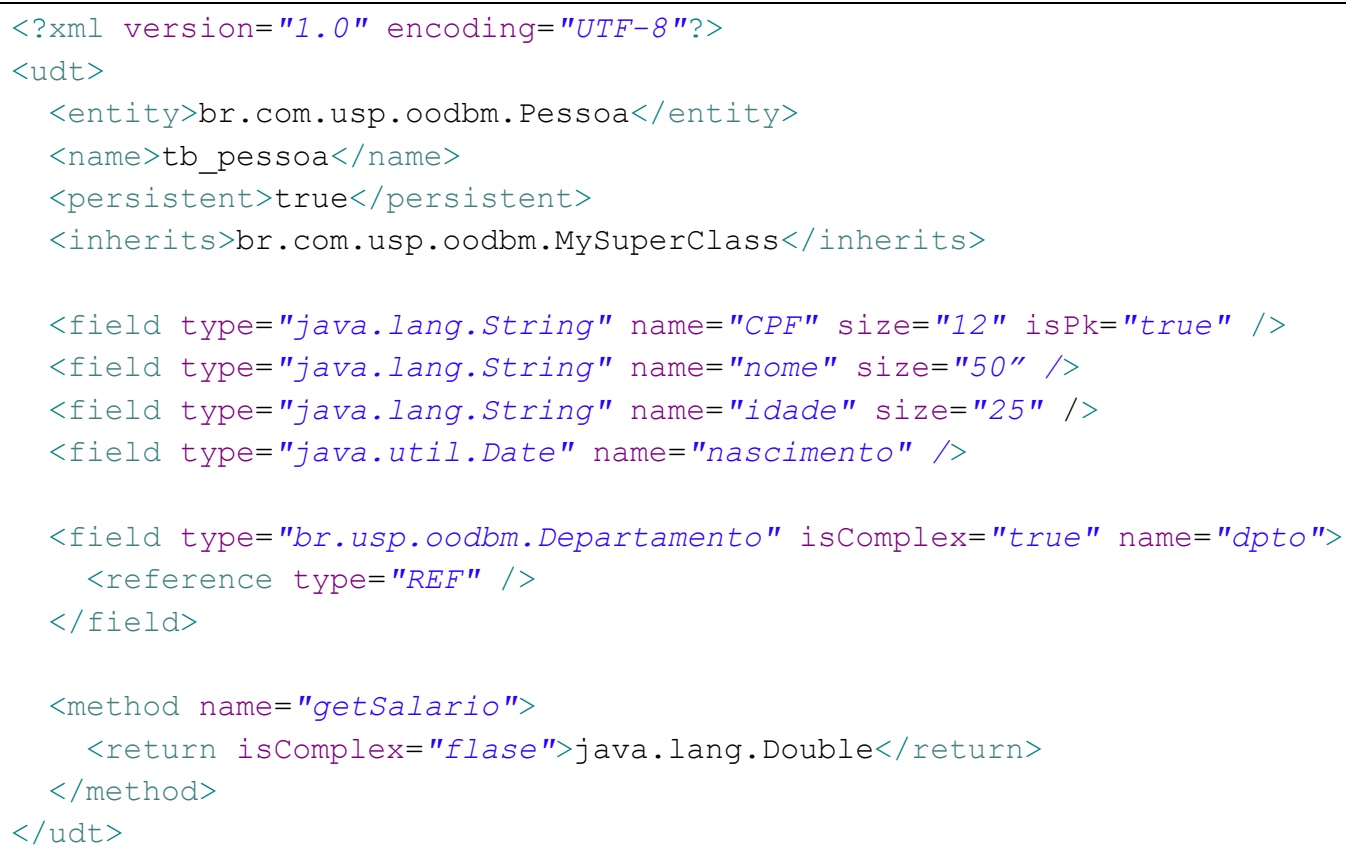

Figura 9 - Exemplo de XML seguindo a definição do Esquema XML-SQL 


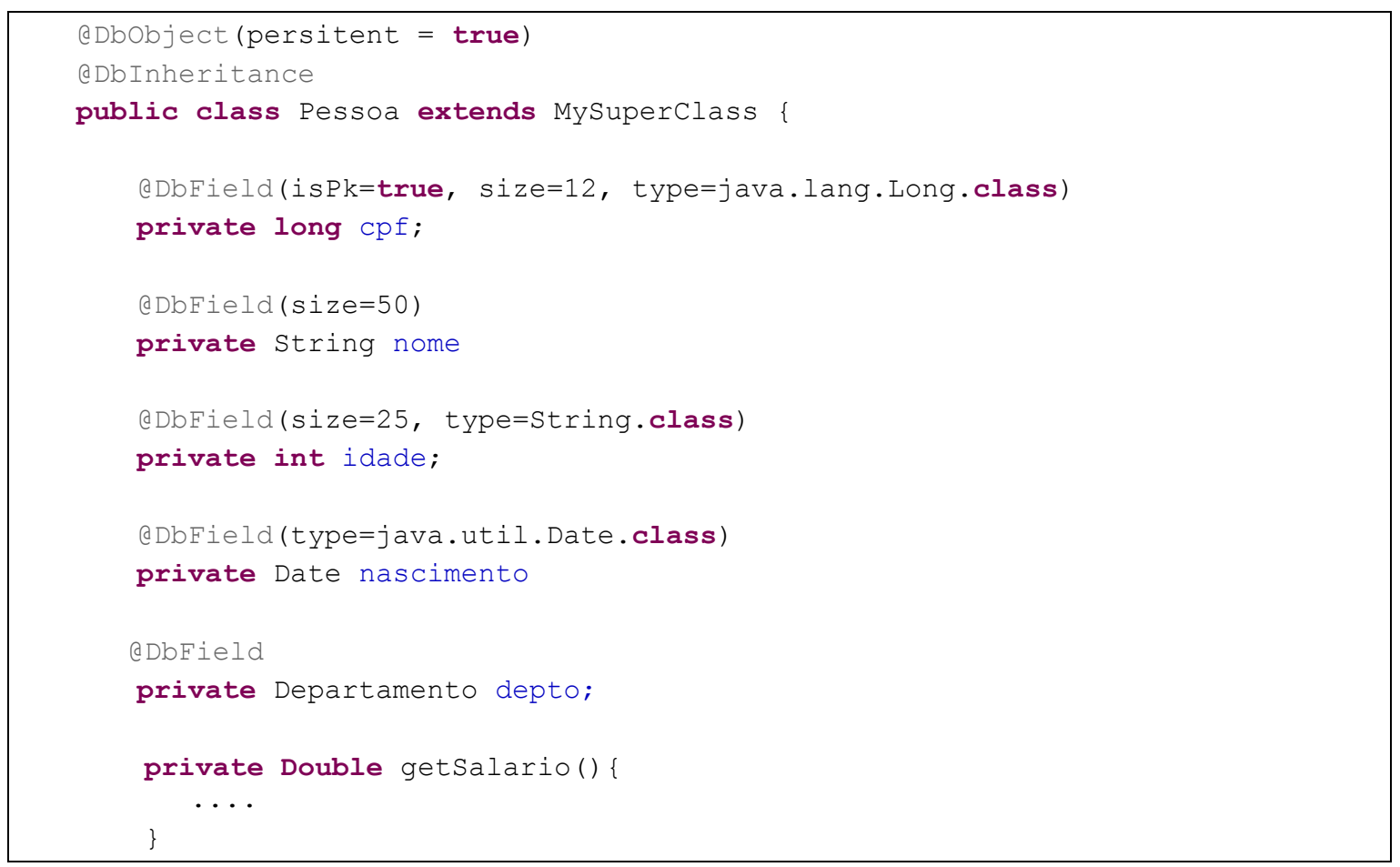

Figura 10 - Exemplo de anotações disponibilizadas pelo Framework.

Gerente de Conversão: é responsável por gerar os scripts SQL necessário à interação com o BD, seja para criação das estruturas (geração do esquema físico) ou para a manipulação de dados. O Gerente de Conversão utiliza o arquivo SGBD Layout apropriado para traduzir o código XML-SQL para o dialeto SQL apropriado. A saída deste módulo é então o script SQL, que é submetido ao SGBD pelo componente Gerente de Conexão.

Gerente de Conexão: para interagir com o SGBD é necessário abrir, fechar e ajustar uma conexão, todas as operações do Framework com o SGBD como, por exemplo, execução de scripts SQL para criar estruturas, persistir e recuperar objetos são feitas através de uma conexão. Este componente é responsável por gerenciar as conexões como SGBD de forma transparente para o usuário. Sempre que o usuário solicitar uma operação ao Framework, uma conexão automaticamente é aberta. Para controlar as transações associadas às conexões, o Framework conta com o componente Controlador de Transações.

Controlador de transações: é responsável por gerenciar todas as transações com o SGBD. Quando uma transação é aberta este componente é acionado e toda vez que uma conexão precisar ser fechada este componente é consultado a fim de verificar/garantir que não haja nenhuma transação aberta para aquela conexão. Neste processo, transações podem ter de serem encerradas (rollback ou commit), ou a conexão não é fechada. Este componente 
ainda gerencia o tempo de inatividade de uma transação encerrando-a automaticamente, isto ocorre se a transação atingir o tempo limite sem ter sido fechada por solicitação do usuário.

Anotações: O Framework disponibiliza um conjunto de anotações para que o usuário possa especificar quais classes são persistentes e, opcionalmente, qual a estratégia de persistência. As anotações definidas na JPA por tratarem especificamente do mapeamento e conversão para BDR, não são aqui utilizadas, tendo sido criadas novas anotações a fim de especificar características OR. As anotações possuem uma série de configurações padrões possibilitando que um usuário sem profundos conhecimento de DB possa usar o Framework, e também permite que usuário com conhecimentos avançados possa ter um maior controle sobre o Framework alterando estas configurações. Por exemplo, no mapeamento de um relacionamento, o usuário leigo pode apenas anotar um atributo dizendo que faz referência a um objeto (ou seja, que representa um relacionamento), o Framework usará uma estratégia padrão para representar este relacionamento, no entanto um usuário avançado pode escolher qual será a estratégia para este relacionamento, por exemplo, se vai ser um MULTISET de REF, ou se apenas um MULTISET, ou ARRAY, etc.

Com o uso das anotações é possível especificar se deve ser criado um objeto no banco de dados, ou seja, se será persistente; se possui uma hierarquia (herança) e se esta hierarquia também será criada no BD; informar quais atributos do objeto serão criados no DB, assim como o tipo de dados no BD; especificar restrições como chave-primaria, se é obrigatório ou não (null ou not null), dentre outras. É possível especificar também se é auto incrementável.

A Tabela 12 apresenta as anotações disponibilizadas pelo Framework. 
Tabela 12 - Anotações disponibilizadas pelo Framework.

\begin{tabular}{|c|c|}
\hline Anotação & Descrição \\
\hline @DbObject & $\begin{array}{l}\text { É usada na declaração de uma classe informando se fará parte do contexto de } \\
\text { persistência. }\end{array}$ \\
\hline$@$ DbField & $\begin{array}{l}\text { È usado nos atributos da classe, informando quais atributos fazem parte do contexto } \\
\text { de persistência. }\end{array}$ \\
\hline @DbMethod & $\begin{array}{l}\text { É usado para indicar se o método será criado no BD, ou seja, se o respectivo objeto } \\
\text { no BD também possuíra tal método. }\end{array}$ \\
\hline @DbParam & $\begin{array}{l}\text { É opcionalmente usado nos parâmetros de um método anotado com @ DbMethod } \\
\text { Caso um usuário com conhecimentos avançados de BD queira especificar qual o tipo } \\
\text { do parâmetro ao invés de deixar o Framework escolher. }\end{array}$ \\
\hline @ DbInhetitance & $\begin{array}{l}\text { Serve para indicar que o objeto faz parte de uma hierarquia. Neste caso, } \\
\text { Framework além do olhar para as características do objeto irá olhar também para o } \\
\text { objeto "pai" na hierarquia. Em outras palavras, especifica que um objeto pertence a } \\
\text { uma hierarquia, assim a hierarquia será propagado para o BD, caso os ancestrais não } \\
\text { tenham sido anotados com DbObject, apenas os objetos filhos serão criados no BD, } \\
\text { entretanto as características herdadas serão replicadas no BD. }\end{array}$ \\
\hline$@$ DbRelation & $\begin{array}{l}\text { Ė usado para indicar que o atributo de um objeto faz uma referência a outro objetc } \\
\text { (ou seja representa uma associação). Para representar uma associação atributos são } \\
\text { inclúdos nas classes associadas e fazem referências entre si, dependendo da } \\
\text { cardinalidade da associação, essa referência pode ser a um objeto ou a uma coleção } \\
\text { de objetos. O Framework através do tipo de dados do atributo infere a cardinalidade } \\
\text { da associação. O tipo de dado pode ser ou não multivalorado (representando uma } \\
\text { coleção de objetos) e obrigatório ou não. Por exemplo, se for o tipo multivalorado em } \\
\text { ambos os lados, será uma relacionamento N-N, se multivalorado em apenas um lado, } \\
\text { neste caso é levado em consideração a obrigatoriedade do atributo no outro lado, caso } \\
\text { seja obrigatório seria um relacionamento } 1-\mathrm{N} \text { e se não for obrigatório } 0 \text {-N. }\end{array}$ \\
\hline
\end{tabular}

Além das anotações apresentadas na Tabela 12 ainda existem alguns atributos que permitem que usuários com conhecimentos em BD possam ter um maior controle sobre o

Framework. Estas configurações, apresentados na Tabela 13, são opcionais. 
Tabela 13 - Configurações avançadas usando as anotações disponibilizadas pelo Framework.

\begin{tabular}{|c|c|c|c|}
\hline Anotação & Parâmetro & Valor padrão & Descrição \\
\hline \multirow{5}{*}{ @DbObject } & isFinal, & Não final & $\begin{array}{l}\text { Um objeto anotado como final (isFinal) não pode } \\
\text { ser especializado, ou seja, ser estendido. }\end{array}$ \\
\hline & name & $\begin{array}{l}\text { Mantem o nome do } \\
\text { atributo }\end{array}$ & $\begin{array}{l}\text { O nome com o qual o objeto será criado no BD, } \\
\text { sendo ele uma tabela, tabela tipada ou UDT. }\end{array}$ \\
\hline & OIDColumn & oid & $\begin{array}{l}\text { Especifica o nome da coluna que irá armazenar o } \\
\text { OID (Object Identification). }\end{array}$ \\
\hline & OIDStratgey & system_genereated & $\begin{array}{l}\text { Especifica a estratégia com o que o OID será } \\
\text { gerado, de acordo com norma existem três formas } \\
\text { de gerenciar um OID. Primeira, deixar o SGBD } \\
\text { gerenciar os valores de OID (system_gererated). } \\
\text { Segunda, o usuário gerencia os OID } \\
\text { (user_generated). A terceira consiste em vincular o } \\
\text { OID a uma coluna já existente, por exemplo, uma } \\
\text { primary key, ou uma coluna que tenha valores } \\
\text { únicos. }\end{array}$ \\
\hline & persistent & Sim & $\begin{array}{l}\text { Indica se o objeto será persistente ou transiente. } \\
\text { Objetos transientes são objetos que não serão } \\
\text { persistidos, como por exemplo, uma classe abstrata } \\
\text { [48]. Já um objeto persistente gera uma tabela } \\
\text { tipada para poder persistir instâncias. }\end{array}$ \\
\hline \multirow[b]{4}{*}{$@$ DbField } & Size & $\begin{array}{l}255 \text { para textos e } \\
\text { para numéricos }\end{array}$ & $\begin{array}{l}\text { Especifica o tamanho máximo de um atributo, por } \\
\text { exemplo, a quantidade máxima de caracteres em } \\
\text { um campo texto. }\end{array}$ \\
\hline & isPK & não & $\begin{array}{l}\text { Indica se este atributo será definido como primary } \\
\text { key. }\end{array}$ \\
\hline & autoIncremet & não & $\begin{array}{l}\text { Indica se o SGBD será responsável por gerar e } \\
\text { controlar a unicidade do atributo. }\end{array}$ \\
\hline & Type & $\begin{array}{l}\text { O arquivo SGBD } \\
\text { Layout possui os } \\
\text { tipos equivalentes } \\
\text { em BD para os } \\
\text { tipos da aplicação, } \\
\text { o Framework irá } \\
\text { usar o tipo } \\
\text { equivalente. }\end{array}$ & $\begin{array}{l}\text { Especifica qual o tipo de dados que será usado no } \\
\text { BD. }\end{array}$ \\
\hline \multirow[b]{2}{*}{ @DbMethod } & Name & $\begin{array}{l}\text { Mantém o nome do } \\
\text { método. }\end{array}$ & $\begin{array}{l}\text { Especifica o nome com que método será criado no } \\
\text { BD }\end{array}$ \\
\hline & Type & $\begin{array}{l}\text { O arquivo SGBD } \\
\text { Layout possui os } \\
\text { tipos equivalentes } \\
\text { em BD para os } \\
\text { tipos da aplicação, } \\
\text { o Framework irá } \\
\text { usar o tipo } \\
\text { equivalente. }\end{array}$ & Especifica o tipo de retorno do método, caso exista. \\
\hline @DbRelation & relationType & $\begin{array}{l}\text { multiset_ref, } \\
\text { aplicando } \\
\text { mecanismo } \\
\text { controle } \\
\text { integridade. }\end{array}$ & $\begin{array}{l}\text { Especifica o tipo de associação, podendo ser, um } \\
\text { Multiset de objetos (multiset_objects). Um Array } \\
\text { de objetos (array_objects), um Multiset de } \\
\text { referencias (multiset_ref), um Array de referências } \\
\text { (array_ref), uma única referência (ref), uma chave } \\
\text { estrangeira (fk) ou ainda uma tabela de } \\
\text { relacionamento (join_table) }\end{array}$ \\
\hline
\end{tabular}


A Figura 11 ilustra uma classe Java anotada, seguindo as anotações definidas no Framework.

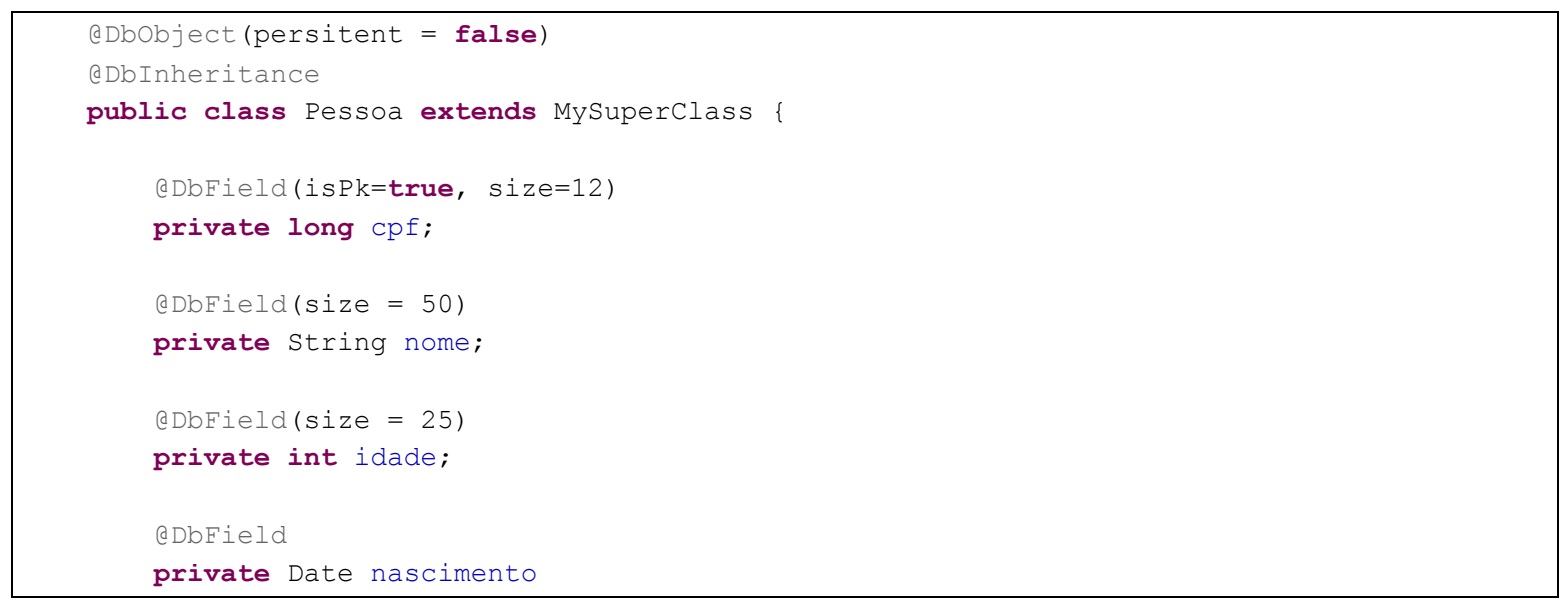

Figura 11 - Exemplo de anotações

Esquema XML-SQL: O Framework possui um XSD formalizando a estrutura do arquivo Esquema XML-SQL. Conforme comentado anteriormente, este arquivo pode provir do Processador de Configuração ou de uma ferramenta de modelagem, e neste caso, o arquivo precisa ser validado a fim de garantir que está na estrutura esperada pelo Framework, para tanto é usado o XSD. A Figura 12 apresenta parte deste XSD. 


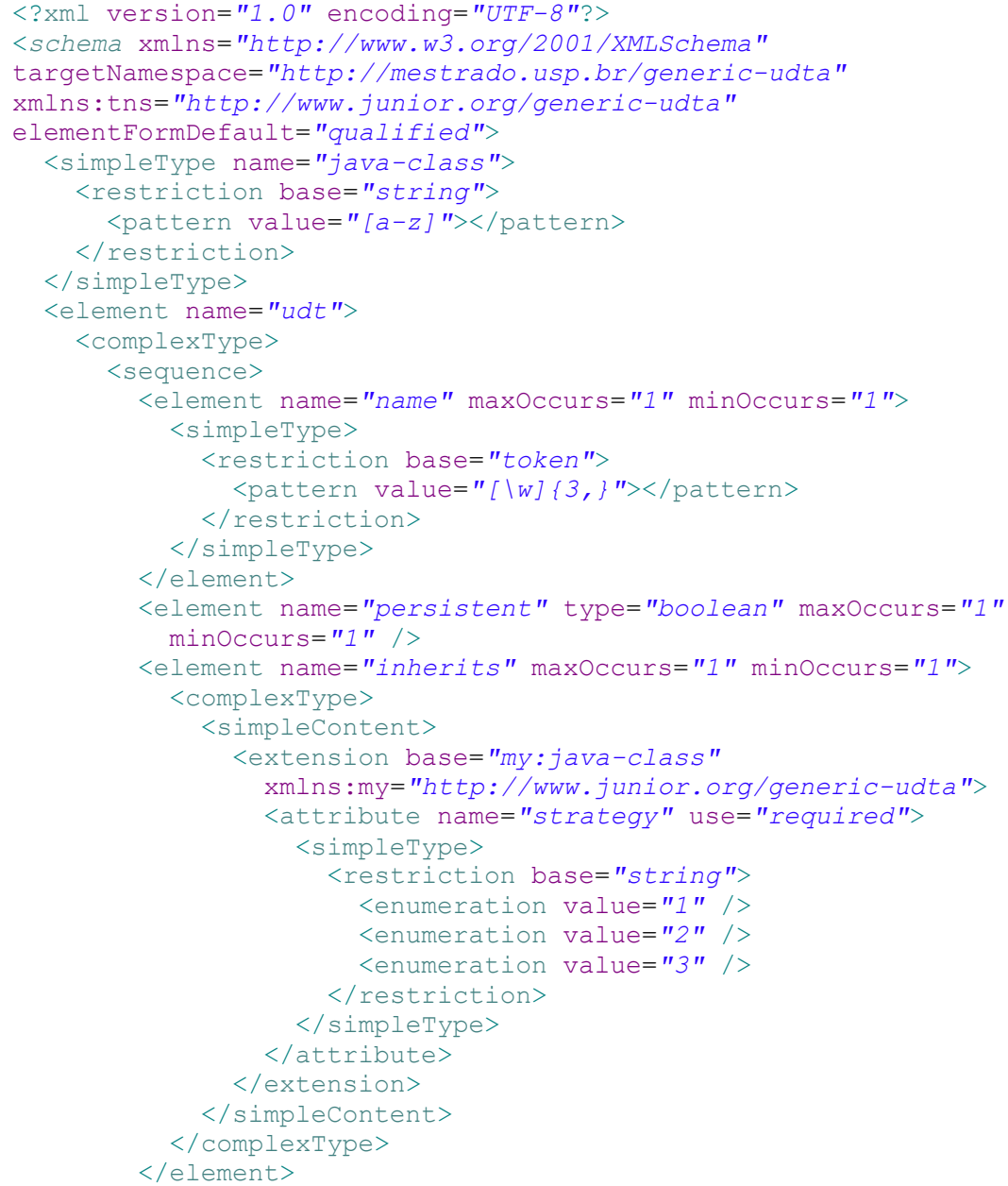

Figura 12 - Parte do XSD responsável por validar o Esquema XML-SQL

SGBD Layout: Semelhante ao Esquema XML-SQL o Framework também possui um XSD para validar a estrutura do arquivo SGBD Layout, uma vez que este pode sofrer alterações por parte do usuário, sendo então, necessário validar se está correto conforme a estrutura esperada pelo Framework. A Figura 13 apresenta parte deste XSD responsável por validar o SGBD Layout. 


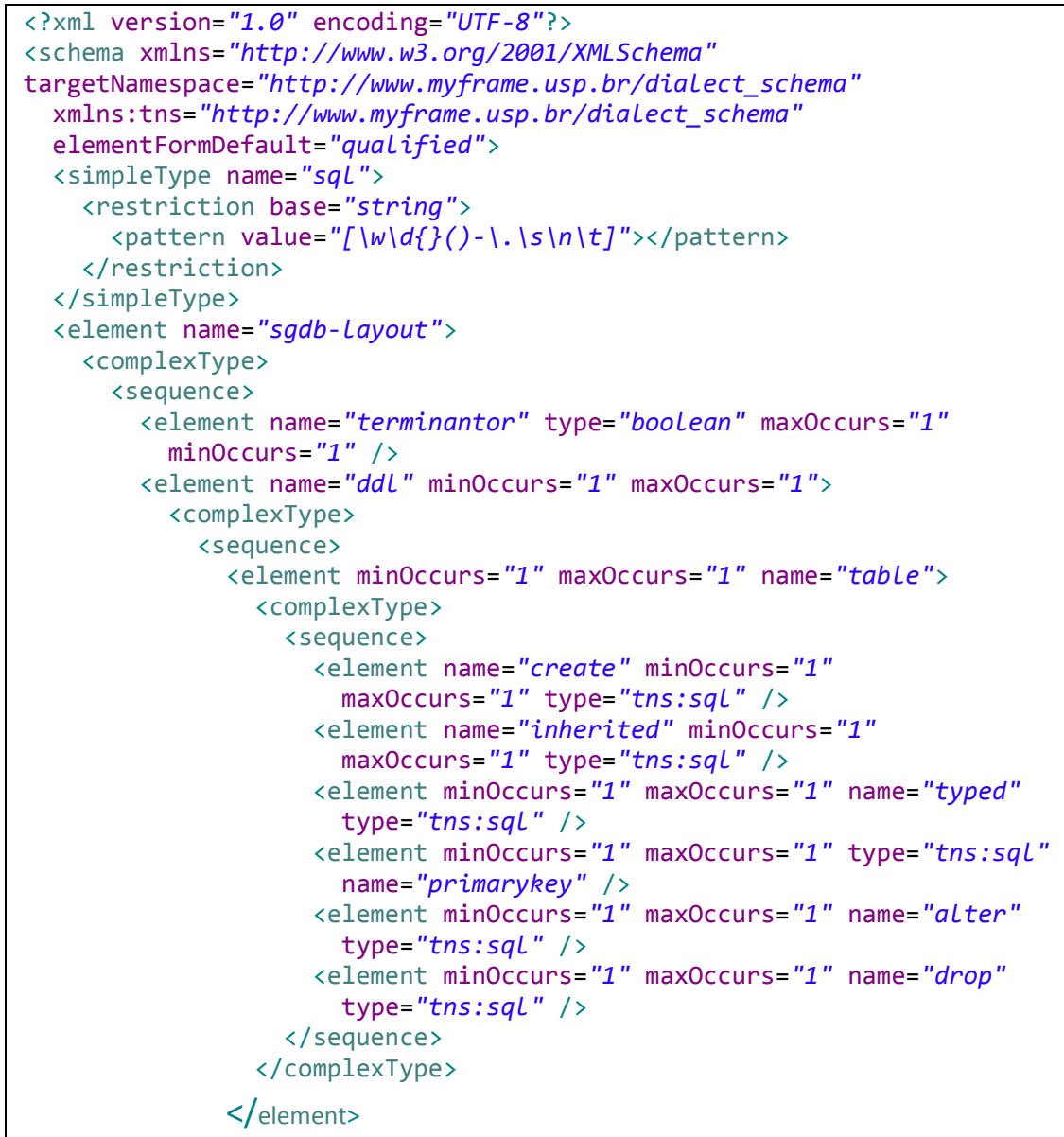

Figura 13 - Parte do XSD responsável por validar o SGBD Layout 


\section{Avaliação do Framework O-ODBM}

Para avaliar o Framework O-ODBM foram utilizados o conjunto de requisitos definidos na seção 4.2 e uma aplicação exemplo. Os resultados são apresentados neste capítulo. Primeiro, discute-se a conformidade do Framework em relação aos requisitos pré-definidos (seção 4.2); posteriormente, a resposta ao exemplo.

\subsection{Conformidade com os Requisitos}

A Tabela 14 apresenta a conformidade do Framework O-ODBM em relação ao conjunto de requisitos especificados na seção 4.2. Para facilitar a leitura, um resumo dos requisitos, e não apenas sua numeração, é apresentado. 
Tabela 14 - Avaliação do Framework O-ODBM

\begin{tabular}{|c|c|}
\hline Requisitos & Framework O-ODBM \\
\hline $\begin{array}{l}\mathrm{R} 1 . \text { Associado a FK } \\
\text { e a regra de } \\
\text { integridade } \\
\text { referencial }\end{array}$ & $\begin{array}{l}\text { pode-se definir chaves estrangeiras, usando para isso a anotação DbRelation, ou } \\
\text { seja, o código Java deve trazer esta anotação. O Framework implementará } \\
\text { automaticamente os métodos para valer a regra de integridade referencial. }\end{array}$ \\
\hline $\begin{array}{l}\text { R2. Multiplataforma } \\
\text { de Banco de Dados }\end{array}$ & $\begin{array}{l}\text { O Framework apresenta suporte apenas para Oracle e DB2, contudo a alteração de } \\
\text { um para outro é muito simplificada para o desenvolvedor, pois este apenas informa } \\
\text { qual dos dois será empregado naquele momento e o código apropriado é gerado } \\
\text { pelo Framework. O número de SGBDs disponíveis com suporte a OR é pequeno } \\
\text { comparado com o número de SGBDRs e isso obviamente, limita a aplicação desse } \\
\text { requisito. Contudo, o uso dos dois SGBDs mostra que o requisito é atendido. }\end{array}$ \\
\hline $\begin{array}{l}\text { R3. Oferecer uma } \\
\text { linguagem ou um } \\
\text { mecanismo de } \\
\text { manipulação de } \\
\text { objetos próximo às } \\
\text { linguagens OO }\end{array}$ & $\begin{array}{l}\text { Não define de fato uma linguagem de acesso, no entanto as interações } \\
\text { (persistência, consultas e atualizações) podem ser feitas usando objetos do próprio } \\
\text { Framework. Para usuários sem conhecimento de BD, basta anotar as classes que o } \\
\text { Framework realiza a persistência, Para usuários com conhecimentos em BD } \\
\text { existem anotações permitindo uma maior flexibilidade. }\end{array}$ \\
\hline $\begin{array}{l}\text { R4. Gerenciar } \\
\text { conexões com o } \\
\text { SGBD }\end{array}$ & $\begin{array}{l}\text { Toda a conexão com o SGBD é controlada pelo Framework de forma transparente } \\
\text { ao desenvolvedor. }\end{array}$ \\
\hline $\begin{array}{l}\text { R5. Gerenciar a } \\
\text { execução de } \\
\text { transações }\end{array}$ & $\begin{array}{l}\text { Disponibiliza uma interface para o usuário especificar onde começa e termina a } \\
\text { transação. O controle de fato da transação é delegado para o JDBC que por sua vez, } \\
\text { delega para o SGBD. }\end{array}$ \\
\hline $\begin{array}{l}\text { R6. Gerar código } \\
\text { para criação de } \\
\text { esquema e acesso }\end{array}$ & $\begin{array}{l}\text { Com base nas classes anotadas, o código para interação com o SGBD é } \\
\text { automatizado pelo Framework. }\end{array}$ \\
\hline $\begin{array}{l}\text { R7. ponto de acesso } \\
\text { à base de dados }\end{array}$ & $\begin{array}{l}\text { O Framework funciona como ponto centralizado de acesso aos dados, mas caso } \\
\text { queira, o desenvolver pode usar outro. }\end{array}$ \\
\hline $\begin{array}{l}\text { R8. Facilmente } \\
\text { configurável }\end{array}$ & $\begin{array}{l}\text { A utilização dos conceitos de anotações teve como propósito facilitar a interação } \\
\text { do desenvolvedor com o Framework. }\end{array}$ \\
\hline $\begin{array}{l}\text { R9. Implementar } \\
\text { conceitos de herança }\end{array}$ & $\begin{array}{l}\text { A herança é implementada da mesma forma que na aplicação (OO). No SGBD, } \\
\text { além da herança de estruturas, como na aplicação, existe a herança de dados. Ou } \\
\text { seja cada objeto filho persistido, gera também um objeto na entidade pai. A } \\
\text { sincronia entre estes objetos é feita pelo SGBD e de forma transparente. }\end{array}$ \\
\hline $\begin{array}{l}\text { R10. Implementar } \\
\text { associações usando } \\
\text { preferencialmente } \\
\text { REF }\end{array}$ & $\begin{array}{l}\text { O desenvolvedor indica que A que possui } \mathrm{N} \text { associações com } \mathrm{B} \text {, e da mesma } \\
\text { forma, que B possui } \mathrm{N} \text { (ou 1, dependendo da cardinalidade) associações para A. } \\
\text { Assim o Framework, por padrão, cria em A uma lista de referencias para B e vice } \\
\text { versa. Caso a associação seja } 1 \text { e não } \mathrm{N} \text {, a referência é para um objeto e não para } \\
\text { uma lista de objetos. Desta forma, fica semelhante a aplicação (OO). }\end{array}$ \\
\hline $\begin{array}{l}\text { R11. Não } \\
\text { degradar o } \\
\text { desempenho da } \\
\text { aplicação }\end{array}$ & $\begin{array}{l}\text { Para avaliar esse requisito decidiu-se por gerar o esquema da base de dados objeto- } \\
\text { relacional manualmente, fazer a conexão com o SGBD usando uma JDBC e medir } \\
\text { o tempo para tal, ou seja, o tempo gasto para acesso a base de dados com e sem o } \\
\text { uso do framework. }\end{array}$ \\
\hline $\begin{array}{l}\text { R12. Recuperar } \\
\text { dados sobre demanda }\end{array}$ & $\begin{array}{l}\text { As estratégia lazy e eager são implementadas pelo Framework, o que permite } \\
\text { diminuir o número de acessos desnecessários ao SGBD. }\end{array}$ \\
\hline $\begin{array}{l}\text { R13. Persistir } \\
\text { dados sobre demanda }\end{array}$ & $\begin{array}{l}\text { O Framework permite que a estratégia cascade (JPA) seja especificada para a } \\
\text { persistência de objetos. }\end{array}$ \\
\hline
\end{tabular}




\subsection{Exemplo de uso}

Com o propósito de testar a aplicabilidade do Framework O-ODBM um exemplo de uso foi preparado. Três aspectos foram considerados como pontos principais: produtividade, suporte a características OR descritas na norma SQL:2008 e por último, desempenho no acesso aos dados persistentes via o Framework. A avaliação de desempenho feita aqui preferencialmente procura avaliar o comportamento quando consultas são submetidas a objetos que pertencem a hierarquias, ou que sejam parte de outros objetos, ou ainda, que estejam associados a outros a partir de referências. Contudo, essa avaliação não é suficiente para fazer afirmações mais contundentes a cerca do desempenho de SGBDOR. Assim, no futuro cabe uma avaliação mais criteriosa, mas que está fora do escopo deste trabalho.

O exemplo consistiu na implementação de uma aplicação cujo esquema de objetos persistentes é apresentado na Figura 14, tendo cada classe sido anotada com as anotações disponibilizadas pelo Framework O-ODBM (vide Tabela 12 e Tabela 13 da seção 4.3).

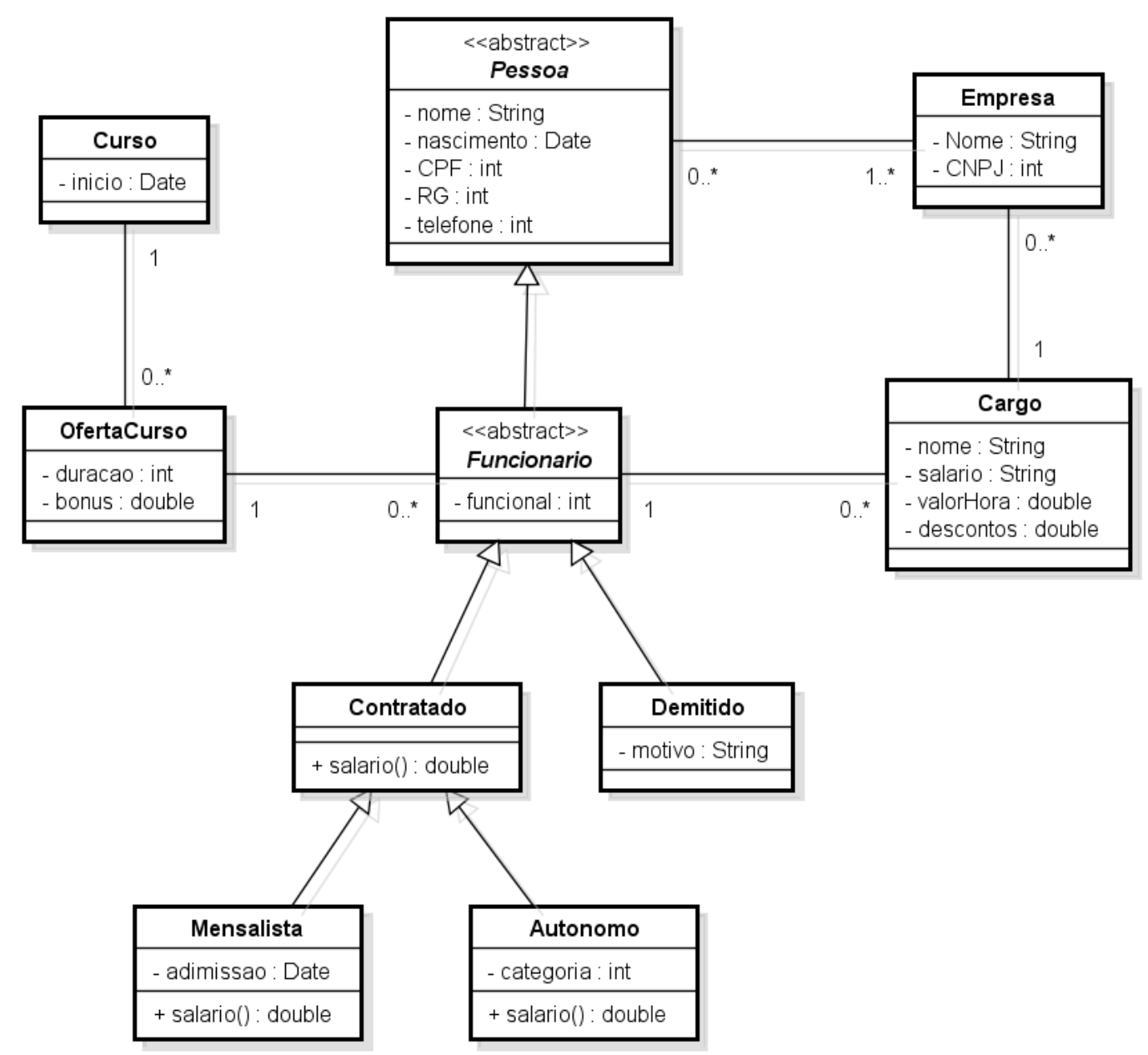

Figura 14 - Diagrama de classe usado como estudo de caso 
Teve-se o cuidado de reproduzir uma "interface" semelhante ao do Hibernate. Assim, a forma de utilização é muito similar, a qual é feita usando-se o eclipse [19], ou qualquer outra IDE, e incorporando-se a API do Framework ao projeto. Então, utilizam-se as anotações disponibilizadas. Para o exemplo, foram usadas apenas as anotações mínimas (Tabela 12), ou seja, as anotações necessárias para o funcionamento, sem nenhuma otimização com o intuito de melhorar o desempenho.

Com as classes anotadas, foi gerada uma classe $\mathrm{DAO}^{6}$ para cada classe persistente. E então usando o Framework O-ODBM, o script SQL para criação do respectivo esquema no banco de dados foi gerado e executado. Após o esquema ter sido criado no BD, foram executadas operações de inserção, seleção, atualização e remoção para cada classe, usando as classes DAO. Estes procedimentos foram executados primeiro usando o SGBD DB2, e na sequência, foram mudadas as diretivas de configuração do Framework para usar o SGBD Oracle. O código para a geração do esquema e acesso as classes foi executado no Oracle. É importante ressaltar que na mudança de um SGBD para outro não houve nenhuma modificação nas classes (persistentes e DAO) e nem em suas anotações, tendo sido mudado apenas as diretivas de configuração.

\subsubsection{Resultados}

Conforme dito anteriormente, para avaliação dos resultados, foram consideradas três métricas, sendo elas:

Produtividade: aqui se entende como produtividade de um Framework, a quantidade de código que usuário necessita gerar para interagir com o Framework, em comparação à quantidade de código que deveria ser gerada sem o uso do Framework. Cabe ressaltar aqui que deve-se considerar que o código gerado pelo Framework apresentará menor quantidade de erros quando comparado ao código gerado pelo desenvolvedor. Além disso, no caso do Framework, o erro que pode ser gerado é sistêmico (uma vez detectado é mais facilmente resolvido), enquanto que no caso do desenvolvedor é aleatório. Outro ponto importante está associado ao tempo de aprendizado do desenvolvedor para utilização do Framework. Tal fator também tem impacto direto na produtividade.

\footnotetext{
${ }^{6}$ DAO (Data Access Object) é um padrão de projeto, que centraliza todo o acesso de uma classe ao meio de persistência em uma Classe DAO.
} 
Desempenho: aqui desempenho está sendo medido apenas como o tempo de resposta de uma determinada operação. Verifica-se que não há degradação, ou aumento no tempo de resposta, com o uso do Framework.

Suporte às características OR: Entende-se como suporte OR fornecido pelo Framework a capacidade de ao fazer o mapeamento, representar em BD as características OO suportadas pela aplicação, como por exemplo: representação de objeto, herança, agregação, composição, referências, estruturas multivaloradas, entre outras descritas neste trabalho.

O uso de anotações auxiliou o ganho de produtividade, pois tornou a utilização do Framework mais simples e intuitiva do ponto de vista do desenvolvedor. Uma alternativa ao uso de anotações seria a utilização de arquivos de configuração, caso em que seria necessário conhecer a sintaxe de tais arquivos, e despender mais tempo/esforço para manter sincronizado o arquivo e o esquema de classes (o que não ocorre com as anotações, uma vez que estão presentes nas classes, ou melhor, no código Java).

Considerou-se também que com o uso de anotações o aprendizado foi facilitado, pois como o conjunto de anotações disponíveis fica integrado à interface do ambiente de programação, o desenvolvedor interage com as mesmas de forma mais natural, similarmente ao que se faz com outros Frameworks como o Hibernate.

Outro ponto importante que deve ser ressaltado é que ao usar as anotações, o desenvolvedor não necessariamente precisa ter conhecimentos mais específicos sobre o meio de persistência e, muito menos sobre os objetos definidos no mesmo. Em outras palavras, se foram criados UDTs, tabelas tipadas, REFs, etc., isso é transparente para o desenvolvedor. Isso afeta diretamente a produtividade, pois diminui a quantidade de diferentes conceitos com que o mesmo precisa lidar.

Em contrapartida, no acesso direto (JDBC) foi necessário a criação manual de todo o código responsável por todas as interações com o SGBD, incluindo o gerenciamento de conexões (e transações). Nesse caso, necessariamente o desenvolvedor precisa ter conhecimentos detalhados de SGBDs, dos tipos disponíveis e da linguagem de acesso.

Para que o desenvolvedor pudesse definir suas transações, uma "interface", semelhante às demais ferramentas ORM como exemplo o Hibernate, foi acrescentada ao Framework OODBM.

Para a criação do esquema de banco de dados usando o Framework utilizou-se, como já dito o código anotado. O conjunto de anotações é relativamente pequeno e integrado ao ambiente de programação. Por outro lado, sem o uso do Framework, foi necessário gerar 
todo o esquema do banco de dados diretamente, manualmente, em cada um dos SGBDs utilizados e usar JDBC para fazer a conexão e acesso as cada uma das bases de dados. Assim, o desempenho para a geração do esquema de banco de dados considerando essas duas abordagens não pode ser comparado. Por outro lado, o desempenho, considerando essas duas abordagens para operações como inserção, atualização e recuperação, foi muito próximo, não havendo diferenças significativas, A Tabela 15 apresenta os tempos obtidos em cada operação. Ressalta-se que a avaliação do desempenho (tempo de resposta no acesso aos dados) não era o foco deste trabalho, apenas fez testes com um exemplo relativamente simples e com pequena massa de dado. Para uma real avaliação de desempenho, um trabalho específico precisa ser definido, considerando os diferentes tipos de objetos que podem ser criados no banco de dados, herança, composição, REFs, etc., além de uma massa expressiva de dados armazenada nestas estruturas.

Ainda sobre desempenho, apesar de não fazer parte do escopo, é inevitável comparar os resultados do O-ODBM com os demais Frameworks estudados (principalmente o Hibernate), Cabem aqui alguns comentários sobre esta comparação.

Em relação ao tempo de resposta o O-ODBM apresentou diferenças significativas em alguns pontos. Por exemplo, na criação e execução do esquema de objetos no BD, o tempo medido foi aproximadamente a metade em relação aos demais. Considera-se que essa diferença seja devida ao maior número de funcionalidades presentes nos demais Frameworks. Outro aspecto que pode ter influenciado essa diferença é relativo ao número de objetos que são criados na base de dados. No mapeamento para BD relacional cada associação muitos para muitos gera uma nova tabela, já no caso de BD objeto-relacional, referências são usadas e nenhuma nova tabela precisa ser criada. O mesmo acontece com as associações um para um e um para muitos, onde no primeiro caso, campos e dados são incluídos nas tabelas apropriadas; já no segundo caso, referências, no lugar de campos, são incluídas em tabelas apropriadas.

Outro ponto com significativa diferença foi a inicialização da aplicação. Toda vez que a aplicação é inicializada, uma conexão com o SGBD é aberta (situação presente em todos os Frameworks estudados), e todo o esquema da aplicação é carregado em memória. Neste aspecto o O-ODBM apresentou um tempo que chegou a ser três vezes menor. Novamente esta diferença pode ser justificada pelo maior número de funcionalidades presente nos demais Frameworks.

Nas demais operações não houve diferenças significativas no tempo de reposta, os quais estão são apresentados na Tabela 15. Novamente ressaltando que os testes de desempenho 
realizados neste trabalho não são suficientes para afirmar que o Framework O-ODBM é mais ou menos performático que as demais soluções, e também a grande diferença do número de funcionalidades entre os Frameworks dificulta a obtenção de conclusões mais assertivas.

Tabela 15 - Tempos de reposta por operação

\begin{tabular}{|l|c|c|c|}
\hline & JDBC & Hibernate & O-ODBM \\
\hline Criação do esquema & $\mathrm{n} / \mathrm{a}$ & $5348 \mathrm{~ms}$ & $2689 \mathrm{~ms}$ \\
\hline Inicialização & $512 \mathrm{~ms}$ & $2363 \mathrm{~ms}$ & $734 \mathrm{~ms}$ \\
\hline Inserção & $129 \mathrm{~ms}$ & $155 \mathrm{~ms}$ & $141 \mathrm{~ms}$ \\
\hline Atualização & $198 \mathrm{~ms}$ & $214 \mathrm{~ms}$ & $216 \mathrm{~ms}$ \\
\hline Recuperação & $155 \mathrm{~ms}$ & $195 \mathrm{~ms}$ & $173 \mathrm{~ms}$ \\
\hline
\end{tabular}

Em relação ao suporte as características OR, o Framework O-ODBM fez o mapeamento usando o suporte a objetos disponibilizados pelos SGBDs, tendo sido utilizado herança, agregação, composição, referências e estruturas multivaloradas. Para isso o Framework fez uso de UDTs, REFs, MULTSETs e ARRAYs presentes na SQL:2008 e nos SGBDs usados neste trabalho. Vale ressaltar que mesmo havendo diferenças entre as implementações Oracle e DB2 e a SQL:2008, o Framework gerou o código apropriado para o mapeamento e acesso aos SGBDs usando os mesmos conceitos OR.

Por fim, o Framework O-ODBM ainda é um protótipo, muitas funcionalidades ainda precisam ser implementadas e/ou melhoradas para que a ferramenta possa ser empregada de forma mais efetiva e até comercialmente. Mas, o protótipo foi efetivo para demonstrar a viabilidade da proposta. 


\section{Comentários e Conclusões}

Quando se fala em persistência de objetos a melhor forma de fazê-lo é acessando diretamente o $\mathrm{BD}$, controlando a conexão e transações de forma manual, da mesma forma gerando todos os comandos SQL manualmente. Entretanto, este tipo de abordagem acaba não tendo uma produtividade adequada, e uma série de desvantagens (discutidas neste trabalho). Nesse contexto, o uso de ferramentas ORM pode proporcionar melhora na produtividade.

Por outro lado, SBDOR disponibiliza novos tipos de dados permitindo que objetos da aplicação sejam mapeados em objetos de banco de dados, eliminando o problema do descasamento de impedância.

Como os Frameworks ORM existentes não fazem uso dos tipos disponibilizados por SBDOR, este trabalho propôs a criação de um novo Framework voltado para SBDOR, denominado O-ODBM. Assim como os demais, provê um mecanismo transparente para criação do esquema de "objetos" no banco de dados. Diferenciando-se pelo uso de SBDOR, enquanto os demais usam SBDR. A melhora na produtividade pode ser conseguida com o uso de anotações disponibilizadas pelo O-ODBM que permitem o mapeamento usando os recursos de objetos do SGBDOR, além da geração automática do código SQL e da facilidade de alteração para outros SGBDORs.

A utilização do O-ODBM apresenta-se eficiente de acordo com a avaliação realizada neste trabalho. Onde são evidenciadas vantagens como: maior proximidade das linguagens de programação OO, não exigindo conhecimento de novos conceitos para sua utilização; desempenho permanecendo próximo ao acesso direto; automatização da geração de todo o código responsável pela persistência dos objetos; persistência de objetos em sua forma nativa (OO); não sendo necessário o usuário conhecer sobre SQL ou SBD; sendo configurado através de anotações; uso de tipos de dados e conceitos OR definidos na SQL:2008; prover um mecanismo de persistência transparente ao usuário. Estas vantagens, entre outras descritas neste trabalho, confirmam a viabilidade de Frameworks utilizando SBDOR. Da mesma forma confirmam sua vantagem sobre os Frameworks que utilizam SBDR, entretanto para um uso mais efetivo de SBDOR, existe o problema do baixo nível de conformidade dos SGBD disponíveis no mercado com a norma SQL. E para que esta solução (ORM+SBDOR) seja difundida, uma especificação de persistência em SBDOR 
deve ser criada, afim de, suportar e padronizar o desenvolvimento de novas ferramentas ORM SBDOR.

\subsection{Trabalhos futuros}

Entende-se que este trabalho necessita de estudos comparativos sobre desempenho entre o Framework O-ODBM e as abordagens tradicionais (ORM e acesso direto aos SBDR e SGBDOR). Da mesma forma estudos comparativos sobre a produtividade e a usabilidade podem ser feitos.

A arquitetura deste Framework foi projetada com o intuito de possibilitar a integração com ferramentas externas de modelagem (diagrama de classes). Esse foi o motivo da criação do componente SQL-XML. Tal intenção foi inspirada pelo trabalho [12], bastando uma extensão deste, para seja gerado um XML no formato esperado pelo Framework (descrito no componente SQL-XML). Da mesma forma o Framework Torque integra com algumas ferramentas de modelagem relacional (Entidade Relacionamento) [05].

Outras funcionalidades descritas nas especificações JPA e JDO poderiam ser empregadas no Framework, como por exemplo: cache de objetos na aplicação (cache de segundo nível).

Uma funcionalidade não menos importante é o desenvolvimento de uma estratégia para migração de processamento da aplicação para o banco de dados. Alguns SGBDs como Oracle e DB2 suportam rotinas externas [28] [50], desta forma é possível que um método implementado em Java seja migrado para um método em um UDT, assim sendo, processado no SGBD. Em outras palavras seria migrar a implementação de um método em uma classe Java para um método em um UDT no SGBD, tendo uma diferente distribuição de processamento. Cabe a um próximo trabalho avaliar a viabilidade e as vantagens e desvantagens desta abordagem.

Novamente sobre métodos em UDT, seria importante para a comunidade, o desenvolvimento de metodologias e técnicas de modelagem que tivessem um maior aproveitamento dos métodos (UDT). Eles possibilitam a parte comportamental dos objetos em Banco de dados. O que na opinião do autor, construída durante o estudo realizado neste trabalho, é uma funcionalidade subaproveitada.

Por último, pretende-se como trabalho futuro o desenvolvimento de uma especificação tratando sobre Frameworks de persistência ORM usando base de dados SGBDOR, ou seja, 
estender as funcionalidades descritas aqui com o intuito de torná-las uma especificação a ser seguida por outras soluções. 


\section{Referências Bibliográficas:}

[01] APACHE. About Apache JDO. Disponível em: $<$ http://db.apache.org/jdo/index.html>. Acessado em dezembro de 2010.

[02] Which Persistence specification?. Disponível em: <http://db.apache.org/jdo/jdo_v_jpa.html>. Acessado em dezembro de 2010.

[03] Which ORM specification?. Disponível em: <http://db.apache.org/jdo/ jdo_v_jpa_orm.html>. Acessado em dezembro de 2010.

[04] Framework Apache torque. Disponível em: <http://db.apache.org/Torque/>. Acessado em Agosto de 2010.

[05] _ . Transforming other formats from to torque format. Disponível em <http://db.apache.org/Torque/tools/index.html>. Acessado em setembro de 2011.

[06] Welcome to the Apache OpenJPA project. Disponivel em: <http://openjpa.apache.org/>. Acessado em outubro de 2011.

[07] ARAVACA. JPA implementations comparison: hibernate, toplink essentials, openjpa, eclipselink. Disponível em: <http://terrazadearavaca.blogspot.com/2008/12/jpa-implementationscomparison.html>. Acessado em : outubro de 2010.

[08] AMBLER, S.W. The object-relational impedance Mismatch. $2002 ? 2003$. Disponnível em: <http://www.agiledata.org/essays/impedanceMismatch.html>. Acesso em agosto de 2010

[09] BARRY, D. K. ; STANIENDA T. Solving the Java object storage problem. Institute of Electrical and Electronics Engineers, Inc, 1998. Disponivel em : $<$ http://doi.ieeecomputersociety.org/10.1109/2.730734>. Acessado em outrubro de 2010.

[10] BISWAS, R. ; ORT, E. The Java persistence API - a simpler programming model for entity persistence. Oracle. 2006. Disponivel em: <http://www.oracle.com/technetwork/articles/javaee/index-135149.html>. Acessado em outubro de 2010. 
[11] CASTRO, T. R., SOUZA, S. N. A. e SOUZA, L. S. Proposta de um modelo para projetos Lógicos Gráficos para Bancos de Dados Objeto-Relacionais (BDORs). In: Anais. SEMINCO - Seminário de Computação. Blumenau, SC. 2010.

[12] CASTRO, T. R. . Projeto Lógico para BDOR de acordo com SQL:2003, proposta de uma ferramenta CASE. 2011. Dissertação Mestrado - Escola Politécnica, Universidade de São Paulo, São Paulo, 2011.

[13] CESCHIATTI, G. B. M. . Persistência de Objetos com Java e Software Livre em Ambiente J2EE: Análise e Estudo Comparativo. 2006. 103 p. Dissertação Mestrado - Escola Politécnica, Universidade de São Paulo, São Paulo, 2006.

[14] CHUNG, J.-Y.; LIN, Y.-J.; CHANG, D. T. Objects and relational databases. OOPS Messenger, v. 6, n. 4, p. 164-169, out. 1995. ISSN 1055-6400. Disponível em: <http://portal.acm.org/citation.cfm?id=260273\&dl=ACM\&coll=DL\&CFID=3055257\&CFT OKEN=25794046>

[15] COSTA, H. L. C.; MURTA, L. G. P.; BRAGANHOLO, V. Armazenando Dados em Aplicações Java - Parte 3 de 3. SBC Horizontes, p. 54 - 58, 01 ago. 2009. Disponível em: <http://www.ic.uff.br/ leomurta/papers/costa2009b.pdf>. Acessado em outubro de 2010.

[16]

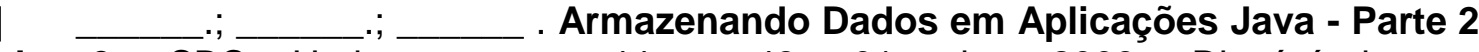
de 3. SBC Horizontes, p. 44 - 48, 01 abr. 2009. Dispónível em: <http://www.ic.uff.br/ leomurta/papers/costa2009.pdf>. Acessado em outubro de 2010.

[17] Armazenando Dados em Aplicações Java - Parte 1 de 3. SBC Horizontes, p. 57 - 61, 01 dez. 2008. Disponivél em: <http://www.ic.uff.br/ leomurta/papers/costa2008.pdf>. Acessado em outubro de 2010.

[18] DATE, C. J. Introdução a Sistemas de Banco de Dados. Rio de Janeiro: Ed. Campus, 2004.

[19] ECLIPSE. The Eclipse Foundation open source community website. Disponivel em:< http://eclipse.org/>. Acessado em dezembro de 2010.

[20] EISENBERG, A; KULKARNI, K; MELTON, J; MICHELS, J; ZEMKE, F. SQL:2003 Has Been Published. New York: ACM SIGMOD, 2004.

[21] EISENBERG, A; MELTON, J; SQL:1999, formerly known as SQL3. New York: ACM SIGMOD, 2004. Disponivel em: < http://portal.acm.org/citation.cfm?id=974121.974142>. Acessado em: novembro de 2009. 
[22] FEUERLICHT , G.; POKORNÝ, J.; RICHTA, K. Object-Relational Database Design: Can Your Application Benefit from SQL:2003? Galway, Ireland: Springer , 2009. p 1-13.

[23] FOWLER, M.; SCOTT, K. UML Essencial. [S.I.]: Bookman, 2000. ISBN 8573077298.

[24] FOWLER, M. Padrões de Arquitetura de Aplicações Corporativas. São Paulo, SP: Artmed, 2008.

[25] Free Software Foundation. Disponível em: <http://www.fsf.org/>. Acessado em agosto de 2010.

[26] GOLOBISKY, M. F.; VECCHIETTI, A. Mapping UML Class Diagrams into Object-Relational Schemas. Rosario, Argentina: Proceedings of ASSE, 2005. p 6579.

[27] GOSLING, J.; JOY, B.; STEELE, G. The Java Language Specification. AddisonWesley,1996.Disponnível em: <java.sun.com/docs/books/jls/html/index.html> Acesso em: outubro de 2010.

[28] IBM. DB2 9.7 for Linux, UNIX and Windows Information Center. Disoponível em: <http://publib.boulder.ibm.com/infocenter/db2luw/v9r7/index.jsp>. Acessado em setembro de 2010.

[29] JBOSS. Hibernate Documentation. Disponível em: <http://www. Hibernate.org/>. Acessado em abril de 2010.

[30] JCP. Java Community Process. Disponível em: <http://www.jcp.org>. Acesso em: outubro de 2010.

[31] KING, D.; BAUER, C.; RYDAHL, M.; BERNARD, E.; EBERSOLE, S. "HIBERNATE - Relational Persistence for Idiomatic Java" Capitulo 14 e 19; 2009. Disponínel em: $<$ http://docs.jboss.org/Hibernate/core/3.3/reference/en/html/> acessado em: maio de 2011.

[32] KROENKE, D. M.; Database Processing: Fundamentals, Design and Implementation; 6a edição. Prentice-Hill. 1996.

[33] LAUX, Fritz; Object-relational Design \& DB2 Universal Database support for SQL:2003. 2004. Disponível em: <http://www.inf-classic.reutlingenuniversity.de/dbweb/content/ORDB2/SQLORDesignDB2.pdf>. Acessado em: dezembro de 2010; 
[34] LEE, G; ZEMKE, F. SQL 2003 Standard Support in Oracle Database 10g. ORACLE, 2010.

[35] LINDHOLM, T.; YELLIN, F. The JavaTM Virtual Machine Specification. Segunda edição. Disponível em:<http://java.sun.com/docs/books/jvms/>. Acessado em dezembro de 2010.

[36] MARCOS, E.; VELA, B.; CAVERO, J. M. A Methodological Approach for Object-Relational Database Design using UML. Heidelberg : Springer Berlin, 2003. p 59-72.

[37] Object-Relational Database Design, Vilnius, Lithuani: Advances in Databases and Information Systems - ADBIS' 2001, 2001.

[38] MELTON, J. Database languages SQL: Part 1 Framework (SQL/Framework). ISO-ANSI WD 9075, ISO, Working Group WG3, 2003.

[39] J. Database languages SQL: Part 2 Foundation. ISO-ANSI WD 9075, ISO, Working Group WG3, 2003.

[40] J. Database languages SQL: Part 1 Framework (SQL/Framework). ISO-ANSI WD 9075, ISO, Working Group WG3, 2008.

[41] ․ Jatabase languages SQL: Part 2 Foundation. ISO-ANSI WD 9075, ISO, Working Group WG3, 2008.

[42] _ J. Database languages SQL. ISO-ANSI WD 9075, ISO, Working Group WG3, 1999.

[43] MICROSOFT. Microsoft SQL Server Library. Disponível em: <http://msdn.microsoft.com/en-us/library/bb545450.aspx>. Acessado em abril de 2010.

[44] MOK, W Y. Designing Nesting Structures of User-Defined Types in ObjectRelational Databases. Newton, MA: Information and Software Technology, 2007.

[45] MUKHERJEE, P. Hibernate Vs JDBC Performance. 2009. Disponivel em: $<$ http://ezinearticles.com/?expert=Pinaki_Mukherjee> Acessado em Setembro de 2010.

[46] NAVATHE, B. S; ELMASRI, R. Fundamentals of Database Systems. 6a. edição. Addison-Wesley, 2010. 
[47] ODMG. Object Data Management Group. Disponivel em: http://www.odbms.org/odmg/>. Acessado em: dezembro de 2010.

[48] OMG. Unified Modeling Language - version 2.2. 2009. Disponível em: <http://www.omg.org/spec/UML/2.2/Infrastructure/PDF/>.

[49] ORACLE. Annotations. $2003 . \quad$ Disponivel em: $<$ http://download.oracle.com/javase/tutorial/java/javaOO/annotations.html>. Acessado em outubro de 2010.

[50] Oracle Database 11g Documentation. Disponivel em: $<\mathrm{http}: / /$ www.oracle.com/technetwork/database/enterpriseedition/documentation/index.html>. Acessado em outubro de 2010.

[51] - Java Data Objects (JDO). Disponivel em: <http://www.oracle.com/technetwork/java/index-jsp-135919.html>. Acessado em Outubro de 2010.

[52] _ . The Java Persistence API - A Simpler Programming Model for Entity Persistence. Disponivel em: <http://www.oracle.com/technetwork/articles/javaee/jpa137156.html>. Acessado em Outubro de 2010. <http://download.oracle.com/docs/cd/B28359 01/server.111/b28286/ap standard sql0 04.htm>. Acessado em Agosto de 2010.

[54] PARDEDE, E.; RAHAYU, J. W.; TANIAR, D. New SQL Standard For ObjectRelational Database Applications. Institute of Electrical and Electronics Engineers, Inc, 2004. p 191- 203.

[55] Encyclopedia of Information Science and Technology, 2005. . Impact of New SQL Standard to Database Modeling.

[56] ROMBALDO, C. A. Jr.; CASTRO, T. R.; SOUZA, S. N. A. Banco de Dados Objeto-Relacional: comparação do suporte oferecido por SGBDs para a persistência de objetos. Natal, RN: EPOCA'09 - Escola Potiguar de Computação e suas Aplicações, 2009. p 40-45.

[57] SILBERSCHATZ, A.; KORTH, H.; SUDARSHAN, S.; Sistemas de Banco de Dados; Campus, 1a edição; 2006.

[58] SOMMERVILLE, lan. Engenharia de Software. São Paulo: Pearson Education, 2009. 
[59] SUN. JDBC 4.0 API Specification. Disponivel em: <http://java.sun.com/products/jdbc/download.html> Acessado em dezembro de 2010.

[60] "Annotations"

Disponível em: $<$ http://cupi2.uniandes.edu.co/web/javadoc/j2se/1.5.0/docs/guide/language/annotations .htmlhttp://download.oracle.com/javase/tutorial/java/javaOO/annotations.html>. Acessado em maio de 2011.

[61] WALNES, J. et al. Java Open Source Programming. [S.I.]: Wiley, 2003. ISBN:0471463620.

[62] Wikipédia the Free Encyclopedia. List of object-relational mapping software. Disponível em: $<$ http://en.wikipedia.org/wiki/List_of_objectrelational_mapping_software>. Acessado em outubro de 2011.

[63] W3C. World Wide Web Consortium. Disponivel em: <http://www.w3schools.com/>. Acessado em outubro de 2010. 


\section{APÊNDICE A Recursos OR presentes na norma que foram empregados no trabalho.}

Nesta seção do trabalho será apresentado uma breve descrição dos tipos definidos pela SQL:99 e revisados na SQL:2003 e SQL:2008, tipos referentes ao suporte objeto relacional oferecido pela norma.

\section{LOB (Large Object)}

LOB são utilizados para armazenamentos de grandes volumes de dados. Este ainda se divide em dois tipos: CLOB (Character Large Object) e BLOB (Binary Large Object).

A Figura 15 demonstra a utilização de um BLOB.

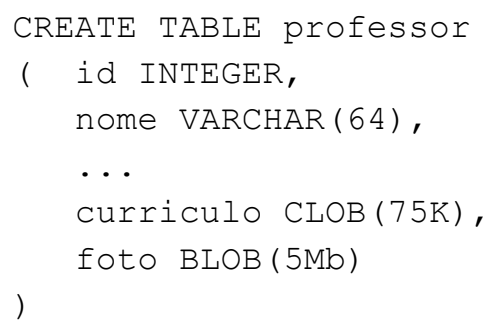

Figura 15 - Demonstração da utilização de LOBs

\section{ARRAY}

É um tipo de dados complexo que armazena uma coleção de dados do mesmo tipo, possui uma dimensão (cardinalidade), ou seja, um número máximo de elementos, o qual é obrigatoriamente definido na declaração do objeto. Cada elemento dessa coleção está associado a uma posição ordinal. Trata-se de um tipo necessariamente construído (instanciado), devido à necessidade de explicitar sua cardinalidade. Entretanto os elementos podem possuir um tipo predefinido ou UDT(mais adiante existe uma descrição sobre UDT). Um ARRAY mantém a ordem de inserção de seus elementos e não permite 
duplicidade. A Figura 16 contempla a criação de ARRAY usando um tipo predefinido (telefones) e um UDT cursos.

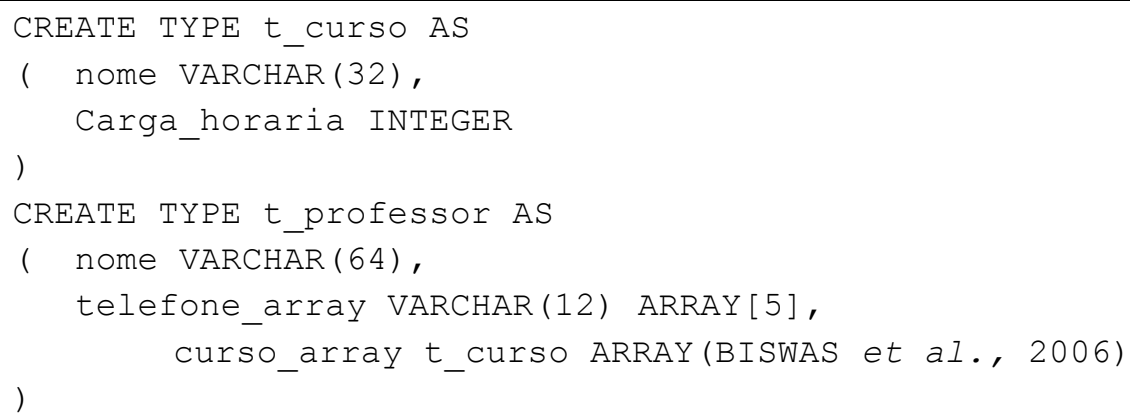

Figura 16 - Demonstração da criação de um ARRAY

A Figura 17 mostra como inserir um ARRAY para atribuir na coluna "telefone_array" do tipo" t_professor" descrito acima.

ARRAY [ '01133334444', '01544445555', '01966667777']

Figura 17 - Demonstração de como popular uma coluna do tipo ARRAY

Para acessar / atualizar elementos dentro de um ARRAY, basta apenas usar a posição ordinal (índice), a Figura 18 mostra como isto pode ser feito:

Telephone_array [1] = '01688889999';

Figura 18 - Demonstração da atribuição em uma ARRAY

Outro ponto importante na manipulação não só de ARRAYs, mais de dados multivalorados em geral. É a capacidade de consultar um valor dentro da estrutura aninhada. Na Figura 19 seguem duas das muitas formas de se realizar esta consulta:

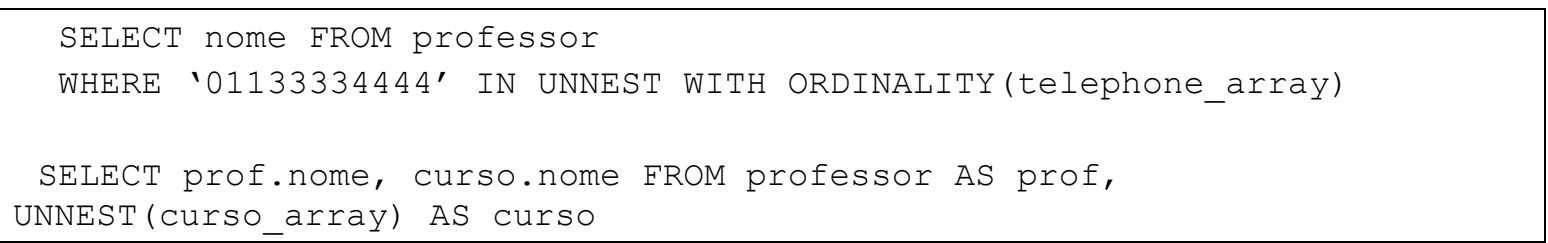

Figura 19 - Demonstração de como realizar consultas em ARRAYs

Repare que nos dois comandos existe a cláusula UNNEST, entretanto no primeiro ela vem precedida da cláusula WITH ORDINALITY, a qual significa que o resultado o UNNEST será ordenado seguindo a ordem de inserção. Este processo que foi mostrado é chamado de "desaninhamento", o processo inverso também existe e é chamado de "aninhamento", o exemplo a seguir mostra como obter uma estrutura aninhada a partir de uma estrutura na 
primeira forma normal [57][18]. A Tabela 16 representa a estrutura desaninhada e o comando apresentado na Figura 20 demonstra o processo de aninhamento desta estrutura.

Tabela 16 - Estrutura a ser aninhada

\begin{tabular}{|l|l|}
\hline Nome & Telefone \\
\hline Jose Pereira & 1122223333 \\
\hline Jose Pereira & 1144445555 \\
\hline Maria Augusta & 1566667777 \\
\hline Maria Augusta & 1988889999 \\
\hline Maria Augusta & 1911110000 \\
\hline
\end{tabular}

SELECT nome, COLLECT(telefone) GROUP BY nome

Figura 20 - Comando usado para aninhar a estrutura da Tabela 16

ROW

Este tipo define uma estrutura composta por elementos, onde cada elemento é definido pelo Figura 21 demonstra a criação de um ROW .

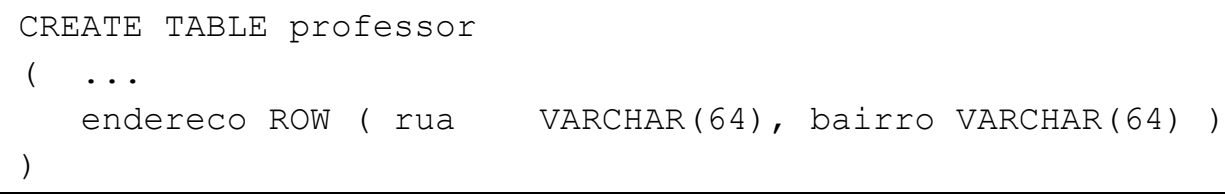

Figura 21 - Demonstração da criação de ROW

\section{UDT (User Defined Type)}

Consiste na criação de um novo tipo a partir da extensão de um tipo pré-definido pelo SGBD. Um tipo estruturado (UDT) pode ser formado por um ou mais atributos, podendo ainda possuir métodos e funções para manipulação. Tipos estruturados podem ser submetidos a hierarquias, ou seja, suporta herança, o que é um conceito muito importante na abordagem OO. Outra característica importante dos UDTs é que seus métodos podem ser implementado usando a linguagem SQL como também podem usar linguagens externas 
como JAVA e C++ (através da implementação de funções externas descrito na norma SQL).

Seguem alguns exemplos de definições de UDTs. A Figura 22 especifica a criação do tipo t_pessoa, com três atributos e um método. A cláusula NOT FINAL especifica que o tipo pode ser estendido, gerando outros subtipos em uma hierarquia.

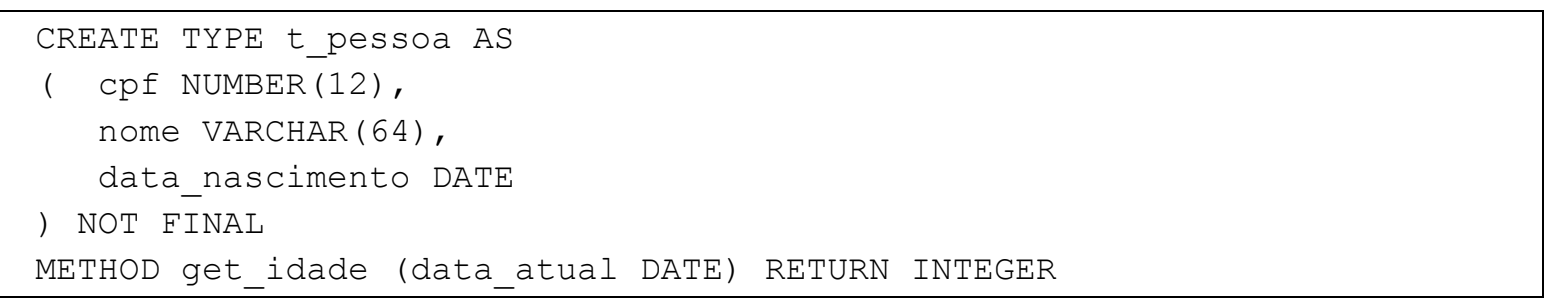

Figura 22 - Demonstração da criação de um UDT

Repare que o UDT criado na Figura 22 menciona um método que não foi descrito, portanto agora segue a implementação do método na Figura 23.

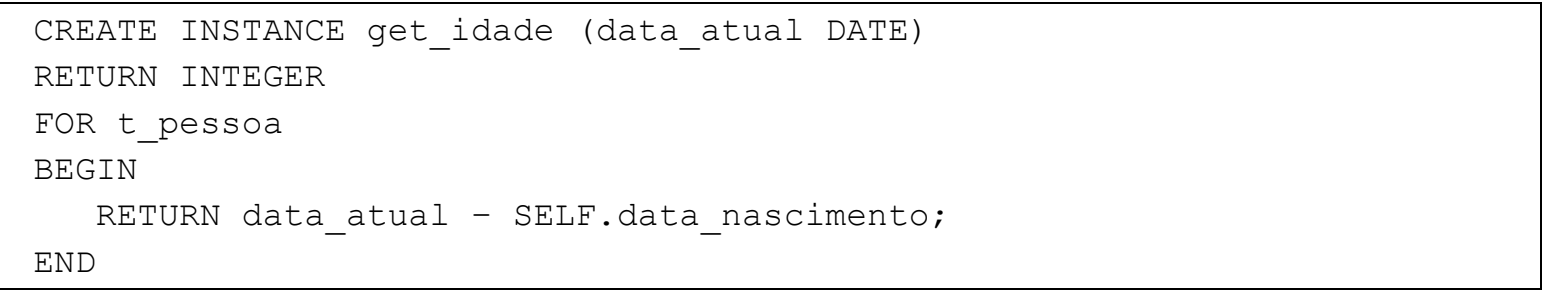

Figura 23 - Demonstração da implementação de um método em um UDT

UDTs são tipos e, portanto, não podem persistir dados, para tanto devem possuir uma tabela tipada, a qual possui a mesma estrutura que seu UDT. A Figura 24 mostra uma tabela tipada, pessoa, originada a partir do UDT t_pessoa.

CREATE TABLE pessoa OF t_pessoa

Figura 24 - Demonstração da ciração de uma tabela tipada

Os métodos definidos no UDT t_pessoa são propriedades da tabela tipada pessoa e, assim, podem ser manipulado tal qual qualquer outra propriedade. A Figura 25 demonstra tal afirmação.

SELECT nome, cpf, get_idade (NOW) FROM pessoa

Figura 25 - Demonstração da obtenção de um ROW

Vale ressaltar que no UDT não é possível definir restrições como, por exemplo, chaves primárias ou estrangeiras, ou ainda restrições de checagens, enfim, não é possível atribuir 
restrições nos UDT, restrições só podem ser atribuídas em tabelas (neste caso tabelas tipadas). A Figura 26 demonstra a definição de restrições em tabela tipadas.

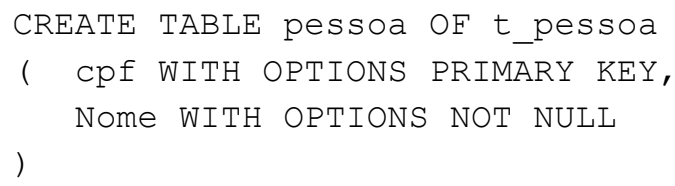

Figura 26 - Demonstração da criação de restrições em tabelas tipadas

Ainda em relação à Figura 22, como a cláusula "NOT FINAL" foi definida, subtipos poderiam ser definidos a partir do UDT t_pessoa, exemplos são apresentados na Figura 27.

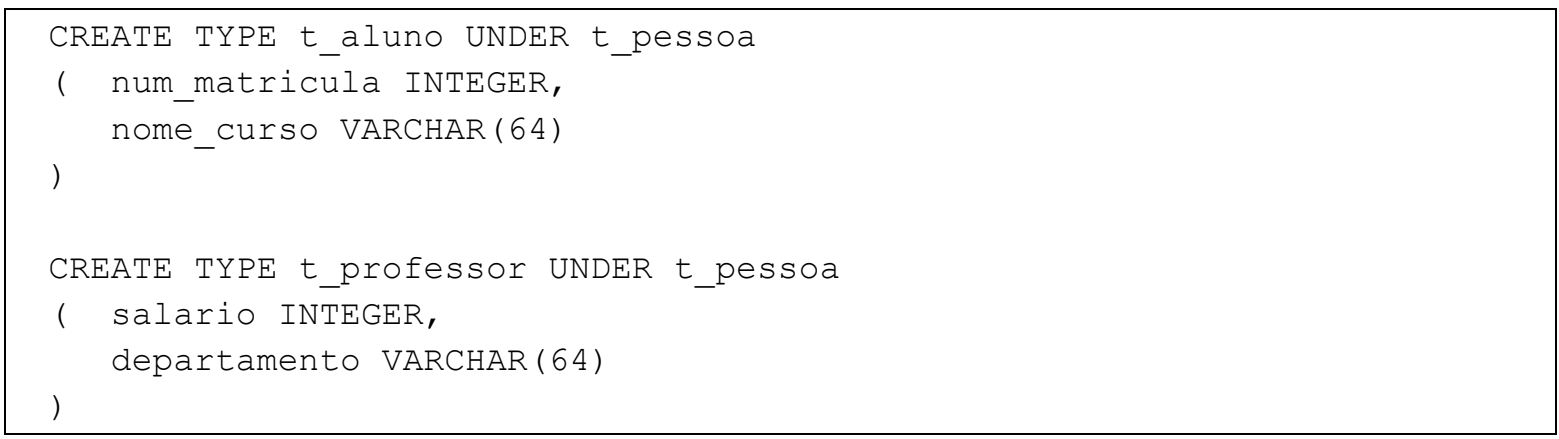

Figura 27 - Demonstração de hierarquias e polimorfismo.

Os subtipos t_aluno e t_professor herdam as propriedades de t_pessoa. Sobre herança existem dois conceitos importantes, sobrecarga e sobrescrita.

Sobrescrita consiste de um método consistem em uma nova implementação mantendo-se a assinatura ${ }^{7}$. Sobrecarga consiste na criação de um novo método com o nome de um já existente, sem manter a assinatura.

Em relação a Figura 22, a especificação da cláusula "FINAL", no lugar de "NOT FINAL" indicaria que o UDT não pode ser especializado.

\section{Herança.}

Quando se cria uma hierarquia de UDTs, os objetos filhos herdam a estrutura (atributos e métodos) do objeto pai. Se tabelas tipadas forem criadas a partir desta hierarquia de UDTs,

\footnotetext{
${ }^{7}$ Assinatura de um método é composta pelo seu nome, o tipo de dados do retorno e dos tipos de dados dos parâmetros passados (mantendo a ordem a qual eles foram criadas).
} 
os dados armazenados nestas tabelas não serão submetidos à hierarquia, ou seja, os dados armazenados nas tabelas pais não terão relação com os armazenados nas tabelas filhas. $\mathrm{O}$ mesmo vai acontecer com as restrições e permissões atribuídas nas tabelas e que não pertencem ao UDT que a originou. Para garantir essa hierarquia entre os dados e as características pertencentes à tabela, a norma SQL define a herança de tabelas.

\section{Construtores de UDT}

Falando em acesso à UDTs, segue agora descrições sobre como conseguir uma instancia deste objeto. Por padrão todo tipo estruturado possui um construtor sem argumentos (parâmetros), neste caso é atribuído os valores padrões em todos os atributos do UDT, no caso de algum atributo não possuir valor padrão, neste é atribuído vazio. Na Figura 28 é apresentado como obter uma instancia do tipo "t_aluno":

NEW t_aluno ();

Figura 28 - Demonstração de funções construtoras

Em alguns casos pode ajudar muito ter um construtor onde seja possível especificar os valores dos atributos do objeto. Pode-se fazer uso da sobrecarga para criar uma função construtora possuindo parâmetros. Tal função deve possuir o mesmo nome do UDT no qual ela vai gerar instâncias. Uma demonstração pode ser encontrada na Figura 29

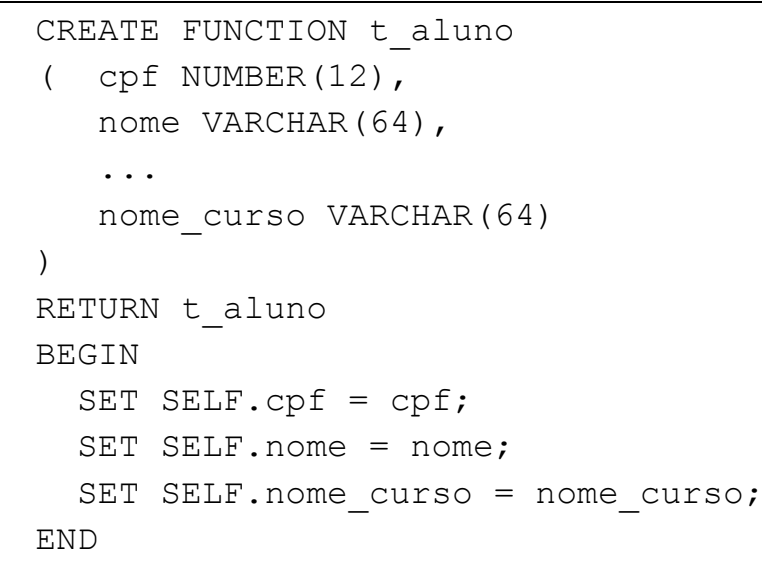

Figura 29 - Demonstração sobre como crias funções construtoras

Neste caso, a Figura 30 ilustra uma chamada a função construtora.

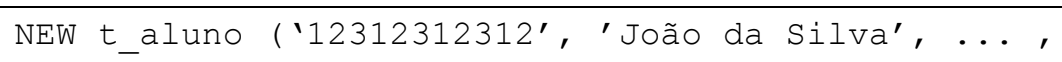

Figura 30 - - Demonstração de chamada de função construtora 


\section{REF e OID}

O tipo REF armazena uma referência para um objeto armazenado em uma tabela tipada. $\mathrm{O}$ objeto a ser referenciado necessariamente deve possuir um OID (Object IDentifier). Um OID pode ser obtido de três formas: pode ser gerado automaticamente pelo SGBD, pode-se deixar a cargo do usuário fornecer o OID ou ainda pode-se derivar uma coluna já existente para obter o OID (podendo este ser a chave primária). Devido a importância deste para o trabalho, abaixo segue detalhes sobre sua utilização:

A Figura 31 demonstra a utilização de REF. O atributo professor do UDT t_curso armazena referencias (REF) para o UDT t_professor armazenado na tabela tipada tb_professor. A cláusula SCOPE define em qual tabela tipada estão persistidos os UDT referenciados, no caso tb_professor.

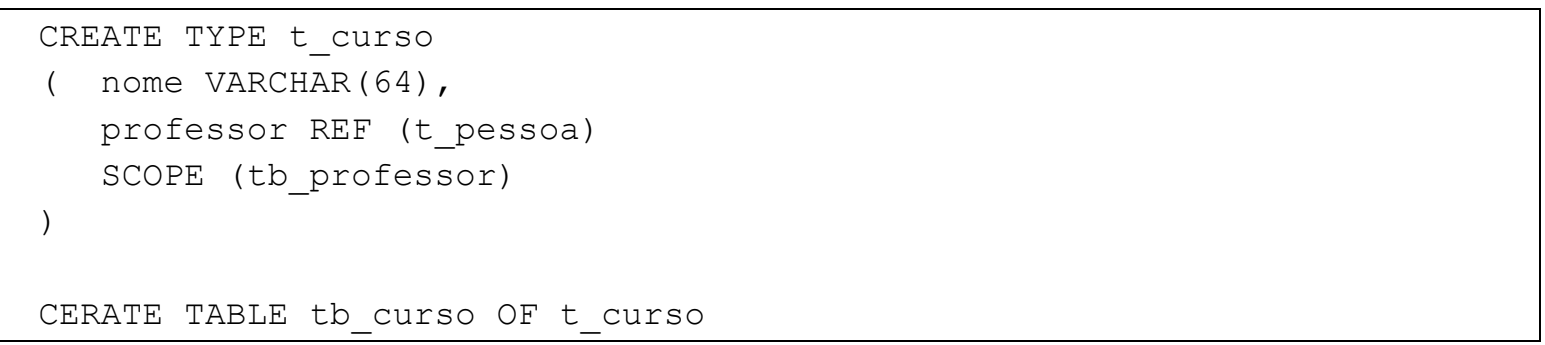

Figura 31 - Definição de um REF

A Figura 31 apresentou a definição do SCOPE na criação do UDT, porém o UDT ainda poderia ter sido criado sem especificar o SCOPE, o qual seria especificado na criação da tabela tipada. A Figura 32 apresenta a definição do SCOPE na criação da tabela tipada:

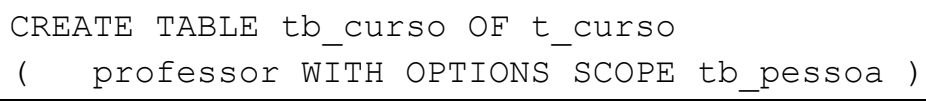

Figura 32 - - Especificação do escopo em um REF

A criação do tipo t_pessoa ficou por último para mostrar a as três formas de se obter o OID:

Gerado automaticamente pelo SGBD

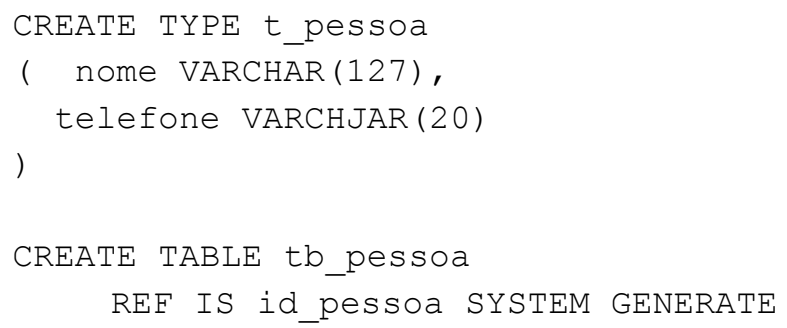

Figura 33 - OID Gerado automaticamente. 
Fornecido pelo usuário

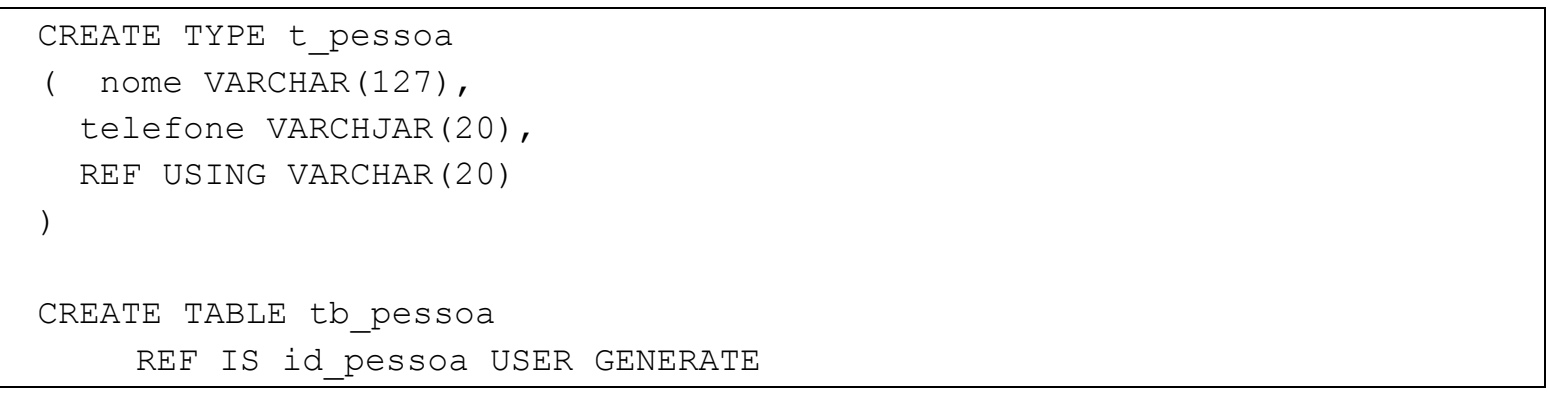

Figura 34 - OID fornecido pelo usuário

Derivado de uma coluna existente.

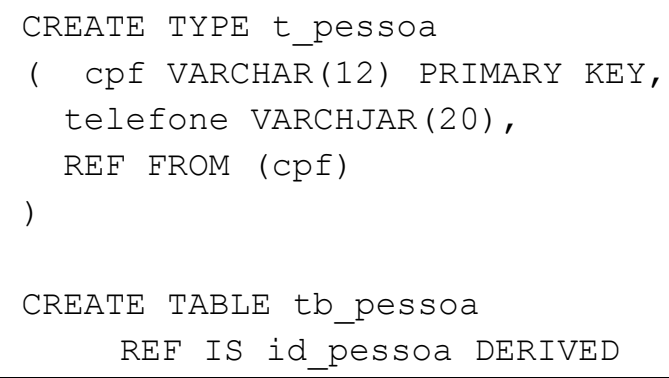

Figura 35 - OID derivado de uma coluna já existente

Em referências (REF) é possível acessar/navegar até o atributo ou métodos do objeto referenciado, a Figura 36 demonstra como isto pode ser feito.

SELECT professor->nome FROM tb_curso

Figura 36 - Recuperando um a tributo de um objeto referenciado por um REF

A Figura 36 apresentou como acessar atributos e métodos dos objetos referenciados, sem precisar obter objeto, a Figura 37 demonstra o contrário, ou seja, como acessar atributos e métodos através da instancia do objeto, usando a cláusula DREF.

SELECT DREF(professor) . nome FROM tb_curso

Figura 37 - Resgatando um objeto referenciado por um REF

O tipo REF simplifica uma consulta tanto para o usuário que não precisa mais especificar qual é a cláusula da junção, quanto para o SGBD que não vai precisar realizar um filtro (seleção) dessa junção e nem ter que calcular tal consulta.

É importante ressaltar que um REF não tem controle de integridade, ou seja, não existe garantia por parte do SGBD que o objeto referenciado ainda exista, caso ele não exista a operação DREF retornara NULL. 


\section{MULTISET}

É uma estrutura multivalorada semelhante ao ARRAY, no entanto permite valores duplicados, não possui ordenação e cardinalidade, ou seja, um número máximo de elementos explícito na criação do objeto. Sua criação do objeto é um pouco diferente, porem seu acesso é semelhante ao ARRAY (não permitindo o uso da cláusula WITH ORDINALITY, pois não possui ordenação). Junto com o MULTISET vieram várias funcionalidades para manipulação de estruturas aninhadas, no final da descrição e dos exemplos sobre MULTISET será mostrado sobre estas funcionalidades.

A Figura 38 mostra com se obter uma instância de um MULTISET

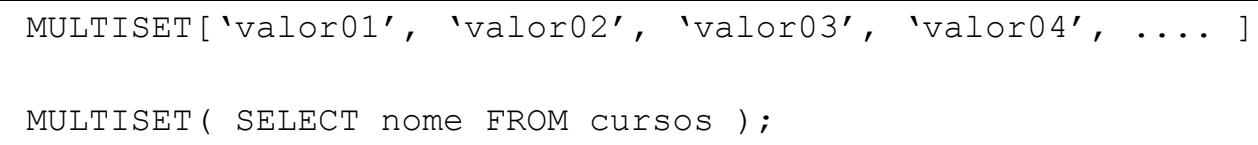

Figura 38 - Demonstração de como obter um MULTISET

\section{Operações com MULTISET}

\section{MULTISET UNION}

É um operador que computa a união de dois MULTISETs, ainda podendo ter a cláusula DISTINCT que remove a duplicidade de elementos entre as estruturas, ou a cláusula ALL que não verifica se existe repetição.

\section{MULTISET INTERSETC}

É um operador que computa a intersecção entre dois MULTISETs

\section{MULTISET EXCEPT}

É um operador que computa a diferença entre dois MULTISETs

Todas as operações listadas anteriormente podem ainda possuir duas cláusulas, a DISTINCT onde todas as repetições no resultado da operação são removidas ou a ALL que ignora as repetições. 
Além de todos os tipos listados anteriormente, ainda existem alguns operadores que não serão pouco descritos neste trabalho, mas podem ser encontrados em [41]. Alguns dos operadores: 


\section{APÊNDICE B Avaliação dos Frameworks Hibernate e Apache Torque.}

Neste apêndice é apresentada uma avaliação dos Frameworks Hibernate e Apache Torque, tomando como métrica os requisitos definidos no item 4.2 deste trabalho. Tais requisitos foram compilados baseando-se nas especificações JPA e JDO, sofrendo extensões para o acréscimo de suporte OR. Portanto entende-se que esta comparação ajuda a comprovar a necessidade da criação de Frameworks com suporte a OR. A Tabela 17 apresenta tal avaliação.

Tabela 17 - Avaliação / comparação dos Frameworks Hibernate e Apache Torque usando os requisitos definidos em 4.2

\begin{tabular}{|c|c|c|}
\hline & Hibernate & Apache Torque \\
\hline R1. & \multicolumn{2}{|c|}{$\begin{array}{l}\text { Implementa desde que o usuário especifique em sua "modelagem". Feito isso o controle é } \\
\text { delegado ao SGBD o qual faz uso de chaves primárias e estrangeiras. }\end{array}$} \\
\hline R2. & \multicolumn{2}{|l|}{ Sim, apenas modificando diretrizes de configuração. } \\
\hline R3. & $\begin{array}{l}\text { Possui a linguagem HQL, ou pode ainda fazer uso } \\
\text { da JPQL definido em [31]. Entretanto em alguns } \\
\text { casos se faz necessário que o usuário tenha } \\
\text { conhecimentos de BD. }\end{array}$ & $\begin{array}{l}\text { Não define de fato uma linguagem de } \\
\text { acesso, no entanto as interações podem ser } \\
\text { feitas manipulando classes específicas do } \\
\text { Framework. Desta forma não obrigando o } \\
\text { usuário a possuir conhecimento de BD. }\end{array}$ \\
\hline $\mathrm{R} 4$. & \multirow{2}{*}{\multicolumn{2}{|c|}{$\begin{array}{l}\text { Faz a gerencia da conexão. } \\
\text { Disponibiliza uma interface para o usuário especificar onde começa e termina a transação. O } \\
\text { controle de fato da transação é delegado para o JDBC que por sua vez delegado para o SGBD. }\end{array}$}} \\
\hline R5. & & \\
\hline R6. & $\begin{array}{llllll}\begin{array}{l}\text { Todos os scripts SQL são gerados de forma } \\
\text { automática }\end{array} & & & & \\
\end{array}$ & $\begin{array}{l}\text { Não somente os Scripts SQL são gerados de } \\
\text { forma, as classes Java também são. }\end{array}$ \\
\hline R7. & \multicolumn{2}{|c|}{$\begin{array}{l}\text { Sim ambos funcionam como ponto centralizado de acesso aos dados. Podendo o desenvolver } \\
\text { possuir outro, mas não sendo necessário }\end{array}$} \\
\hline R8. & $\begin{array}{l}\text { Da versão } 3 \text { em diante, faz uso de anotações, o que } \\
\text { traz ganhos de produtividade. Caso contrario o } \\
\text { desenvolvedor deveria especificar o esquema de } \\
\text { objetos da aplicação em um arquivo XML, } \\
\text { minimizando a produtividade. }\end{array}$ & $\begin{array}{l}\text { Em partes. Pois o usuário necessita } \\
\text { especificar qual o esquema de objetos em } \\
\text { um arquivo XML e como saída, o } \\
\text { Framework produz a codificação do } \\
\text { esquema de objetos em Java (aplicação) e } \\
\text { (SQL). O preenchimento de arquivos de } \\
\text { configuração minimiza a produtividade, no } \\
\text { entanto o fato de gerar também as classes } \\
\text { acaba compensando a existência de arquivos } \\
\text { de configuração. Em contrapartida, a } \\
\text { aplicação fica "engessada" às classes } \\
\text { geradas. }\end{array}$ \\
\hline
\end{tabular}




\begin{tabular}{|c|c|c|}
\hline R9. & $\begin{array}{l}\text { Não implementa herança, entretanto disponibiliza } \\
\text { como alternativa criar tabelas que representam os } \\
\text { níveis da hierarquia. Pode ser feito de três formas: } \\
\text { Primeiro, criar uma tabela para cada nível da } \\
\text { hierarquia. Tendo como desvantagem a necessidade } \\
\text { da aplicação gerenciar o sincronismo das } \\
\text { informações contidas nestas tabelas ao longo da } \\
\text { hierarquia; Segundo, declarar somente as tabelas } \\
\text { filhas ignorando a hierarquia acima e } \\
\text { consequentemente, perdendo a reutilização provida } \\
\text { pela herança, e ainda impossibilitando a herança } \\
\text { entre os dados. Terceiro, uma única tabela contendo } \\
\text { todas as características de todas as classes ao longo } \\
\text { da hierarquia. Contendo um campo para especificar } \\
\text { a qual nível da hierarquia o registro pertence. Os } \\
\text { problemas desta abordagem são: modificações na } \\
\text { estrutura dos dados; adição de complexidade, uma } \\
\text { vez que a aplicação teria que realizar esta } \\
\text { segregação; diminui a eficiência do SGBD ao alocar } \\
\text { espaço em disco para os registros, sendo que cada } \\
\text { registro contem os atributos de todas as classes o } \\
\text { que na pratica serão alocados e não usados; aumento } \\
\text { de processamento na recuperação de dados, devido } \\
\text { a necessidade de usar filtros especificando qual o } \\
\text { nível da hierarquia a consulta representa. }\end{array}$ & Não possui suporte a herança. \\
\hline R10. & \multicolumn{2}{|c|}{$\begin{array}{l}\text { A implementação de relacionamentos N-N é feita seguindo a abordagem relacional, ou seja, usando } \\
\text { tabelas para fazer os relacionamentos N-N. O usuário deve especificar a tabela de relacionamento, } \\
\text { determinando quais vão ser suas colunas (referenciando colunas das tabelas referenciadas); } \\
\text { Esta aborda não suporta conceitos como agregação e composição, além da necessidade de } \\
\text { conhecimento de BD para que o usuário consiga realizar os relacionamentos. }\end{array}$} \\
\hline R11. & \multicolumn{2}{|c|}{$\begin{array}{l}\text { Em teoria ambos degradam a performance, pois é existe um processamento extra ao desmembrar os } \\
\text { objetos em colunas a tabelas. Estudos que comprovem tal afirmação não foram realizados, } \\
\text { pretende-se em trabalhos futuros. }\end{array}$} \\
\hline R12. & $\begin{array}{l}\text { Permite ao usuário especificar qual a estratégia de } \\
\text { recuperação dos objetos relacionados. Desta forma } \\
\text { têm um maior controle sobre a performance do } \\
\text { Framework, diminuindo o numero de acessos } \\
\text { desnecessários ao SGBD }\end{array}$ & Não possui suporte. \\
\hline R13. & $\begin{array}{l}\text { Permite ao usuário especificar o conjunto de } \\
\text { situações em que os objetos relacionados também } \\
\text { serão persistidos. }\end{array}$ & Não possui suporte. \\
\hline
\end{tabular}

